\title{
Micro-Level Impacts of Conflict and the Duration of Armed Groups
}

\author{
Dissertation \\ zur Erlangung des wirtschaftswissenschaftlichen Doktorgrades der \\ Wirtschaftswissenschaftlichen Fakultät der Universität Göttingen
}

\author{
vorgelegt von \\ Dominik Noe, M.A. \\ geboren in Eckernförde
}

Göttingen, 2013 
Erstgutachter:

Zweitgutachter:

Drittprüferin:

Tag der mündlichen Prüfung:
Prof. Stephan Klasen, Ph.D.

Prof. Dr. Axel Dreher

Prof. Inmaculada Martínez-Zarzoso, Ph.D.

16. August 2013 


\section{Acknowledgments}

Writing this dissertation would not have been possible without the help and contribution of many people. I want to express my gratitude to Stephan Klasen for being my supervisor, giving me the opportunity to write this thesis and for his advice and support. I am very grateful to Axel Dreher and Inmaculada Martínez-Zarzoso who have given me very helpful comments and advice.

I have also profited from the collaboration, ideas and suggestions of many of my colleagues at the Courant Research Centre 'Poverty, Equity, and Growth' and the Development Research Group at the University of Göttingen and I would like to thank them all for creating such a great work environment. In this context I want to specifically mention my co-authors Admasu and Johannes, for their great teamwork and help; and Susanne who has done a great job of taking care of everyone at the centre. Also, thank you to Marcela and Gerhard for their support, suggestions and for challenging every thought and idea I brought to them. Special thanks go to Chris Müris who offered me valuable advice and a solution when I was really stuck.

Moral support and hugely entertaining lunch breaks helped me to keep my sanity and get over all those little frustrating moments that I guess are just inevitable in research. Thank you very much: Carsten, Nils, Eva, Rita, Julian, Lore, Christoph, Fatima, Merle, Steffen, Malte and all the others.

Lastly, my gratitude to the ones who were most important in bringing me to this point. I am grateful to my wife for her love, for standing by me through everything and for always cheering me up when I need it. I will be forever indebted to my family for all the love and support I have received from them throughout my whole life. 


\section{Table of Contents}

$\begin{array}{lr}\text { List of Tables } & 6 \\ \text { List of Figures } & 7 \\ \text { Introduction } & 8\end{array}$

\section{CHAPTER 1: VIOLENT BEHAVIOUR -}

THE EFFECT OF CIVIL CONFLICT ON DOMESTIC VIOLENCE IN COLOMBIA _ 16

I.1 Introduction _ 17

I.2 Theory and Literature Review _ 19

I.3 Data and Estimation Strategy___ 23

I.4 Analysis and Results _ 30

I.4.1 General models 30

I.4.2 Different spatial identification and simulation of effect's magnitude __ 34

1.4.3 Different measures of domestic violence __ 35

I.4.4 Possible endogeneity issues___ 36

1.5 Conclusions _ 41

\section{CHAPTER 2: THE IMPACT OF ARMED CONFLICT ON FIRM INVESTMENT}

IN ETHIOPIA _ 43

II.1 Introduction__ 44

II.2 The Effect of Conflict on Firm Behaviour: Theoretical Considerations __ 45

II.3 Literature Review _ 48

II.4 Data _ 50

II.4.1 Firm level data__ 50

II.4.2 Conflict data _ 51

II.5 Empirical Strategy _ 55

II.5.1 A note on endogeneity _ 56

II.6 Descriptive Statistics and Variable Definitions __ 57

II.7 Empirical Results _ 59

II.7.1 General results for investment __ 60

II.7.2 Differential effects of conflict on investment __ 63

II.7.3 Other measures of insecurity ___ 67

II.7.4 Conflict effects on other firm behaviour 67

II.7.5 The case of Addis Ababa __ 69

II.8 Conclusions _ 69 
CHAPTER 3: DETERMINANTS OF THE DURATION AND ENDING OF TERRORIST AND OTHER NON-STATE ARMED GROUPS 71

III.1 Introduction 72

III.2 Definitions and Classifications 73

III.3 Literature Review 76

III.4 Hypotheses and Theoretical Considerations 79

III.4.1 Decision framework 79

III.4.2 The imperative of continuation 80

III.4.3 Rational choice and terrorism duration 81

III.4.4 The effect of time (duration dependence) 84

III.4.5 Hypotheses 85

III.5 Data 86

III.6 Empirical Model 91

III.7 Empirical Analysis 94

III.7.1 Regression results 96

III.7.2 Competing risk regression 100

III.8 Findings Overview and Conclusions 106

REFERENCES 109

APPENDIX A 120

A.1 Additional Tables 120

A.2 Technical Notes 123

APPENDIX B 126

B.1 Additional Figures 126

B.2 Additional Tables 127

B.3 Technical Notes 130

APPENDIX C 132

C.1 Additional Tables 132

C.2 Technical Notes 133 


\section{List of Tables}

Table I.1: Descriptive statistics 28

Table I.2: Descriptive statistics for low and high conflict intensity districts 29

Table I.3: Regression results domestic violence, general and special spatial identification _31

Table I.4: Regression results domestic violence, instrumental variable approaches 39

Table II.1: Summary statistics 58

Table II.2: Regression results firm investment, basic models 61

Table II.3: Regression results firm investment for capital intensive and private firms 64

Table II.4: Regression results firm investment by industry 66

Table II.5: Regression results firm exit and entry 68

Table III.1: Summary statistics 90

Table III.2: Regression results for organization duration, general models 97

Table III.3: Regression results for risk of defeat 101

Table III.4: Regression results for risk of splintering/disappearance 102

Table III.5: Regression results for risk of political ending 103

Table A.1: Different measures of domestic violence 120

Table A.2: Regression results for different measures of domestic violence 121

Table A.3: Regression results for armed confrontations per district 122

Table B.1: Regression results firm investment, different conflict buffer sizes 127

Table B.2 : Regression results firm investment, lagged conflict measures 127

Table B.3: Regression results firm investment, different insecurity measures 128

Table B.4: Regression results for other firm indicators 128

Table B.5: Regression results firm investment in Addis Ababa 129

Table C.1: Regression results organization duration, including political orientation 132 


\section{List of Figures}

Figure 1: No. of countries with internal conflict 9

Figure 2: Map with years of internal conflict in countries 10

Figure I.1: Map of DHS 2005 survey districts 24

Figure I.2: Map with no. of armed confrontations per district 26

Figure II.1: Map of towns with observed firms 51

Figure II.2: Map of battle incidents 53

Figure II.3: Scatterplot Battles vs. Investment 60

Figure III.1: Histogram organization duration 95

Figure III.2: Baseline hazard, model with all endings 99

Figure III.3: Baseline hazard, model for defeat 104

Figure III.4: Baseline hazard, model for splintering/disappearance 105

Figure III.5: Baseline hazard, model for political ending 106

Figure B.1: Map of battle incidents by group 126 


\section{Introduction}

Political instability and political violence have been a major hindrance for development in developing and transition countries. Development and progress for countries is hard to achieve under the presence of violence or conflict, as they can not only cause death and destruction but also deeply affect political and societal institutions. As stated in the World Development Report 2011: "No low-income fragile or conflict-affected country has yet achieved a single MDG. People in fragile and conflict-affected states are more than twice as likely to be undernourished as those in other developing countries, more than three times as likely to be unable to send their children to school, twice as likely to see their children die before age five, and more than twice as likely to lack clean water. On average, a country that experienced major violence over the period from 1981 to 2005 has a poverty rate 21 percentage points higher than a country that saw no violence" World Bank (2011, p. 5). These quite impressive numbers demonstrate the importance of investigating the reasons for and sources of conflict as well as the consequences at all levels of society. A better understanding is needed in order to prevent conflict and violence, to end it, to mitigate the consequences and especially to reconstruct a country, society and political system afterwards and build a peaceful future.

It has only been for a bit more than a decade that civil conflict and civil war have received increased attention in economic research and especially development economics. Blattman and Miguel (2010) note that the topic is still not at all mentioned in major textbooks and mostly not contained in the syllabi of development economics courses at U.S. universities. In research there has been quite some progress in methods and available data for the investigation of conflict, but there are still many open questions to be answered. This doctoral thesis intends to provide some additional insights into the very diverse effects of conflict on different economic agents and the duration of the armed groups that cause it.

Civil conflicts and civil wars in developing countries constitute the great majority of armed conflict in the world since 1960. In comparison violence from interstate wars has become very rare. The UCDP/PRIO Armed Conflict Dataset (Gleditsch et al. 2002) reports, for the time period from 1960 to 2011, 35 interstate wars with a total duration of 100 years, compared to 
169 civil conflicts or civil wars with a total duration of 1688 years. ${ }^{1}$ This does not only show that internal armed conflict is much more frequent, but on average such a conflict lasts about 3 times longer than an interstate war. While the large scale violence of an interstate war might cause major physical destruction it usually ends more quickly and often leaves important societal and state-institutions intact. One reason for this is that the enemy comes from the outside. The long duration and often unclear internal front lines in civil conflict or civil war have a much larger capacity to destroy the internal structures of a society making recovery much more difficult, because it is not enough to recover lost physical capital.

Figure 1: No. of countries with internal conflict

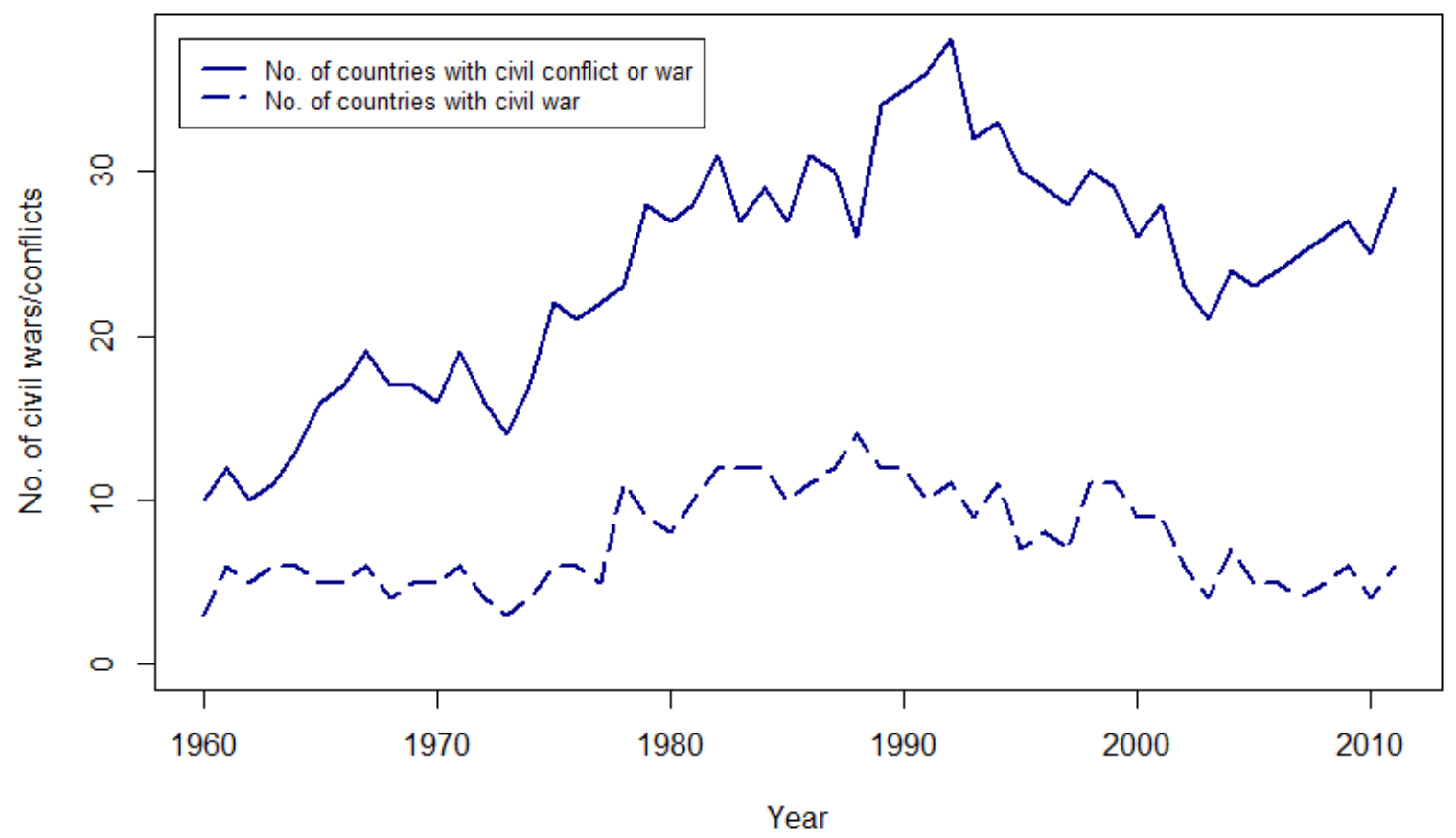

Source: Author's calculations based on the UCDP/PRIO Armed Conflict Dataset (Geditsch et al. 2002)

Figure 1 shows the number of countries that experienced either a civil conflict or a civil war in the period 1960 to 2011. The highest number of civil wars was observed during the late 1980's and it slowly declined since then. While civil conflicts peaked at the beginning of the 1990's and then declined as well, there has been an increase during recent years.

\footnotetext{
${ }^{1}$ Total duration is the sum of years for each conflict. It has to be kept in mind that a country may experience more than one internal conflict at the same time. The definition used by Gleditsch et al. (2002) to distinguish between civil conflict and civil war is the threshold number of victims per year. A civil conflict causes at least 25 battle related deaths per year and a civil war at least 1000 .
} 
The two panels in Figure 2 give an impression of the geographical distribution of internal conflict and an idea of the time each country suffered from it. Large parts of the world have been affected by civil conflict at some point as can be seen from the first panel and quite many countries have experienced such conflict for more than 30 years. Civil wars are mainly concentrated in Africa, the Middle East and South- and South-East Asia.

Figure 2: Map with years of internal conflict in countries
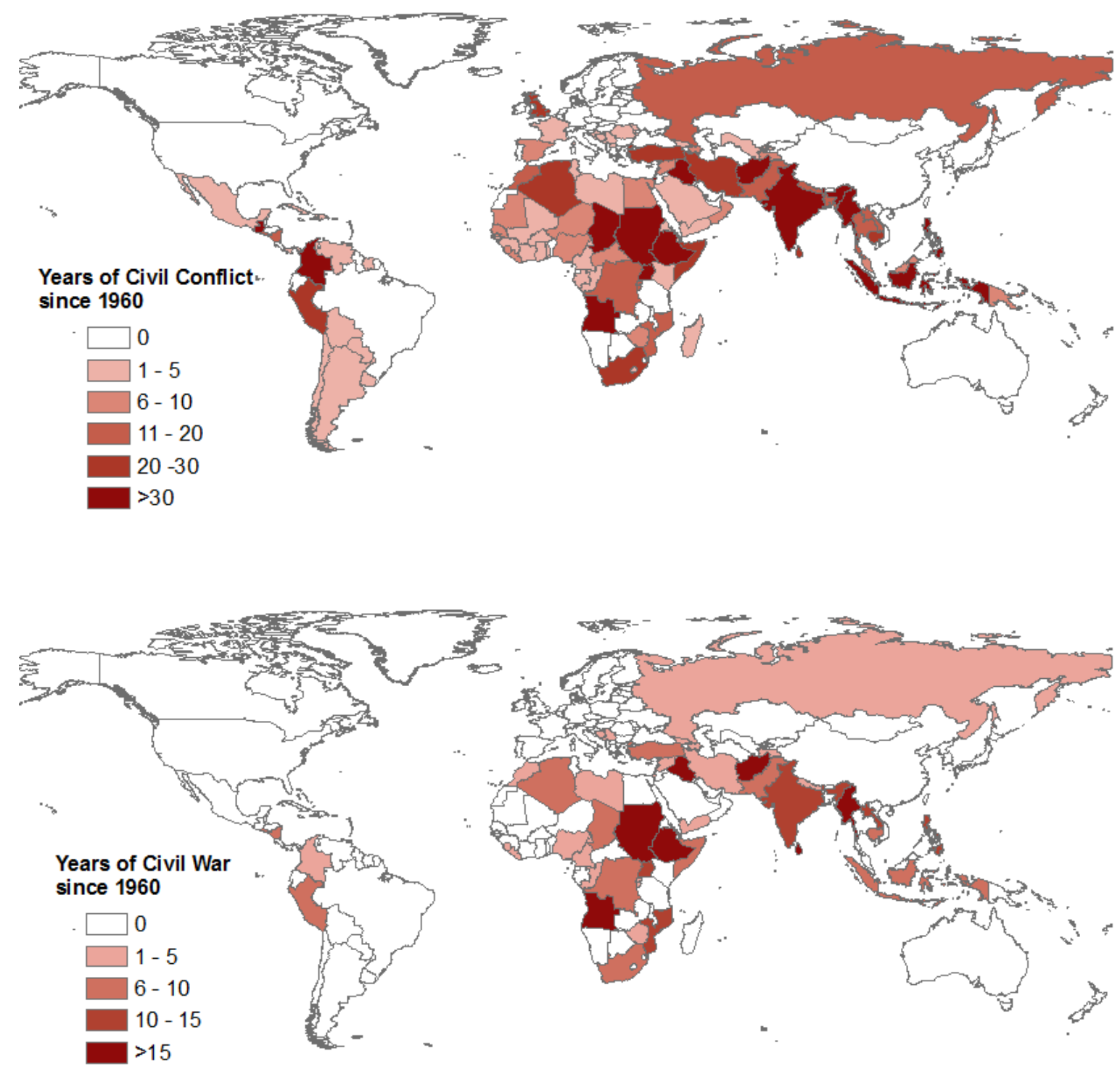

Sources: Author's calculations based on the UCDP/PRIO Armed Conflict Dataset (Geditsch et al. 2002). Map data from DIVA-GIS, available at: http://www.diva-gis.org/Data, last accessed June 13, 2013.

The quantitative empirical investigation of civil war and political violence in economics and political science can be roughly divided into macro and micro level research. The beginning 
of this research field was mainly marked by investigation on the macro level, using country year observations and the presence or absence of civil war. Prominent examples would be Collier (1999) about the consequences of civil war and Fearon and Laitin (2003) and Collier and Hoeffler (2004) about the origins. The micro literature followed somewhat later mainly due to the fact that micro-level data was not so easily available. It was fuelled by prominent projects and research networks like 'MICROCON' and the 'Households in Conflict Network' who focus only on micro research. ${ }^{2}$ These projects have shed light on many of the effects of conflict - especially on the household level - and the conduct and organization of civil war.

This dissertation mainly makes use of micro-data but looks at topics that have been hardly analyzed until now. It investigates behavioural changes of individuals and firms that could be potentially harmful for development and tries to explore the duration and ending of those groups that are behind the conduct of conflict.

The development of a country is in large parts determined by the behaviour of its economic agents, which are individuals and firms. While it is clear that a large scale conflict will cause physical destruction, there is much less research on how conflict in general and especially low scale conflict will impact the behaviour of these agents, which is the topic of the first two chapters of this dissertation. So far this has hardly been investigated and there exists only a very small body of literature on the general topic.

The first chapter - joint work with Johannes Rieckmann - looks at the effect of conflict on behaviour, using individual level data from Colombia. It shows that the experience of conflict in close proximity increases the likelihood of domestic violence which is interpreted as an indication for a behavioural shift towards more violent patterns, due to various factors described in more detail in the chapter. This could increase the violent potential in the society and present a significant hindrance for development, as could also the direct consequences of domestic violence for, e.g., the development of the affected children.

It is a common perception that violence begets violence. In media accounts, violent crimes are often explained with violent experiences in the past of the perpetrator, claiming that often victims become perpetrators themselves. A popular debate is going on about whether

\footnotetext{
2 'MICROCON' is a EU Commission-funded research program using a micro-level approach to the study of conflict: http://www.microconflict.eu/. The 'Households in Conflict Network' is a network of researchers that investigate conflict on the household level: http://www.hicn.org/.
} 
seeing violence, e.g., in the media, movies or video games changes the behaviour or attitude of the consumers. In this case violence is often fictional or happens somewhere else. What does however happen to people who see or experience violence frequently in real life? Does it make a difference whether they see media accounts that deal with real situations that happen close to their home, rather than being fiction or happening far away?

The observation of behavioural change is very difficult and therefore there is not much research on the effect of conflict on behaviour. The first chapter of this dissertation tries to add to exactly this small literature and deals with the question whether incidents of violence during a civil conflict, change the behaviour of people in close spatial proximity.

There are many indications that violence can become a persistent phenomenon. Most of the civil wars that have started during the past years happen in countries that have had similar conflict before (World Bank 2011, p. 57). While this could be due to persistent grievances among the population that have not been solved after a conflict, there is also the striking fact that many countries show high levels of violent crime after conflict episodes (Ibid.) even if there is no recurrence of conflict.

While the first chapter deals with the effects of conflict on individuals, the second chapter joint work with Admasu Shiferaw - has a different focus, which until now has also not received very much attention in research. It investigates the effect of conflict on firms and finds significant reductions in investment caused by increases in battle events within a certain distance of the firms' locations. It is clear that reductions in private investment will reduce aggregate investment and thereby slow down the economic growth and development of a country.

The basic assumption is that conflict and violence create insecurities which make investment less attractive. This argument has been brought forward regularly in the context of foreign direct investment, where it is commonly assumed that civil unrest, high crime rates or political instability present strong reasons for foreign firms not to invest in a country.

This seems quite logical, but even if unstable countries have less foreign investment, there are still firms (local and foreign) operating there. The question is how they react to instability and violence. For an existing firm the decision to exit the market is quite extreme and probably just the last resort if a continuation of operations is completely unfeasible. They 
may however be more careful about new investments which on an aggregate level might significantly slow down economic growth and development.

A growing industry provides work and economic security for the population in an increasingly urbanized world. Employment and income have also been found to be important aspects in creating stability in a country by, e.g., providing the population with alternatives to criminal and violent behaviour.

There have hardly been any systematic studies on whether violence actually affects a firm's behaviour, in which case it might be important to think of policies to mitigate such effects. This chapter uses data from firms in Ethiopia to estimate the effects of violence on firm investment. Ethiopia, after a long history of civil and interstate war, has been subject to a low level conflict in the time span considered. It is found that even such low levels of violence seem to have important negative implications for firm investment in the country.

While these subjects of investigation are obviously very different, they can show how diverse, complex and wide ranging the impacts of conflict are. They demonstrate how development can be hindered in ways that may be sometimes discussed, but the mechanisms of which have hardly ever been tested using quantitative empirical methods.

Both chapters rely heavily on spatial identification strategies which have been made possible by a strong increase in the spatial coding of data. If data has a spatial identifier it can be connected to other data using the location or distance measures. In simple cases this could work by the use of administrative units and if the identification is more detailed the use of specialized software can allow for much more precise connections. Such approaches are especially important in the investigation of conflict because it appears at different times at different locations and in different intensities. This means that not all people or all regions of a country will be equally affected. Spatially coded conflict data makes it possible to distinguish between more and less affected locations and can thereby help to identify the reasons and consequences of conflict.

The third chapter does not investigate the consequences of conflict but another important aspect which is its duration. More specifically it explores the duration of the armed groups, which are the organizational units behind the conflicts. It also generalizes the subject of investigation, not only looking at larger groups in civil wars but also at groups who exercise 
political violence at lower escalation levels, which are often labelled terrorist organizations. Low levels of development are not only a consequence of conflict but are also often used as an explanation for its occurrence, intensity or duration. A lack of development implies low state capacity and a lack of alternatives for the people and is thereby assumed to be a major driver behind the foundation and duration of armed groups which are causing conflict. Completing the vicious cycle, this conflict then again hinders development. There has been practically no quantitative research of the duration of these groups. Such an investigation can however help to understand the processes and conditions that increase or decrease their duration and determine in which way they end. The duration of armed groups is very important for the duration of conflict itself. If only one group participates in a conflict, its demise will also mark the end of the conflict. In any case the ending of a group should reduce violence in a conflict, make its solution easier and could ultimately help to break the vicious cycle.

While the first two chapters focus on civil war and civil conflict, this part considers more categories of political violence, namely terrorism. The actual distinction between terrorism and other types of political violence is very difficult and depends on varying definitions. This study does not distinguish between the different types but it investigates the authors of political violence in general, which are most of the time organized groups of individuals.

As is shown in the first two chapters and is also quite well understood generally, political instability, insecurity and conflict have diverse and important impacts on a society. The duration and ending of groups that create or are consequences of such instability is therefore a major determinant of the time a country is affected by it. It is probably safe to assume that a recovery from conflict becomes harder, the longer the conflict had time to destroy institutions and change the behaviour and perceptions of a society.

Despite the fact that organized groups are behind most terrorist attacks and virtually all larger conflicts, there has been hardly any quantitative research on the topic. This study uses a large dataset of terrorist organizations and tests a wide array of hypotheses. It is found that armed groups stabilize over time, that international operation increases their duration, that restrictions of civil liberties do not make their defeat more likely and that motivation and local support matter for their duration. 
To better understand conflict can help to mitigate its effect or even to end it. "Countries emerging from severe violence have made striking development gains [...]" World Bank (2011, p. 51). So if a conflict has ended, understanding how the conflict might have affected individuals and firms will then be very helpful for designing policies to make the recovery more effective and longer lasting. 


\title{
Chapter 1
}

\section{Violent Behaviour}

\section{The effect of civil conflict on domestic violence in Colombia}

Joint work with Johannes Rieckmann ${ }^{\ddagger}$

\begin{abstract}
In this chapter we analyze the impact of civil conflict on domestic violence in Colombia and find that higher conflict intensity increases the likelihood of women to become a victim of domestic violence. The idea behind our approach is that the experience of conflict changes behaviour, attitude and culture. We consider domestic violence to be an observable outcome of this change in behaviour. Taking advantage of the uneven spatial distribution of the conflict we assess its impact, using micro data from Colombia.
\end{abstract}

\section{Acknowledgements}

We would like to thank Chris Müris for his help and support as well as Walter Zucchini. Furthermore we would like to thank Stephan Klasen, Axel Dreher and the participants of seminars in Bonn, Göttingen and Heidelberg as well as the 2011 Arnoldshain conference for helpful comments and discussion contributions. Financial support by the German Research Foundation (DFG) through the CRC-PEG is gratefully acknowledged.

\footnotetext{
${ }^{\ddagger}$ Development Research Group, Georg-August-University Göttingen.
} 


\section{I.1 Introduction}

It is often claimed that violence begets violence. This can mean that the one being stricken strikes back. It can however also mean that witnesses of violent acts are influenced in their own behaviour and therefore might exercise violence themselves.

The idea of this study is that the experience of fighting and bloodshed caused by a civil conflict, will change the behaviour and attitude of the population witnessing it, so that they will be more willing to also use violence. If this was the case, conflict could create a selfreinforcing culture of violence which would hinder its termination, slow down the recovery afterwards or increase the likelihood of new fighting. Culture and attitude are hard to observe and therefore we use differences in observable behaviour to check this hypothesis. Many forms of observable violence could be a direct consequence of the conflict and not necessarily an expression of a behavioural change in the general public. Domestic violence is an observable form of violent behaviour that is not likely to be a direct consequence of a military conflict, but there are plausible mechanisms how the behavioural change caused by such a conflict could lead to the use of violence within the family. The main channels through which we expect conflict to increase domestic violence are increased acceptance of violence if exposure of people to different forms of violence is augmented; and the function of domestic violence as a stress release in an insecure environment.

This research aims at improving the understanding of the consequences of conflict. Blattman and Miguel (2010) state that there is a lack of theory and evidence "in assessing the impact of civil war on the fundamental drivers of long-run economic performance - institutions, technology and culture - even though these may govern whether a society recovers, stagnates or plunges back into war". ${ }^{3}$ While domestic violence is a crime and its investigation and prevention in itself an important issue, we also use it as an indication of behavioural change. It is a threat for the security and cohesion of society as it increases the violent potential for the future. This does not only refer to those people whose behaviour has been changed by the conflict but also to later generations who suffer from this domestic violence and are thereby negatively affected from childhood on.

\footnotetext{
${ }^{3}$ A prominent example for literature on the impact of violence on cultural norms is a paper written by Miguel, Saiegh and Satyanath (2011). The authors find a strong link between a professional football player's violent conduct - measured by red and yellow cards attributed - with the civil conflict history in his country of origin.
} 
In order to analyze the impact of civil conflict on behaviour, attitude and culture we use micro-data from Colombia, considering domestic violence to be an observable outcome of changes in behaviour. Using the uneven spatial distribution of conflict intensity between districts we find that a higher incidence of combat within a district significantly increases the likelihood of women in this district to become a victim of domestic violence.

Colombia was chosen for various reasons. Domestic violence is a very common phenomenon in the country. In our sample up to 20 percent of the interviewed women who are currently in a partnership report physical abuse by their partners. ${ }^{4}$ This is very high compared to other countries. ${ }^{5}$ In our data only women were interviewed and therefore we cannot consider domestic violence from women against men.

Today's conflict in Colombia has its roots in the 1950's and still continues. It involves different guerrilla organizations, of which the most important today, are the FARC and ELN (Ejército de Liberación Nacional). Originating as peasant organizations especially the FARC became a highly organized and effective guerrilla army with thousands of soldiers. As a defence against the guerrilla, private actors - mainly land owners - founded paramilitary organizations which later on joined to become the AUC (Autodefensas Unidas de Colombia). All non-state actors rely heavily on illegal means of financing. The most important sources are drug production and trafficking, kidnapping and extortion. Although the illegal economy was not the source for the conflict it is probably a main cause for its duration and its intensification especially in the 1990 s. $^{6}$

\footnotetext{
${ }^{4}$ The recall period comprises the past twelve months. $12.4 \%$ of the women report to have been subject to have experienced violence by a person other than their partner before that period (see also Table I.1). Note that the lifetime prevalence cannot be found straightforwardly by summing up the two measures, as there will probably be an intersecting set. Also the non-captured prevalence of physical violence inflicted by the current partner longer than twelve months ago could be confounding, although in the other direction (thus underestimating lifetime prevalence).

${ }^{5}$ The World Health Organization (García-Moreno et al., 2005) reports in Table 4.1 exposure to at least one act of physical act of violence within the past twelve months ranging from 3.1\% (urban Japan) to $29 \%$ (provincial Ethiopia); with a non-weighted mean of $14.8 \%$ (own calculation). Ten countries from Africa, Asia, Europe, Oceania and South America are part of the considered sample. Reported lifetime prevalence of domestic violence ranges between $13 \%$ (urban Japan) and $61 \%$ (provincial Peru). In Africa on average the situation seems to be particularly dire. Durevall and Lindskog (2013) report in Table 2 prevalence rates of physical intimate partner violence in eight sub-Saharan countries. DHS data stem from 2005 to 2011, with a recall period of twelve months. Violence rates range between 10.7\% (Burkina Faso) and 56\% (Rwanda), with a non-weighted mean of $31 \%$ (own calculation).

${ }^{6}$ For a short summary of the rather complicated conflict history and involved parties in Colombia since the mid$20^{\text {th }}$ century see, for example, Steele (2007) and Garces (2005). Gutierrez Sanin (2008) provides useful insight on the characteristics of the non-state "armies" entangled in these conflicts.
} 
Despite the long duration of the conflict the state is still functioning, although not in complete control over all of its territory. Because of the existence of such a functional state, high quality data about the conflict is available. Very few countries display both - the incidence and severity of conflict as well as the "rich micro-level data" (Steele, 2007) - as is the case in Colombia.

Our analysis is based on individual-level data from the year 2005. In order to identify the effects of conflict we use the uneven spatial distribution of conflict intensity within the Colombian territory. We find that a woman in a district with high conflict intensity has an up to ten percent higher chance of being a victim of domestic violence than a woman in a district with average or lower conflict intensity.

\section{I.2 Theory and Literature Review}

This chapter is based upon the idea that experiencing or witnessing violent manifestations of conflict will increase the incidence of domestic violence in spatial proximity of these manifestations. This means we expect a behavioural change in people due to conflict. The observation of behavioural change is, in most cases, very difficult and therefore there is not much empirical research in this field. Two of the few exceptions are Voors et al. (2012) who find that people who experience violence from conflict become more risk-seeking and have a higher discount rate; and Blattman (2009) who finds victims of violence to show higher political activity.

We assume that the repeated and sustained witnessing of violent acts in the context of armed combat affects the mind-set. It can lead to "widespread tacit tolerance and acceptance of the use of physical violence to solve private and social problems" and ultimately to an omnipresent culture of violence (Waldmann, 2007, specifically on the case of Colombia). Acclimatization and role models influence the way conflicts are resolved. This applies also within the framework of small social groups like the family, and all the way down to intimate relationships (see, e.g., Adelman, 2003, on the effect of militarization). An environment of violent crime in the community is "associated with elevated risks of both physical and sexual violence in the family" (Koenig et al. 2006). Also, "community-level norms concerning wife beating" (ibid.) have a significant effect on occurrence rates, as well 
as on the consequences the affected wives draw from the experience in terms of, e.g., divorce rates (Pollak, 2004). Wood (2008) argues that "social processes may be reshaped by conflict processes". Another factor might be the "emotional blunting" of victims, witnesses or perpetrators as a consequence of their experiences. This can lower the psychological threshold restraining the use of force at home. Post-traumatic stress disorders can result from exposure to violence, and lead to changes of behaviour. It was found in the United States that veterans with posttraumatic stress disorder (PTSD) are more often perpetrators of domestic violence than the general population (Sherman et al. 2006). We expect a similar effect to apply for witnesses of violence who were not directly involved in combat. We believe number and intensity of violent outbreaks to increase due to this effect.

Domestic violence is usually divided into two categories, one of which is referred to as expressive, the other one as instrumental. In the expressive form perpetrators gain utility from inflicting physical harm on their partners or children by being able to express their feelings in a drastic way, and release their emotional pressure (Winkel, 2007). Living in a conflict zone brings about a general and unassigned feeling of threat, loss of control, helplessness and an elevated level of emotional stress because the usual societal rules that bring a certain protection from physical and other harm do not necessarily apply anymore when the actions of present armed combatants are incalculable. Passing this pressure on onto others within the closest social environment in a "cyclist manner" - ducking and kicking - may serve as a psychological relief valve. When persons feel the aforementioned loss of control they might use violence to prove to have predominance at least over their direct social environment, i.e., at least over some part of their life.

Tauchen et al. (1991) describe not only this expressive aspect of utility creation for the perpetrator, but also include an instrumental function of spouse-beating. Domestic violence in its instrumental function is shaped and intended to modify the victim's behaviour. It aims to "educate" the victim in line with the interests of the perpetrator. The aforementioned emotional blunting will decrease empathy for others and thereby the threshold to resort to violent coercion instead of verbal dispute.

A very important point about domestic violence is its acceptance or non-acceptance by the victims. This is largely determined by cultural norms and the victim's alternatives or exit options. If a victim is economically dependent on the perpetrator it is very difficult to leave 
an abusive relationship; while, e.g., a good education and an independent economic situation could facilitate the exit. Cultural and personal norms determine whether the victim will even recognize domestic violence as an injustice and try to end the relationship; or just accept it as something normal. Whether it is accepted or legally possible to end an abusive marriage also depends on the societal background.

Both sexes are represented among perpetrators and victims of domestic violence (see, e.g., Straus, 1993, Karnofsky, 2005). The majority of perpetrators are male domestic partners, while most victims are female (e.g., Aizer, 2010). This also is the case that we have to focus on in our analysis due to data limitations. In an unsafe external environment both woman and men feel an increased need for protection. We believe that one important source of protection is the closest social environment, which is the family. If physical violence is commonplace in the geographical vicinity of their homes, we suppose that people show an increased reluctance to leave this protection. Compared to a situation without violent conflict, we therefore assume women to accept and endure more domestic violence than they would in a peaceful external environment. Probably this is even more the case for mothers who have to look after children. The fear of losing access to their children could hinder the former to turn their back on the children's father. Fear for the children's physical well-being also makes it difficult for mothers to leave them with their partner if he is a potential threat to the children. In the presence of violent exterior threats it becomes more crucial for the family to persist in order to serve as a protective environment. This function gains in importance as in the "climate of uncertainty, distrust, and polarization" which comes along with violent conflict, "traditional social networks of mutual aid might likewise weaken" (Wood, 2008). The traditional role of the man as provider is widely accepted in Colombia. It can come along with a higher threshold of accepted domestic violence compared to other societies, as women may feel dependent (Karnofsky, 2005, see also Farmer and Tiefenthaler, 1997 on a resource-centred non-cooperative model of domestic violence).

The spatial proximity of violent incidents to households is of relevance because closer events are perceived to be much more threatening than distant ones. Events one learns about by word of mouth or by direct witnessing are more terrifying than those which are taken notice of only from the newspapers or television broadcasting. Studies have shown that an incident of extreme violence can have distinct adverse psychological effects on people even if it 
happened thousands of kilometres away from them. For example, the terror attack against the World Trade Center in Manhattan on September $11^{\text {th }}$ in 2001 has had a traumatizing effect on people all over the United States of America (Cohen Silver et al., 2002). It seems more than comprehensible that combat taking place only a few kilometres away from their homes will feel even more threatening for the Colombian population.

If experiencing or witnessing brutal physical violence - as present in a conflict - causes a behavioural change towards more violent patterns, the consequences which society has to cope with are diverse and serious. We believe that the potential for future violence is increased. High crime rates can be observed in societies afflicted by violent conflict (for the case of Colombia see, for example, Richani, 1997). We think that the sparking of new conflicts becomes more likely and the reconciliation of ongoing ones more difficult. We also expect post-conflict recovery of societies to get hampered. The consequences of the specific behaviour known under the term domestic violence are not only dire for the directly affected victim. Detrimental effects arise for society as a whole from at least two elements. If domestic violence is a widespread phenomenon in a society we believe it to cultivate future conflict due to the lack of peaceful conflict resolution role models. Children whose ability to build affectionate relationships is destroyed are prone to resort to physical violence to resort conflicts in their adult life (Karnofsky, 2005). Furthermore, children who become victimized - or witness family members becoming victimized - often get stunted in their development of a free and confident personality. Fonagy (1999) proposes an attachment theory perspective on violence by men against women, with intimate partner violence being regarded as an "exaggerated response of a disorganized attachment system" in consequence of absence of a male parental role model and a history of abuse. Pollak (2004) introduces an intergenerational model of domestic violence in order to capture the influence of violent parents onto their children's future behaviour and the resulting vicious cycle, or "cycle of violence". In the long run we presume the detrimental effects for children to lead to negative macroeconomic consequences (see also Calderón et al., 2010, on inter-generational consequences of violence).

Research results about the effect of conflict on domestic violence can also be found in Gallegos and Gutierrez (2011) investigating the case of Peru. While the subject is the same their empirical approach is somewhat different. We use contemporaneous conflict and they 
relate conflict data aggregated over the years 1980-2000 to data on domestic violence in the years 2003-2008. Gallegos and Gutierrez find that exposure to conflict during late childhood and early teenage years raises the probability to suffer from domestic violence later in life. Because of the long time period between the conflict and the observed domestic violence the identification in space and time becomes more problematic and it is impossible to determine whether or not the perpetrator of domestic violence has been exposed to conflict. The study however suggests that some of the effects we observe as a direct response to the conflict experience might persist in the long term as well.

We empirically test our theory, using Colombian data because of the long and ongoing conflict and the data availability. In addition Colombia as a whole could probably be justifiably called a violent society not only considering the conflict but also when it comes to crime and violence in everyday life. Waldmann (2007) conducts a qualitative meta-analysis of publications ${ }^{7}$ in economics, political sciences and sociology to trace the "culture of violence" and structural conditions fostering it. He finds that the violence in Colombia is deeply rooted in the society and culture of the country and also analyzes its interaction with the conflict. The violence in Colombia extends into the family where domestic violence is very common, not only occurring as the abuse of partners but also as widespread abuse of children.

\section{I.3 Data and Estimation Strategy}

For our analysis we use individual level data about domestic violence and aggregate data about the conflict and combine both on the basis of spatial location.

The data on domestic violence comes from a Demographic and Health Survey (DHS: Profamilia, 2005) conducted between the end of the year 2004 and the beginning of 2005. In total, 41,344 women between the ages of 13 and 49 years, living in 37,211 households were interviewed. Besides questions about socio economic characteristics, health and reproductive behaviour, this survey contains a specific domestic violence module that asks detailed questions about the experience of domestic violence during the last twelve months and in the time before.

\footnotetext{
${ }^{7}$ Waldmann reviews scientific publications from the English, French, German, and Spanish language area.
} 


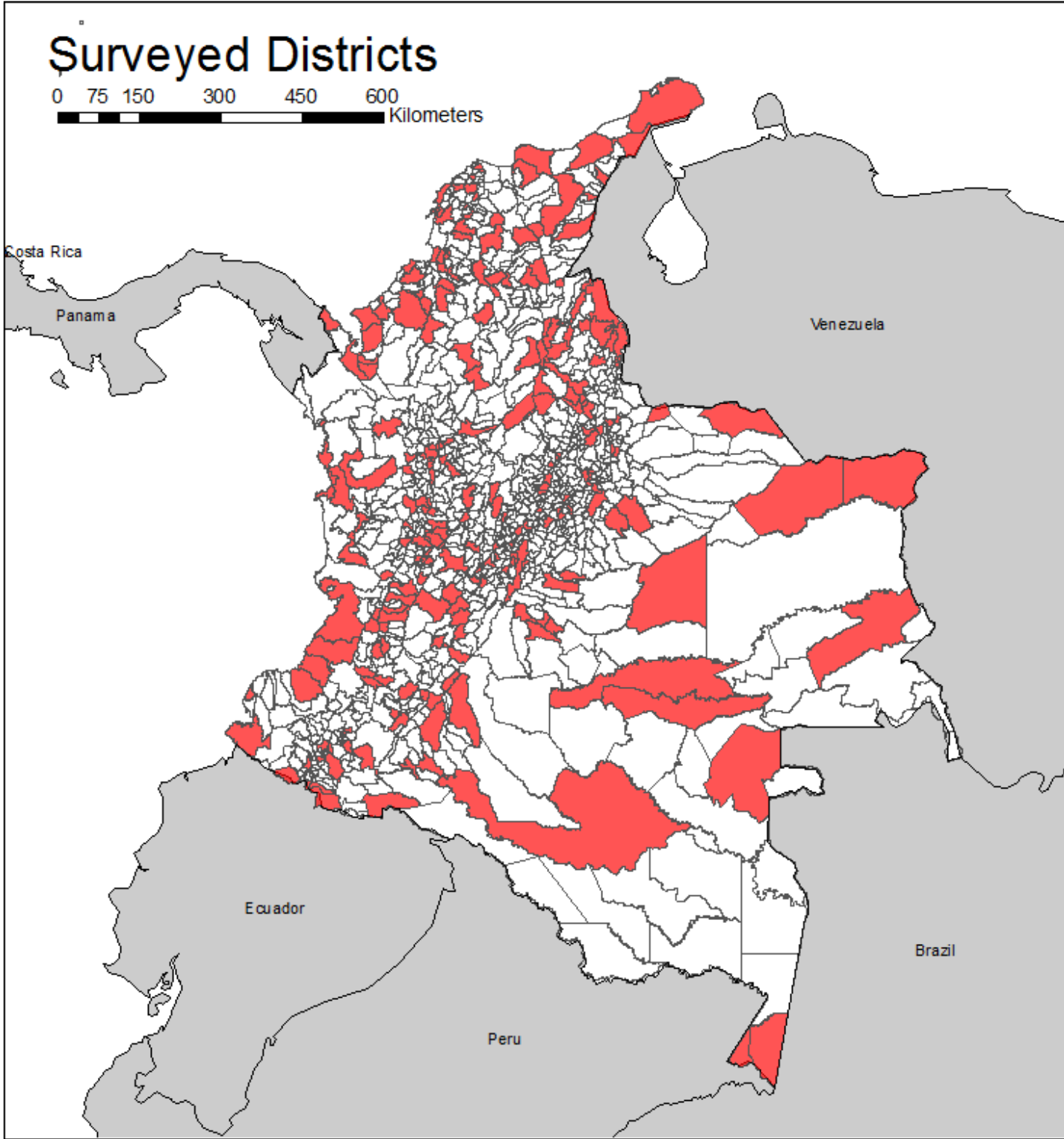

Sources: Author's calculations. DHS Data: Profamilia (2005); Map data for Colombian districts: SIG-OT (2013); Map data for neighbouring features: DIVA-GIS (2013).

In the survey between 17 and 20 percent of the women living in a relationship reported physical abuse by their partner during the past twelve months. The households can be located on the district level and the interviews took place in 230 of the more than 1100 Colombian districts. ${ }^{8}$ The spatial distribution of these districts is shown in Figure I.1. Since we can identify both the location and time of the experience of domestic violence we are able to relate its occurrence to the conflict intensity in the region during the years before.

\footnotetext{
${ }^{8}$ There were interviews in 231 districts but we exclude one district because there was only one woman interviewed who had a partner. The terms municipality and district are used interchangeably in the text.
} 
The data on conflict intensity comes from the Colombian "Presidential Program for Human Rights and International Humanitarian Law" (Programa Presidencial de Derechos Humanos y Derecho Internacional Humanitario, 2010). This project tracks the inner conflict in Colombia as well as directly connected and some other forms of violence like homicides, assassinations of syndicate members, journalists or politicians. The indicator we use to measure conflict intensity is the number of armed confrontations between government and irregular forces per district and year. This indicator is available for all Colombian districts. It does not include other forms of violence like one-sided attacks and massacres and therefore mainly consists of confrontations between guerrilla and government forces (as paramilitaries usually try not to fight government troops). We do believe that the indicator is sufficient for our purpose, as we expect open armed confrontations mainly to happen where the conflict is most intense. Figure 1.2 shows the magnitude of the indicator for all districts of Colombia. As can be seen there the conflict is concentrated in some regions while others are not very much affected. This spatial variation enables us to identify the effect of conflict. ${ }^{9}$

The empirical model is a Probit regression by which we determine the probability for each individual woman in the sample to have become a victim of domestic violence in the previous year.

The model takes the form:

$$
\operatorname{Pr}\left(Y_{i m}=1 \mid C_{m}, X_{i m}\right)=\Phi\left(\beta_{0}+\beta_{1} C_{m}+\beta X_{i m}\right)
$$

Where $Y_{i m}$, the dependent variable, is a dummy variable indicating whether or not woman $\mathrm{i}$ living in municipality/district $\mathrm{m}$ has experienced domestic violence during the last twelve months. $C_{m}$ is our conflict intensity measure for municipality $m$. This is our main explanatory variable and it is defined as the number of armed confrontations in the district in the years 2003 and 2004 which are the two years prior to the interview. ${ }^{10}$ Because of this we only

\footnotetext{
${ }^{9}$ For more detailed information about the data formats, sources and spatial identification refer to the technical notes in appendix A.2.

${ }^{10}$ Note that these years fall into the time period of "Plan Colombia", a multi-billion dollar program of military (and other) cooperation of the United States of America and Colombia. It was implemented between the years 2001 and 2005 and aimed at waging war against organized drug-related crime. Probably the conflict data therefore stem from a rather intense phase of the clashes. For a short introduction and some figures on "Plan Colombia" see Pineda (2005) and Mejia and Restrepo (2008).
} 
include women who have been living for at least two years at the place where they were interviewed. $X$ is a vector of other individual or household specific control variables which we assume to influence the probability of having been the victim of domestic violence. The standard errors are clustered at the municipality level. ${ }^{11}$

\section{Figure I.2: Map with no. of armed confrontations per district}

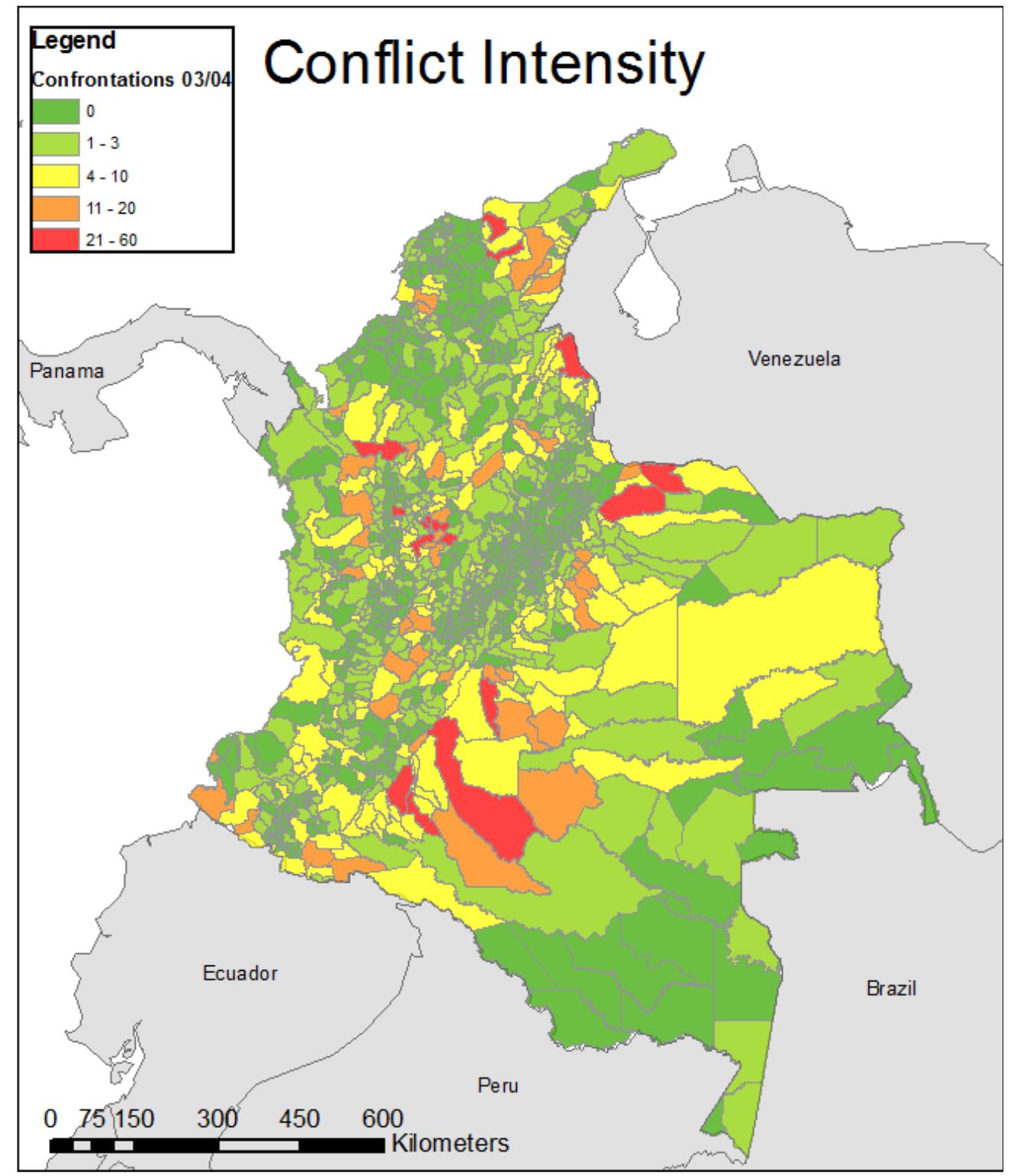

Sources: Author's calculations. Conflict data: Programa Presidencial de Derechos Humanos y Derecho Internacional Humanitario (2010); Map data for Colombian districts: SIG-OT (2013); Map data for neighbouring features: DIVA-GIS (2013).

Our identification in time has shortcomings since the conflict data is only available on a yearly basis. Therefore for the early interviews we might count confrontations that had not

\footnotetext{
${ }^{11}$ The actual data clusters reported in the data are located at a much lower level. Using those instead of the district level reduces the standard errors of our results (not reported).
} 
yet happened (our indicator is for the whole year of 2004 and some interviews started already in October) and for late interviews there might be confrontations we did not count (the interviews continued until the middle of 2005). There are also weaknesses in the spatial identification. Since we only count what happens in the district, the fighting in large districts could have taken place very far from the interviewed household, which would matter if the effect of violence decreases with distance. On the other hand we underestimate the conflict intensity people are exposed to in small districts, where confrontations happening in neighbouring municipalities are still very close but not counted (often they would be only a few kilometres away). We use different approaches to try to account for this. Our findings are however robust to all those different specifications (but not all are reported here). There are also arguments for possible endogeneity issues like reverse causality and unobserved variable bias. Since we do not think that this is a major problem and the discussion is somewhat lengthy, it is not presented in the main results but separately in section I.4.4.

Since our interest is in domestic violence perpetrated by the spouse or partner, not all women interviewed are part of our analysis. ${ }^{12}$ In our different specifications we use basically two samples. The first sample are all women that currently have a partner (married or not) and are living together with this partner. This classification is based on the information given by the women. This group allows us to use all our household specific control variables and comprises 17,319 women. The second group consists of the first group and additionally, all women who state that they are in a relationship, but do not live with their partner. In this case, we are slightly changing the analysis as some control variables are no longer applicable or require a change in their interpretation. The number of observed women is in this case increases to 21,636 .

The incidence of domestic violence is even higher among women who do not live with their partner (close to 33 percent). Including this group in our analysis strongly increases the measured effect of the conflict variable and also increases its significance. Our expectation is that this group contains many women who have actually left their partners because of abuse. Even though in this case we can capture less information with some of the control

\footnotetext{
12 Extending the analysis to include violence exercised by persons other than the partner is not possible, because the questions about domestic violence in the last 12 months only refer to the partners' behaviour. Therefore only women with a partner can be used for the analysis.
} 
variables, we think that the results using the extended group of women tells us more about the real magnitude of the effect of conflict on violent behaviour.

As we want to see the effect of war on non-combatants only, we decided to exclude all women whose partner is in the military. Regular fighters in the FARC hardly have any contact to their family (as described, e.g., in Gutierrez Sanin, 2008). Therefore the only case where the partner of an interviewed woman can be an active combatant is if he is a member of a paramilitary group. Estimates for the relevant time period range between seven to twelve thousand paramilitary fighters (ibid.), so the contamination of our dataset is probably small, since Colombia has a population size of about 40 million.

\section{Table I.1: Descriptive statistics}

\begin{tabular}{|c|c|c|c|c|c|c|}
\hline Variable & Obs & Mean & Std. Dev. & Min & Max & \\
\hline Physical domestic violence & 17319 & 0,1766846 & 0,3814125 & & 0 & 1 \\
\hline Serious Threats & 17319 & 0,1791674 & 0,3835035 & & 0 & 1 \\
\hline Physical violence + threats & 17319 & 0,2554997 & 0,4361543 & & 0 & 1 \\
\hline Poorest & 17319 & 0,2149662 & 0,4108108 & & 0 & 1 \\
\hline Poorer & 17319 & 0,2449333 & 0,4300601 & & 0 & 1 \\
\hline Middle & 17319 & 0,2187193 & 0,4133897 & & 0 & 1 \\
\hline Richer & 17319 & 0,181477 & 0,385424 & & 0 & 1 \\
\hline Richest & 17319 & 0,1399042 & 0,3468976 & & 0 & 1 \\
\hline Rural & 17319 & 0,2770368 & 0,4475477 & & 0 & 1 \\
\hline No. of children & 17319 & 2,17807 & 1,558069 & & 0 & 12 \\
\hline No. of female adults in $\mathrm{HH}$ & 17319 & 1,378775 & 0,7370249 & & 0 & 8 \\
\hline Respondent's Age & 17319 & 33,72019 & 8,746874 & & 13 & 49 \\
\hline No Education & 17319 & 0,0420348 & 0,2006743 & & 0 & 1 \\
\hline Primary Education & 17319 & 0,3633582 & 0,4809806 & & 0 & 1 \\
\hline Secondary Education & 17319 & 0,4495063 & 0,4974582 & & 0 & 1 \\
\hline Higher Education & 17319 & 0,1451008 & 0,3522126 & & 0 & 1 \\
\hline $\begin{array}{l}\text { Respondent currently working } \\
\text { Earnings significant share in }\end{array}$ & 17319 & 0,5033201 & 0,5000034 & & 0 & 1 \\
\hline household spendings & 17319 & 0,7822623 & 0,4127201 & & 0 & 1 \\
\hline At least 6 months pregnant & 17319 & 0,024424 & 0,1543661 & & 0 & 1 \\
\hline Experienced violence in the past & 17319 & 0,123506 & 0,3290266 & & 0 & 1 \\
\hline Partner's age & 17319 & 38,48998 & 10,43356 & & 16 & 98 \\
\hline Partner's Education: None & 17319 & 0,0551418 & 0,2282633 & & 0 & 1 \\
\hline Partner's Education: Primary & 17319 & 0,384722 & 0,4865436 & & 0 & 1 \\
\hline Partner's Education: Secondary & 17319 & 0,4122062 & 0,4922461 & & 0 & 1 \\
\hline Partner's Education: Higher & 17319 & 0,1384607 & 0,3453928 & & 0 & 1 \\
\hline No. armed confrontations $03 / 04$ & 17319 & 3,686067 & 6,044844 & & 0 & 33 \\
\hline
\end{tabular}

Our main dependent variable is constructed from questions about physical violence perpetrated by the partner during the twelve months before the interview. It contains the 
following categories: Being pushed or shaken; hit with the hand; hit with an object; bitten; kicked or dragged; attacked with a knife, gun or other weapon, being physically forced for an unwanted sex act and whether the partner tried to strangle or burn the woman. We also included it if the woman was threatened by her partner with a knife, gun or other weapon. Although this is not a physical attack we think that in its quality it comes close enough to be included. Our dependent variable is coded one if any one of the mentioned attacks happened and zero otherwise. We later also include other non-physical aspects.

Table I.2: Descriptive statistics for low and high conflict intensity districts

\begin{tabular}{|c|c|c|c|c|c|c|c|c|c|c|}
\hline \multicolumn{11}{|c|}{ Summary statistics: districts separated by conflict intensity } \\
\hline & \multicolumn{5}{|c|}{ Low intensity conflict } & \multicolumn{5}{|c|}{ High intensity conflict } \\
\hline & Obs & Mean & Std. Dev. & Min & Max & Obs & Mean & Dev. & Min & Max \\
\hline Physical domestic violence & 11576 & 0,191 & 0,393 & 0 & 1 & 10060 & 0,225 & 0,418 & 0 & 1 \\
\hline Serious Threats & 11576 & 0,211 & 0,408 & 0 & 1 & 10060 & 0,231 & 0,422 & 0 & 1 \\
\hline Physical violence + threats & 11576 & 0,283 & 0,451 & 0 & 1 & 10060 & 0,312 & 0,463 & 0 & 1 \\
\hline Poorest & 11576 & 0,258 & 0,438 & 0 & 1 & 10060 & 0,134 & 0,341 & 0 & 1 \\
\hline Poorer & 11576 & 0,266 & 0,442 & 0 & 1 & 10060 & 0,232 & 0,422 & 0 & 1 \\
\hline Middle & 11576 & 0,207 & 0,405 & 0 & 1 & 10060 & 0,256 & 0,436 & 0 & 1 \\
\hline Richer & 11576 & 0,159 & 0,366 & 0 & 1 & 10060 & 0,213 & 0,410 & 0 & 1 \\
\hline Richest & 11576 & 0,110 & 0,313 & 0 & 1 & 10060 & 0,166 & 0,372 & 0 & 1 \\
\hline Rural & 11576 & 0,349 & 0,477 & 0 & 1 & 10060 & 0,144 & 0,351 & 0 & 1 \\
\hline No. of children & 11576 & 2,237 & 1,632 & 0 & 12 & 10060 & 2,130 & 1,532 & 0 & 11 \\
\hline No. of female adults in $\mathrm{HH}$ & 11576 & 1,490 & 0,829 & 0 & 8 & 10060 & 1,471 & 0,804 & 0 & 6 \\
\hline Respondent's Age & 11576 & 34,103 & 8,780 & 13 & 49 & 10060 & 33,988 & 8,775 & 13 & 49 \\
\hline No Education & 11576 & 0,050 & 0,218 & 0 & 1 & 10060 & 0,033 & 0,178 & 0 & 1 \\
\hline Primary Education & 11576 & 0,382 & 0,486 & 0 & 1 & 10060 & 0,322 & 0,467 & 0 & 1 \\
\hline Secondary Education & 11576 & 0,437 & 0,496 & 0 & 1 & 10060 & 0,483 & 0,500 & 0 & 1 \\
\hline Higher Education & 11576 & 0,131 & 0,338 & 0 & 1 & 10060 & 0,162 & 0,368 & 0 & 1 \\
\hline Respondent currently working & 11576 & 0,526 & 0,499 & 0 & 1 & 10060 & 0,572 & 0,495 & 0 & 1 \\
\hline $\begin{array}{l}\text { Earnings significant share in } \\
\text { household spendings }\end{array}$ & 11576 & 0,804 & 0,397 & 0 & 1 & 10060 & 0,797 & 0,402 & 0 & 1 \\
\hline At least 6 months pregnant & 11576 & 0,022 & 0,147 & 0 & 1 & 10060 & 0,022 & 0,146 & 0 & 1 \\
\hline Experienced violence in the past & 11576 & 0,110 & 0,314 & 0 & 1 & 10060 & 0,137 & 0,344 & 0 & 1 \\
\hline Partner's age & 9451 & 38,657 & 10,376 & 16 & 98 & 7868 & 38,290 & 10,499 & 16 & 98 \\
\hline Partner's Education: None & 11576 & 0,065 & 0,246 & 0 & 1 & 10060 & 0,043 & 0,203 & 0 & 1 \\
\hline Partner's Education: Primary & 11576 & 0,395 & 0,489 & 0 & 1 & 10060 & 0,332 & 0,471 & 0 & 1 \\
\hline Partner's Education: Secondary & 11576 & 0,399 & 0,490 & 0 & 1 & 10060 & 0,448 & 0,497 & 0 & 1 \\
\hline Partner's Education: Higher & 11576 & 0,122 & 0,328 & 0 & 1 & 10060 & 0,160 & 0,367 & 0 & 1 \\
\hline No. armed confrontations $03 / 04$ & 11576 & 0,658 & 0,773 & 0 & 2 & 10060 & 7,364 & 7,527 & 3 & 33 \\
\hline
\end{tabular}

High intensity: more than 2 armed confrontations in the considered time period.

Descriptive statistics of our variables are presented in Table I.1 and Table I.2. Table I.1 presents the descriptives for the whole sample of women who are living together with their partners. In this table we do not include women who do not live with their partner as the household characteristics are not the characteristics of the household of the perpetrator. If 
they are included, the values are very similar, except that the percentage of victims of violence is increased by about three percentage points from 17.7 to 20.7 percent.

In Table I.2 the statistics are presented separately for conflict intensive districts and others. Here we define districts as conflict-intensive if there had been more than two armed confrontations during the time considered. The percentage of women who reported physical abuse by their partners is about three percentage points higher in the conflict zones. Also, more women in conflict zones report to have experienced violence in the past (not by their current partner). Surprisingly most other indicators that turn out to increase the incidence of domestic violence in our analysis are looking more positive in those regions which are more conflict-intensive. On average, people in these areas are wealthier and more educated than those in more quiet districts. Including women in these statistics who do not live with their partners (not reported), does not change these trends. So just looking at the descriptive statistics already gives a hint that conflict might increase violent domestic behaviour. More information about the variables is given in the next section.

\section{I.4 Analysis and Results}

This section presents the results of our main specifications and those of various robustness checks, consisting of changes in variables or the analyzed samples. The basic, as well as the alternatives specifications, confirm our central theory that the experience of conflict changes behaviour towards more violent patterns, which can be observed by a higher incidence of domestic violence.

\section{I.4.1 General models}

Our basic models can be found in Table 1.3 in the first two columns. The dependent variable is whether the woman has experienced physical domestic violence within the last twelve months. The two different columns present the results for the two different samples of women. Including the women who are in a relationship but do not live with their partner does not affect the sign of the coefficients but their magnitude. There are also no important changes in the significance levels. 
Table I.3: Regression results domestic violence, general and special spatial identification

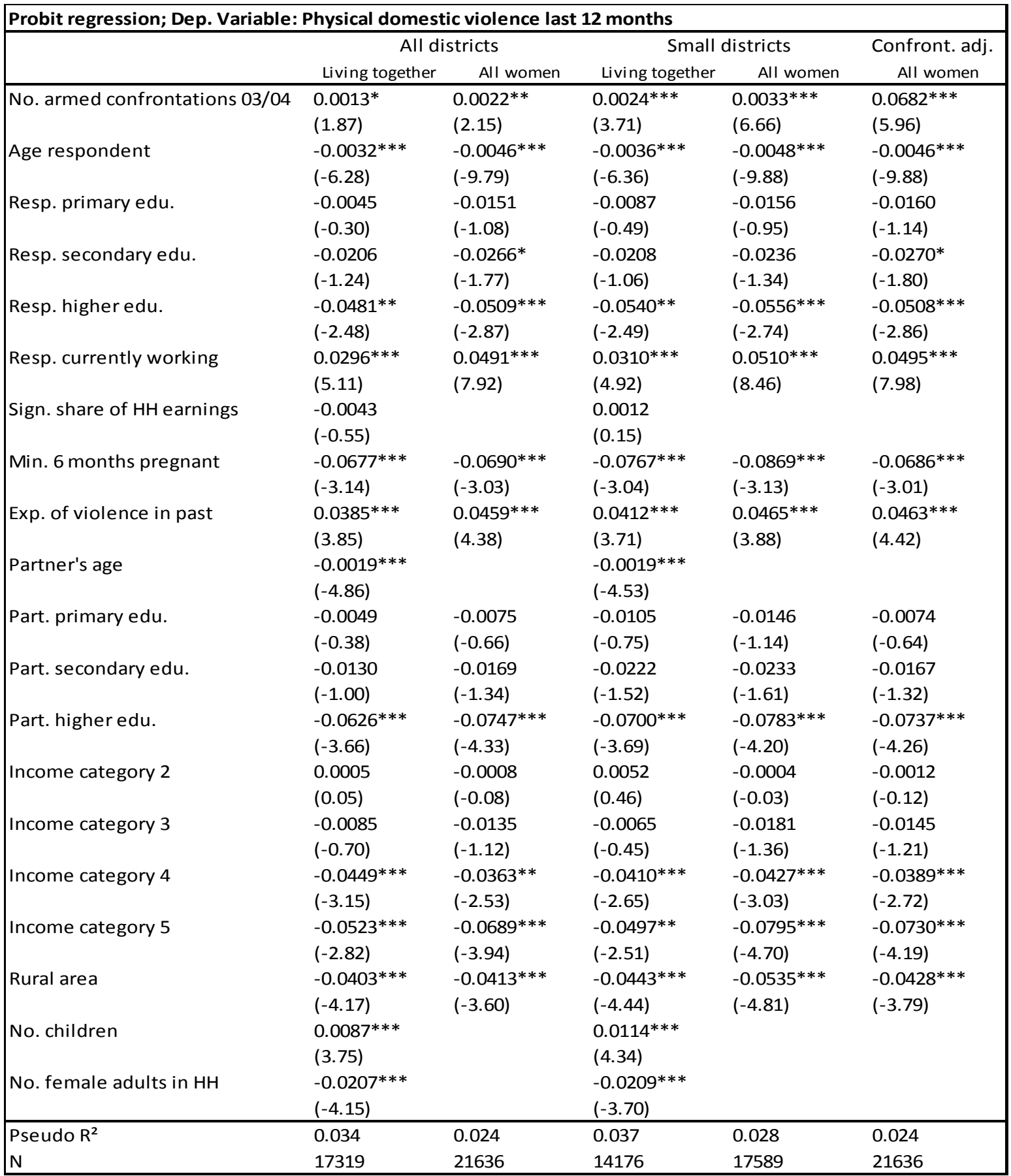

Average marginal effects reported, standard errors are clustered at municipality level; t-statistics in parentheses; in the last column the armed confrontations variable has been divided by the square root of the distric size; asterisks denote the following significance levels: ${ }^{*} \mathrm{p}<0.10, * * \mathrm{p}<0.05, * * * \mathrm{p}<0.01$.

Our main variable of interest - the number of armed confrontations - is positive and highly significant. This shows that living in an area of higher conflict intensity increases the risk of being the victim of domestic violence. The average marginal effects of our conflict variable are 0.0013 and 0.0022 for the two samples respectively. Taking the difference between the 
most peaceful and the most conflict-intensive region, this would present a risk-increase between four to seven percentage points.

Theory suggests that the occurrence of domestic violence depends on the characteristics of the perpetrator and furthermore on the characteristics of the victim. An important point here is also whether and to which extent the victim accepts the violence before it decides to leave the relationship. This is influenced by incentives for remaining in the abusive relationship and the options to leave. In order to try to capture these possible determinants of domestic violence we introduce an array of control variables into our analysis.

The first control variables are wealth dummies. Since DHS surveys do not ask for income this is calculated from household assets and contained in the survey data. The reference category is the group of the poorest households. It can be seen that the risk of being victimized is significantly reduced in the two highest wealth categories. Wealth can be seen as stress reducing and wealthy people might rather be able to protect themselves, reducing the incidence of domestic violence. When including women that are not living with their partners, these variables can be interpreted as the alternative option because they refer to the wealth of the household where women can go if they do not live with their partner. Living in a rural location also seems to reduce the risk of victimization. A larger number of children is however associated with more domestic violence. The reason for this could be more stress in the family because of its size. It could also be an indication for more "traditional" family values, which promote having children and attach less intrinsic value to women. Children also represent an incentive for women to stay in the household as described in the theory part. We expect that in households with more female adults they might be better able to protect each other. Controlling for this we find that higher numbers of female adults in the household indeed reduce victimization. The number of children and the number of female adults are not included when using the larger sample, as they do not always refer to a common household of the potential victims and perpetrators.

When it comes to the personal characteristics we find that older women are less likely to be abused. There can be various reasons why age should matter. One could guess that age increases experience and can give higher social status. Younger, less experienced women might be more easily convinced by their partner to stay using false promises and be less respected. Older partners also are less likely to be perpetrators of domestic violence 
because on the one hand the relationship probably already proved to be stable and maybe people just become calmer with age.

Looking at education one should expect it to reduce violence, since more educated women have much better options to leave a relationship and do not need economic support from a male partner. Higher education will probably also be connected with more modern values, coming along with a reduced acceptance of violence against women. When it comes to the partner's education, the more educated men will most likely also have less "traditional" values and a higher capability of resolving disputes without violence. Since partners are often similar in both age and education, we expect these factors to have a strong effect and use dummy variables for the different education levels as control variables. We find no significant effect for primary and secondary education (the reference category being no formal education, variables with a confidence level lower than $90 \%$ are considered insignificant in this study). Only women with a higher education have a significantly lower risk of becoming victims of domestic violence. Equally for the partner's education, only the higher education dummy is negative and significant (at more than the $99 \%$ level). Colombia is a highly unequal country and this picture could be a result of the strong separation between classes not only in financial aspects, but also in attitudes.

An unexpected result is that women who are currently working become victims more often, while one would expect that for them it would be easier to leave and thus become victimized less often. Our best explanation is that although the women say that they are working, the job or income are unobserved and therefore we know little about the actual character of the employment situation and level of independence it can render. Second we suspect that the higher incidence of violence in this case could be a result of jealous partners, because women who are working are more likely to leave the house and have contact with other men.

We try to control for the economic importance of the women's income for the household. Women are asked in how far their income is used for coverage of current expenses of the household; or if it is mainly saved. Our dummy variable, which assumes the value of one if the income of the women is at least partially used for current expenses, is not significant. 
As a control we also use a dummy variable that assumes the value of one if the woman has, at the time of the interview, been pregnant for at least six months. We expect men to show more restraint when it comes to pregnant women in order to not harm the child. The variable captures whether the woman has been pregnant for at least half of the time the questions about domestic violence refer to. The result is as expected, the coefficient is negative and significant at the one percent level.

In the survey women are questioned whether they had been the victim of violence in the past. It is a known phenomenon that people who were the victims of violence in the past have a higher tendency of becoming a victim again. To check for this we use a dummy assuming the value of one if the woman was in any way physically abused in the past by someone other than her current partner. The variable turns out positive and highly significant in all specifications.

In conclusion, it can be said that nearly all of our variables are significant at more than the $90 \%$ level and their signs in accordance with the theoretical considerations.

\section{I.4.2 Different spatial identification and simulation of effect's magnitude}

As mentioned before, problems might arise with the spatial identification when it comes to very large districts. In some Colombian districts the distance from one border point to another exceeds 400 kilometres. In this case our identification is more problematic because the fighting could have taken place very far from the interviewed households. In order to control for this we exclude all districts with an area of more than 2500 square kilometres. The results are reported in columns three and four of Table 1.3 for the two different samples respectively. In these cases the coefficients of the confrontations variable increase strongly, as do the t-statistics. In column four, the average marginal effect for the conflict variable now reaches 0.0033 . To give an idea of the dimensions of the effect we make use of a simulation. For the model including all women in a relationship, in districts smaller than 2500 square kilometres, without observed conflict, the average probability of having been the victim of domestic violence in the last twelve months is about 19.8 percent. Keeping all other characteristics for these women constant, but changing the conflict indicator to the highest observed level in the sample (33 confrontations in the two years considered), the 
probability of victimization is predicted again and the average increases to 32.1 percent, which corresponds to an increase of 12.3 percentage points.

As another way to incorporate the differences in spatial identification, we adjust the conflict variable by the district size. ${ }^{13}$ Again our variable of interest (conflict incidence) is highly significant. It now has a larger marginal effect (but the range of the variable is of course much smaller than before).

The opposite issue - likewise briefly mentioned above - is that people are most likely affected by the conflict in proximal districts especially if districts are rather small (some districts cover an area of less than 40 square kilometres). We do not suspect this to be a problem, because the conflict usually does not sharply stop at a district border, which is why conflict intensity measures for neighbouring districts are anyway correlated. We also use model specifications where we include the armed confrontations of nearby districts into the measure (not reported). These approaches show similar coefficients and significance values, thereby confirming our results, but not offering any further insights.

\section{I.4.3 Different measures of domestic violence}

Domestic violence does not only have physical aspects. There are many other possibilities of mistreatment in a relationship. Control over another person can for example also be achieved by means of threats (which can include threats of violence). To include nonphysical aspects we use models with different definitions of domestic violence and check for the influence of external conflict. The indicators contained in the variables are listed in Table A.1 (in appendix A.1).

The first alternative measure includes threats as an indicator. It is coded one if the woman reports that her partner used at least one of the following threats against her in the last twelve months: threat to abandon her; to take away the children; to withdraw economic support; or if she was threatened with a weapon (as in our first indicator). We use these as

\footnotetext{
${ }^{13}$ The number of attacks is divided by the square root of the district area. The square root is used since we are more interested in distances than area sizes. Even though this is by far not perfect, it is a simple measure that comes closer to what we actually want to observe than using the area. Also the range of values is much smaller than for area sizes.
} 
they are all assertive and serious threats. The survey contains other questions about nonphysical aspects that we did not include. These are whether the partner did use expressions like "you are good for nothing"; did not allow the woman to see friends; limited contact with the family; or wanted to know where she was "all the time". We do not include these questions because we think that they could be mainly driven by jealousy (which we consider not to be conflict related) and at least some of them also depend on the personal perception of the woman.

The results of the model using threats as the dependent variable can be found in Table A.2 in the first and second column for both samples of women. As can be seen the coefficient of our conflict variable hardly changes. For the other variables there are changes in the coefficients; and even some variables that were statistically insignificant before now turn significant. The main interesting finding is that threats are already reduced at lower income and education levels.

When using the combined indicator including physical violence and threats, we also see nothing contradicting our prior findings. The results are reported in Table A.2 in columns three and four.

\section{I.4.4 Possible endogeneity issues}

Different arguments could be raised that suggest an endogeneity problem in the analysis. The first idea is that of reverse causality. Domestic violence could lead to women leaving their partner and because of a lack of alternatives they might subsequently join the guerrilla and participate in combat. Female soldiers in the Colombian guerrilla troops are common and this could theoretically increase the number of fighters and thereby also conflict intensity. The same argument could be made about children who experience or witness domestic violence at home and therefore leave, subsequently joining the irregular forces. Child soldiers are also common in the Colombian conflict and most studies agree that many of the child soldiers join voluntarily to escape domestic violence or sexual abuse (e.g., Brett, 2003, p.10). The argument about the conflict intensity is the same as for the women. 
While we consider domestic violence to be a possible source for violent potential in the society and thereby future conflict, we do not think that this mechanism is very problematic for our spatial identification. The bias would only exist if domestic violence increased conflict intensity in exactly the district where the domestic abuse takes place. We consider this to be unlikely. The guerrilla troops are highly organized and disciplined military-like organizations. The locations of fighting are subject to strategic military choice. This means the guerrilla troops will not fight where they have the best recruiting opportunities, but instead will redeploy the recruits to the places where the fighting takes place. If therefore conflict intensity is determined by military strategy there will be no bias because of reverse causality. A comprehensive overview over the organizational structures and composition of the irregular forces is given in Gutiérrez Sanín (2008).

We think that roughly the same argument holds for unobserved factors. We consider it unlikely that there are factors that would influence military strategy at the group or state level and at the same time domestic violence. Even though both are forms of violence they are exercised in completely different settings. Using violence against a partner is an individual decision. Armed confrontations are a mixture of planning, strategic interest and chance. Despite not considering it likely we try to control for an unobserved variable bias, caused by some unknown factor, underlying higher numbers of armed confrontations and higher incidence of domestic violence in the districts. We do this by using a two-stage instrumental variable approach. As instruments we employ geographical characteristics that influence the conflict by offering military advantages or economic incentives for the irregular forces. The instruments used are the range in elevation in a district (difference between the highest and the lowest point in the district) and whether or not it is an oil region. The elevation-range is a measure for how mountainous the terrain is. It was calculated using high resolution satellite elevation data from the International Center for Tropical Agriculture CIAT (90m SRTM Data). ${ }^{14}$ High ranges indicate a more rugged terrain offering cover and concealment for the guerrilla forces. If the district is characterized by oil production or exploration (referred to as oil region), it is more interesting for irregular forces, since an important source of money for all insurgents is the extortion of the oil industry, mainly through sabotage (destruction of pipelines). Therefore oil regions show more armed

\footnotetext{
${ }^{14} \mathrm{~A}$ detailed description of the sources and how this and other variables were defined and calculated can be found in the technical notes in the appendix A.2.
} 
confrontations. The data on oil regions was obtained through SIG-OT (Sistema de información geográfica para la planeación y el ordenamiento territorial).

We expect these instruments to influence the conflict but not to have any effect on domestic violence. Domestic violence as discussed in the theory section has an instrumental and expressive function and will also depend on traditions or values. We cannot see any way how our geographical indicators could influence the perceived need of spouses to discipline their partner or create additional stress except through conflict. Looking at traditions and values, if a more mountainous terrain was associated with more secluded regions, it could be argued that a larger distance to civilization could mean less contact and more traditional values favouring violence against the partner. To check for this we looked at the correlation between the instruments and some general indicators of seclusion or isolation. On average the municipalities with mountainous terrain are somewhat closer to larger cities (most Colombian towns are located on the three mountain chains) and show slightly higher levels of development (measured by the percentage of households with unsatisfied basic needs, a multidimensional poverty measure published by the Colombian national statistics department DANE) so the exclusion argument is not valid. ${ }^{15}$ The correlations between the oil region indicator and city distance or development measures are around -0.05 and 0.05 respectively. So there seems to be no important correlation. For both instruments the correlation with telephone coverage as a proxy for social isolation is between 0.03 and 0.05 . Since we find no support for systematic differences between more or less mountainous or oil rich districts, we expect our instrument to have no other impact on domestic violence than through the channel of conflict.

The most common technique used for instrumental variable estimation is probably the twostage least squares estimation. ${ }^{16}$ We present the results for this approach in column 3 of Table I.4. The coefficient of the conflict variable is positive and highly significant. The Fstatistic in the first stage does not imply a weak instrument problem and the Sargan-score for the overidentification test cannot reject the null hypothesis that our instruments are

\footnotetext{
${ }^{15}$ To check for seclusion and similar arguments, municipality level variables were added to the original model (distance to cities, forest density, coca production, etc.). While some of them had some explanatory power, the conflict indicator still remained significant (results not reported).

${ }^{16}$ We use the Stata command 'ivregression' with the 2sls option to estimate this model.
} 
valid at a conventional level. In this setting the effect of conflict is positive and highly significant.

Table I.4: Regression results domestic violence, instrumental variable approaches

\begin{tabular}{|c|c|c|c|}
\hline \multicolumn{4}{|l|}{ IV two-stage regression models } \\
\hline & Base model & $\begin{array}{l}\text { Two-stage } \\
\text { process: NB - } \\
\text { Probit }\end{array}$ & $\begin{array}{l}\text { Two-Stage } \\
\text { Least Squares }\end{array}$ \\
\hline No. armed confrontations $03 / 04$ & $\begin{array}{l}0.0022^{* *} \\
(2.15)\end{array}$ & $\begin{array}{l}0.0070^{* * *} \\
(7.84)\end{array}$ & $\begin{array}{l}0.0105^{* * *} \\
(7.94)\end{array}$ \\
\hline Age respondent & $\begin{array}{l}-0.0046 * * * \\
(-9.79)\end{array}$ & $\begin{array}{l}-0.0046 * * * \\
(-13.91)\end{array}$ & $\begin{array}{l}-0.0044 * * * \\
(-12.94)\end{array}$ \\
\hline Resp. primary edu. & $\begin{array}{l}-0.0151 \\
(-1.08)\end{array}$ & $\begin{array}{l}-0.0142 \\
(-1.01)\end{array}$ & $\begin{array}{l}-0.0130 \\
(-0.89)\end{array}$ \\
\hline Resp. secondary edu. & $\begin{array}{l}-0.0266^{*} \\
(-1.77)\end{array}$ & $\begin{array}{l}-0.0260^{*} \\
(-1.77)\end{array}$ & $\begin{array}{l}-0.0231 \\
(-1.51)\end{array}$ \\
\hline Resp. higher edu. & $\begin{array}{l}-0.0509 * * * \\
(-2.87)\end{array}$ & $\begin{array}{l}-0.0509 * * * \\
(-2.97)\end{array}$ & $\begin{array}{l}-0.0453^{* * *} \\
(-2.58)\end{array}$ \\
\hline Resp. currently working & $\begin{array}{l}0.0491^{* * *} \\
(7.92)\end{array}$ & $\begin{array}{l}0.0490 * * * \\
(8.58)\end{array}$ & $\begin{array}{l}0.0489 * * * \\
(8.40)\end{array}$ \\
\hline Min. 6 months pregnant & $\begin{array}{l}-0.0690 * * * \\
(-3.03)\end{array}$ & $\begin{array}{l}-0.0699 * * * \\
(-3.56)\end{array}$ & $\begin{array}{l}-0.0631 * * * \\
(-3.31)\end{array}$ \\
\hline Exp. of violence in past & $\begin{array}{l}0.0459 * * * \\
(4.38)\end{array}$ & $\begin{array}{l}0.0432^{* * *} \\
(5.44)\end{array}$ & $\begin{array}{l}0.0478^{* * * *} \\
(5.67)\end{array}$ \\
\hline Part. primary edu. & $\begin{array}{l}-0.0075 \\
(-0.66)\end{array}$ & $\begin{array}{l}-0.0080 \\
(-0.73)\end{array}$ & $\begin{array}{l}-0.0056 \\
(-0.49)\end{array}$ \\
\hline Part. secondary edu. & $\begin{array}{l}-0.0169 \\
(-1.34)\end{array}$ & $\begin{array}{l}-0.0174 \\
(-1.50)\end{array}$ & $\begin{array}{l}-0.0128 \\
(-1.06)\end{array}$ \\
\hline Part. higher edu. & $\begin{array}{l}-0.0747^{* * *} \\
(-4.33)\end{array}$ & $\begin{array}{l}-0.0767 * * * \\
(-5.25)\end{array}$ & $\begin{array}{l}-0.0643 * * * \\
(-4.37)\end{array}$ \\
\hline Income category 2 & $\begin{array}{l}-0.0008 \\
(-0.08)\end{array}$ & $\begin{array}{l}-0.0021 \\
(-0.23)\end{array}$ & $\begin{array}{l}-0.0066 \\
(-0.71)\end{array}$ \\
\hline Income category 3 & $\begin{array}{l}-0.0135 \\
(-1.12)\end{array}$ & $\begin{array}{l}-0.0165 \\
(-1.63)\end{array}$ & $\begin{array}{l}-0.0268 * * \\
(-2.50)\end{array}$ \\
\hline Income category 4 & $\begin{array}{l}-0.0363^{* *} \\
(-2.53)\end{array}$ & $\begin{array}{l}-0.0391 * * * \\
(-3.53)\end{array}$ & $\begin{array}{l}-0.0522 * * * \\
(-4.48)\end{array}$ \\
\hline Income category 5 & $\begin{array}{l}-0.0689 * * * \\
(-3.94)\end{array}$ & $\begin{array}{l}-0.0706^{* * *} \\
(-5.51)\end{array}$ & $\begin{array}{l}-0.0826 * * * \\
(-6.28)\end{array}$ \\
\hline Rural area & $\begin{array}{l}-0.0413^{* * *} \\
(-3.60)\end{array}$ & $\begin{array}{l}-0.0435^{* * *} \\
(-5.39)\end{array}$ & $\begin{array}{l}-0.0354 * * * \\
(-4.23)\end{array}$ \\
\hline Pseudo $R^{2} / R^{2}$ & 0.024 & 0.035 & 0.035 \\
\hline $\mathrm{N}$ & 21636 & 17319 & 21346 \\
\hline $\begin{array}{l}\text { Test statistics for first stage } 2 \mathrm{SLS} \text { : } \\
\text { Test for overidentification } 2 \mathrm{SLS} \text { : }\end{array}$ & $\begin{array}{l}1432.73 \\
\text { gan (score) }\end{array}$ & $2(1)=.4578$ & $(p=0.4987)$ \\
\hline
\end{tabular}

Average marginal effects reported except for $2 \mathrm{SLS}$ model; t-statistics in parentheses; asterisks denote the following significance levels: ${ }^{*} p<0.10, * * p<0.05, * * * p<0.01$.

We do however consider this approach with the standard procedure to be problematic for various reasons. In the first stage we are dealing with count data (the number of confrontations) and in the second stage with binary data. In both cases a linear model is not the best approximation. More importantly the conflict, as well as the instrumental variables, 
are observed at the district level, while everything else is observed at the individual level. This means that each individual observation in the same district carries the same information about the conflict and instruments. Thereby in the first stage the influence of each district on the prediction of conflict depends on the number of individuals observed in the district (the first stage would have to be weighted).

We have about 20.000 observed cases (because of the number of women) but the data originally only observes conflict information for the 230 districts where women were interviewed. The test statistics however are calculated as if there actually were 20.000 conflict observations. All second stage explanatory variables are also incorporated into the first stage. First we do not think that in the Colombian case the characteristics of households and individuals are good predictors of conflict and more importantly, this procedure produces a different prediction of conflict for each individual in the second stage, while actually the prediction should be the same for all individuals in the same district.

Because of this we use an alternative approach as well. For the prediction of the number of armed confrontations in the first stage we use a negative binomial regression, since we are working with count data and we do not include any second stage regressors. The results of the first stage regression are shown in Table A.3, column 1 . Here we can see that our instrumental variables are highly significant but the pseudo $R^{2}$ is relatively low which indicates that the instruments are rather weak.

The second stage regression is, as in our original analysis, a Probit regression. Standard errors in our two-stage process are calculated using bootstrapping of both stages. The results are reported in Table I.4, column 2. All models are calculated using the sample for all women. The dependent variable is - only physical - domestic violence. Again the conflict variable increases domestic violence and is highly significant. The weak instrument problem does however cast some doubt on the validity of the results.

There are other potential instruments we did not use because we could not be sure about the exclusion restriction. Using them together with the elevation and oil variables increases the explanatory power of the model used for the prediction of conflict (see columns 2 and 3 of Table 6), but the $R^{2}$ is never very high. They are however also reported since an exploration of factors determining the conflict intensity might be interesting. Unlike in the 
first stage model, we include all Colombian districts not only the ones where interviews were conducted in these models. If no other source is mentioned the information on the municipality indicators was obtained through SIG-OT (Sistema de información geográfica para la planeación y el ordenamiento territorial). The conflict is more intense in regions with higher coca production (measured as the percentage of land in the district dedicated to growing coca plants, data from the Colombian Drug Observatory ("ODC - Observatorio de Drogas de Colombia"). This is an example for economic incentives since the insurgent forces rely heavily on income from trafficking drugs and intermediate products. If large proportions of the district surface are covered by forest this offers cover and concealment, rest and hiding places for guerrilla troops (Forest cover data source: FAO, Global Forest Resources Assessment 2000). The indicator has a positive and significant effect on conflict intensity. National highways are interesting for all sides as lines of communication, supply and transport of personnel (or interdiction of such). The coefficient of a dummy indicating the presence of a national highway within at least three kilometres of the district is positive and significant. The presence of an oil refinery is insignificant (there are only five in Colombia).

Additional variables are the population density, the presence of an oil pipeline within a distance of less than three kilometres, the distance to the next larger town and to the next army base, ${ }^{17}$ indicating that conflict is actually happening closer to towns but further away from army bases.

In general we do not see indications that the analysis suffers from an endogeneity problem, but due to the lack of better instruments, we cannot give a definite proof for this.

\section{I.5 Conclusions}

We find evidence that the presence of intense conflict seems to increase the risk of women to be the victim of domestic violence. We suspect the effect of conflict to work through behavioural change in the form of higher acceptance of violence and emotional blunting, through more expressive violence as a release for heightened stress and through higher acceptance of domestic violence by the victims who are less willing to give up the protection of their family in an insecure environment. Our highest estimates show an increase of more

\footnotetext{
${ }^{17}$ The raw data to create those indicators was extracted as GIS data in the form of ESRI shape files, from SIG-OT except for the locations of army bases which was determined based on information available from the web pages of the Colombian National Army. For more details see Appendix A.2.
} 
than twelve percentage points in the incidence of domestic violence when comparing a peaceful and a conflict intensive environment which is a very large effect.

We are convinced that the effects of this change in behaviour and the long-term effect that domestic violence has on future generations will have serious consequences for the society as a whole. Violence from a conflict causes more violent behaviour and domestic violence affects future generations in similar ways. This cycle of violence will then be a major hindrance for the resolution of any conflict. The violence could also spread from the military conflict into the civil life, e.g., in the form of different kinds of violent crime.

Colombia has a long history of violence which cannot only be seen in the conflict but also in its enormous crime rates and the intra-family violence. It is probably a sad example of how different forms of violence can reinforce each other. We suspect that the effect of conflict on domestic violence is not necessarily as large in other countries as it is in Colombia. Domestic violence is always very much influenced by the cultural and general environment and this could be more favourable in Colombia than in other conflict regions.

We think that conflict changes attitudes and behaviour even though as shown by Blattman (2009) not always with only negative consequences. Understanding the impacts however is very important for conflict and post-conflict developments. More research on the individual and behavioural effects of conflict, especially on peoples' attitude towards violence and its comparison across regions should therefore prove to be very interesting areas of future research. 


\title{
Chapter 2
}

\section{The impact of armed conflict on firm investment in Ethiopia}

\author{
Joint work with Admasu Shiferaw ${ }^{\ddagger}$
}

\section{$\underline{\text { Abstract }}$}

This study investigates the effect of armed conflict on firm-level investment in Ethiopia using a spatial identification approach. The firm data comes from the Ethiopian manufacturing census and conflict is measured using disaggregated battle-event data from the ACLED project. Using a very precise spatial identification of conflict exposure, we find, that even in a low level conflict environment like Ethiopia, the incidence of conflict in close proximity to the firm cause significant reductions in investment. Labour intensive firms seem more affected by this than others which we attribute - among other factors - to a higher risk aversion of their owners.

\section{Acknowledgements}

We would like to thank Stephan Klasen and the participants of the development research group's staff seminar at the University of Göttingen for helpful comments and discussion contributions. Financial support by the German Research Foundation (DFG) through the CRC-PEG is gratefully acknowledged.

\footnotetext{
${ }^{\ddagger}$ College of William and Mary, Department of Economics.
} 


\section{II.1 Introduction}

Academic research in civil war and armed conflict has increased significantly over the past two decades. While earlier studies mainly relied on cross-country analysis using macro-level data, the past few years have witnessed a large increase in the use of micro-data at the household and individual level. ${ }^{18}$ This development offers much better possibilities to assess the impact of armed conflicts on the behaviour of households and individuals. There has however been remarkably little research about the impact of conflict on firm performance and behaviour. Armed conflict is mainly present in developing countries and its impact on entrepreneurship is presumably one of the mechanisms by which it affects overall economic development. While it is generally assumed that conflict would have a significant negative impact on job creation, investment and other productivity enhancing activities of firms, there have only been very few quantitative empirical studies that estimate these impacts. The article by Blattman and Miguel (2010) gives a very comprehensive overview over the conflict-related literature. While the authors review over 300 articles and books on this topic, there is only one article by Guidolin and La Ferrara (2007) that deals with firms in a conflict environment. Apart from this, the only other studies we have found that assess the impact of conflict on firms are Collier and Dupchonel (2010) who use data from Sierra Leone, Camacho and Rodriguez (2011) who look at firms in Colombia and to a certain extent Pshisva and Suarez (2010) who focus mainly on the effect of conflict related crimes.

This study intends to contribute to this small yet very important field of research using firm level data on manufacturing firms in Ethiopia. The firm level data is obtained from the annual census of manufacturing conducted by the Central Statistical Agency (CSA) of Ethiopia.

For measurements on conflict and insecurity, this study relies on a rather recent development in conflict data analysis. The ACLED project provides highly disaggregated and detailed conflict data with information on the event-level and spatial referencing. The use of

\footnotetext{
${ }^{18}$ Examples for the increased use of micro-level data are the projects 'Households in Conflict Network' (http://www.hicn.org), that started in the early 2000's and 'MICROCON' (http://www.microconflict.eu), founded in 2007.
} 
such data allows a very precise identification of the conflict exposure of economic agents, in our case firms, which until now has not been extensively used.

Ethiopia is an ideal case to test our hypothesis on the effect of conflict. It is one of the largest countries in Sub-Saharan Africa and finds itself in one of the most conflict prone parts of Africa. The country has suffered from internal and inter-state conflict for decades. The sample period for our study includes the border war with Eritrea during 1998-2000 and infighting with different insurgent groups. The conflict since the war however has been a low level conflict and not a civil war.

The availability of firm level panel data and the recurrence of fighting at different levels of intensity would allow us to assess the impact of conflict on firm investment, which is our response variable. Our identification strategy is to exploit the differences in conflict intensity across towns and over time while controlling for firm fixed effects.

We find that even a low-level conflict, like the one in Ethiopia, can have significant negative investment effects on the firm level. Labour intensive firms seem to be especially affected, possibly due to different risk attitudes of firm owners. The effect is only present outside the capital Addis Ababa and there are no major differences across industries, nor do we observe other changes in firm behaviour.

\section{II.2 The Effect of Conflict on Firm Behaviour: Theoretical Considerations}

The role of investment for economic growth has been demonstrated adequately in theory (Solow, 1956) as well as empirical studies. However, economists have been less successful in explaining the investment decisions of firms. The earlier neoclassical models of investment focused entirely on demand and the user cost of capital (Jorgenson, 1967). ${ }^{19}$ The contemporaneous user cost affects the rate of adjustment of capital toward the desired level if there is a non-zero elasticity of substitution between capital and labour; otherwise only demand matters. This framework perceives investment decisions as sensitive to neither

\footnotetext{
${ }^{19}$ The user cost encompasses price of capital goods, interest rate and depreciation as well as taxes and investment incentives.
} 
the expected cash-flow of a project nor to the associated adjustment cost. This static approach assumes that investment decisions can be reversed costlessly if the marginal value product of capital turns out to be less than its marginal cost.

Subsequent theories of investment addressed this caveat by incorporating adjustment costs and expected payoffs directly into the firm's objective function. This class of dynamic investment models, of which Tobin's $Q$ is a leading example, assumes competitive markets and convex adjustment costs (Tobin, 1968). A key implication of these assumptions is a smooth investment process in response to expected returns. While outperforming static models theoretically, dynamic investment models disappoint when tested empirically. Chirinko (1993) provides a thorough discussion of the critique including a very low goodness of fit and an extremely long adjustment period.

Most importantly, investment models with convex adjustment costs fail to explain why most firms have long spells of zero investment followed by a burst of investment outlays as shown for instance in Doms and Dunne (1998) for the US. The degree of investment discontinuity and lumpiness has since been shown to be pronounced in developing countries (Bigsten et al., 1999; Shiferaw, 2009). This observation prompted the development of the relatively recent investment models under uncertainty (Dixit and Pindyke, 1994). These models recognize that if investment is at least partly irreversible, firms would want to delay their investment decisions until more information on payoffs arrives. The larger the degree of uncertainty, the higher the option value of waiting for more information and hence the longer the period of inaction.

While the latest investment models with uncertainty focus mainly on demand uncertainty, the current chapter examines empirically the role of conflict as a source of uncertainty. Some of the impacts of conflict are rather direct and easy to observe. These include destruction of physical assets, disruption of production and loss of lives of employees, firm owners and family members. Such incidents often result from more violent armed conflicts which would lead to more extreme ex-post decisions such as firm exit and/or relocation.

However, developing countries mostly exhibit internal armed conflict of a much lower intensity whose effects could be just as significant but much harder to capture. The frequency of such conflict would shroud the expected payoff of an investment project with 
uncertainty. This could be because of unpredictable disruption of transport and other infrastructural services which could in turn disrupt production. Uncertainty could also arise from the underlying potential for escalation into a high-intensity conflict. This environment would dampen firms' desire to invest in a given locality. Since conflict is a covariate shock, it would also make the investment decisions harder to reverse and hence highly risky as it affects the attractiveness of the entire locality.

Conflict-induced uncertainty could also lead to inefficiency and a lower profit rate in addition to raising its variance. This could arise from ex-ante risk mitigating measures the firm is obliged to take against uninsured risk. The firm may require heightened security features to prevent looting during an outbreak of conflict. Similarly, it may need to stockpile intermediate inputs if supply chains and transport services are susceptible to conflict. Such protective measures come at a cost and may lower the profit rate and curtail investment. However, it could also be argued that firms would only be willing to operate in a conflict prone area if the average profit rate is much higher than elsewhere.

Firms in conflict zones could also be credit rationed because of lenders' perception of their creditworthiness. The high cost of credit or rejection of loan applications could force firms in conflict prone areas to rely on internal sources of finance for investment as compared to their counterparts in tranquil locations. This reality forces firms to delay investment projects even when they are deemed profitable. Therefore investment would be less frequent in conflict zones. The direct and indirect effects of conflict may also result in a sub-optimal choice of production technology. Firms may shift from a capital intensive to a labour intensive process if capital is hard to acquire in the first place but also subject to greater risk of destruction or underutilization. A related issue has been brought up by Hammermesh (1999) who argues that in areas with high crime rates, workers are less likely to work during the night. This in turn prompts employers to adjust their production processes. This sort of adjustment, however, may not be feasible for all firms depending on industry specific factors and the elasticity of substitution between capital and labour. If a firm with a capital intensive technology locates in a conflict zone, its investment decision could be less responsive to conflict because the risk has already been assumed. For labour intensive firms, capacity expansion may be sensitive to conflict intensity. 
The main hypothesis in this chapter is that in the presence of armed conflict firms will reduce investment either deliberately (because of uncertainty and/or adjustments of the production process) or because of credit restrictions. These reactions are not necessarily the consequence of being directly affected by conflict (e.g., by being directly attacked) but could entirely rely on the perception of higher risk through conflict in the area.

\section{II.3 Literature Review}

At the macro-level, Barro (1991) and Alesina and Perotti (1996), show that political instability reduces aggregate investment and economic growth. While investment in any country is primarily a firm level decision, there are very few studies that look at the impact of conflict on firm behaviour. The conflict literature using micro data has mainly focused on the effects on individuals and households (which are however also often production units). Rockmore (2011) shows that a large part of the welfare losses in a conflict-affected society does not come from the direct exposure to violence but from reactions to the risk of such an exposure and Bundervoet (2010), using data from Burundi, finds that conflict increases the likelihood of households to grow low-risk low-return crops. The findings of both these studies do support our theory on the level of households.

The earliest article we found that empirically investigates the relationship between conflict and firms is Guidolin and La Ferrara (2007) who actually find that the ending of the civil war negatively impacted the stock prices of firms in the diamond mining sector in Angola. They explain this with advantages the companies derived from the war and the resulting lack of order and authority. Some of those could have been higher entry barriers for new competitors, less influence from the authorities (e.g., cheaper licenses) and profitable, not strictly legal deals. This is however a very special case which can most likely not be generalized and companies deriving additional profit from such conditions are not very desirable for a country anyway.

Among existing studies that address the effect of violence on firms, Pshisva and Suarez (2010) is to our knowledge the only study that relates firm level investment with insecurity. They find a negative impact of kidnappings of firm owners or management on firm investment in Colombia. Kidnappings in Colombia are often connected to the civil conflict. They do also check for conflict by incorporating guerrilla attacks into the analysis but find no 
significant effect. The reason for this could be that the spatial identification is not exact enough because they use relatively large geographical units (federal states).

Camacho and Rodriguez (2011) do focus on conflict and its effect on firm exit in Colombia using smaller administrative units. They find that an aggregate measure of different kinds of attacks increases the probability of firm exits in that particular district.

Collier and Dupchonel (2010) investigate the effects of civil war on firm performance in Sierra Leone. They evaluate the long-term effects of civil war by analyzing firm number and employment on the chiefdom-level; and size, income and proxies for human capital on the firm-level in 2006, based on the intensity of the conflict that ended in 2002 . They see no effect on the firm number or employment levels, but find that civil war has long-term effects on firms through the destruction of human capital. Due to the long interval between the observations on conflict and firms' responses, this approach is not suitable to identify contemporaneous conflict effects.

Our study is also related to a small body of literature about the effect of crime on firms. Krkoska and Robeck (2009) find a negative impact of the perception of street crime on firm level investments using firm survey data from 26 transition countries (mainly located in Eastern Europe and Central Asia). An interesting aspect of their results is that it is the perception of crime, and not the actual loss of assets due to crime, that drives the negative investment effect. They also find that increased spending on security services lowers investment. McDonald (2008) shows in a survey of small and medium South African enterprises that: 'a quarter of all respondents expressed reluctance or unwillingness to expand or invest in their business because of the threat of crime' (p. 54). In both studies the threat or perception of crime was important, similar to our arguments about increased insecurity.

In general the literature shows that firm investment and even the decision to exit the market are influenced by insecurity through conflict and crime. Especially the study from Sierra Leone also suggests that recovery despite some long term consequences is rather quick. The conflicts in Colombia and Sierra Leone, which are studied in the above mentioned papers, are much more intense than the situation in Ethiopia during the time period we observe. So judging from the studies above, dramatic effects such as firm exit or the large scale 
destruction of human and physical capital are unlikely to prevail in low-intensity conflicts and we do not expect to find strong long-term effects. Still the existence of an investment effect seems likely and has not been shown for conflict at all. Our study therefore contributes to the literature by investigating the impact of low-scale conflicts on firm level investment. Another part of its contribution lies in the precision of spatial identification of conflict intensity and the relatively long firm level panel data which allows us to control for fixed effects.

\section{II.4 Data}

\section{II.4.1 Firm level data}

This chapter uses firm level panel data from the Ethiopian manufacturing sector covering the period 1996-2007. ${ }^{20}$ The data stems from the annual manufacturing census which is conducted by the Central Statistical Agency (CSA) of Ethiopia. It covers all firms with at least 10 workers from all manufacturing sectors except for the arms industry.

Bureaus in the regional states, which are connected to the Federal Ministry of Trade and Industry, issue business licenses for manufacturing firms. Based on their registers, the CSA produces a list of all such establishments and sends enumerators to the firms' addresses in order to fill out the questionnaires. All firms are obliged by law to cooperate with the enumerators. If the enumerators cannot find a company for three consecutive rounds of the survey, it is considered to have exited the market, not contacted again and removed from the firm list.

Using unique identification numbers assigned to each establishment by the CSA we can construct an unbalanced panel dataset. The number of firms increases from 623 in 1996 to 1339 in 2007 and the data contains a total of 10,305 entries (firm-year observations). The dataset also contains the town where the firms are located. An overview over the geographical distribution of towns, where firms were interviewed, can be found in Figure II.1. The towns with firm observations are distributed throughout Ethiopia with the exception of the Somali region where no manufacturing companies where observed. About

\footnotetext{
${ }^{20}$ In the analysis we only use the years 1997-2007 because we have no conflict data before 1997.
} 
60 percent of the companies are located in the metropolitan area of the capital city, Addis Ababa, and about 70 percent are producers with less than 50 employees.

Figure II.1: Map of towns with observed firms

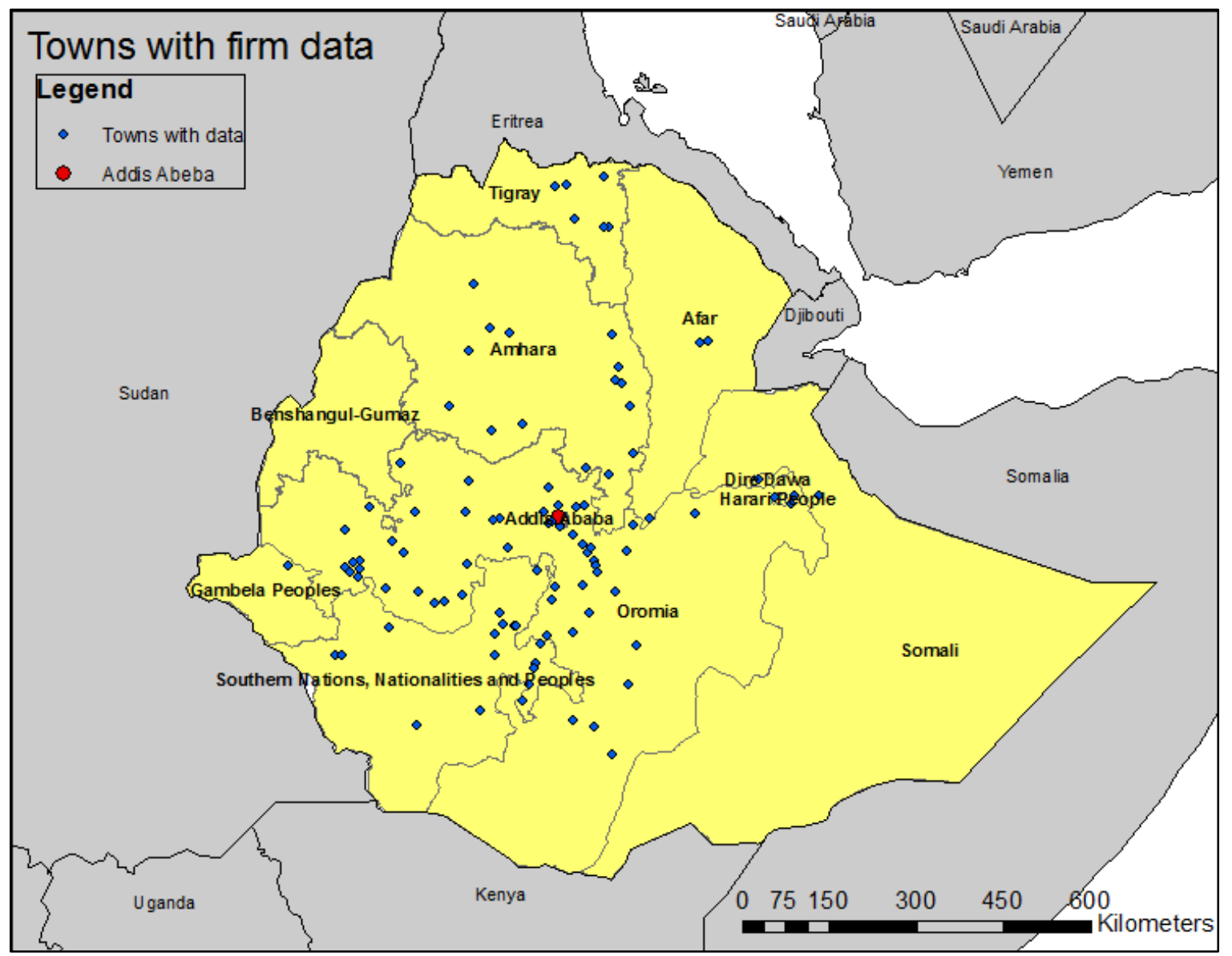

Sources: Author's calculations. Map data for cities: UN-OCHA (2011) and National Geospatial-Intelligence Agency (2013); Map data for Ethiopia and neighbouring features: DIVA-GIS (2013).

\section{II.4.2 Conflict data}

For the sample period considered in this study (1997-2007) there were three main sources of conflict in Ethiopia. One is the historically problematic relationship with Eritrea, which seceded from Ethiopia in 1993, and the others stem from the activities of two insurgent groups, the Ogaden National Liberation Front (ONLF) and the Oromo Liberation Front (OLF) who both fight against the Ethiopian government but pursue different goals.

The data we use to create our measure of conflict intensity comes from the Armed Conflict Location and Events Dataset (ACLED, Raleigh et al., 2010). ACLED records individual information about incidents of political violence. The information includes the type, location 
(as GPS coordinates), date, parties involved and (not available for Ethiopia) the number of victims of each event. This allows for a very detailed tracking of conflicts in the countries observed. The first event categories are battles, which are confrontations between armed groups, independent of the number of casualties. They are distinguished in the data by whether or not there was a territorial change and if so who gained territory. Another category is violence specifically targeting civilians, which is coded as such if an armed group attacks unarmed civilians. The last category are 'riots and protests', which is a rather broad classification. Protests are defined as non-violent gatherings of people with a political purpose, while riots are outbreaks of violence involving at least 3 persons that are gathered for a common purpose. The ACLED project also codes some other non-violent actions which are not discussed here. Between 1997 and 2007 the ACLED database for Ethiopia ${ }^{21}$ contains more than 1100 incidents on Ethiopian territory as well as 130 incidents in Eritrea and a few in Kenya and Somalia, all of which relate to Ethiopia or Ethiopians. Around 750 of the incidents in Ethiopia are classified as battles and are used as our main indicator for the conflict intensity. The Ethiopian military was involved in more than 80 percent of all battle events and the data captures very well the different phases of elevated conflict between the Military Forces of Ethiopia and the three main other parties. The geographical distribution of battles can be found on the map in Figure II.2. This map gives some idea about the intensity of the conflict but not perfectly so because some dots represent various incidents if they have happened in the same places.

Figure B.1 (in appendix B) shows the battle events coloured according to the various factions observed in the data, to whom the incident was attributed. This illustrates that the different actors focus their activities in different regions. They were also mainly active in different time periods.

Eritrea was a part of Ethiopia until its independence in 1993, after a civil war that lasted for about 3 decades. Since the independence, the relationship between the two countries has been tense leading to a border conflict during 1998 and 1999, which shows up with more than 150 events in the northern parts of Ethiopia, mainly in the Tigray Region. The conflict ended with a truce in 2000.

\footnotetext{
${ }^{21}$ The dataset can be downloaded as an ESRI Shapfile or as an Excel file here: http://www.acleddata.com/data/africa/ last accessed March 14, 2013.
} 
The larger part of the conflict incidents however comes from two insurgent organizations. About $24 \%$ of the incidents in the database involve the OLF. The OLF was established in 1973 and claims to fight for the liberation of the Oromo people from the rule of the Ethiopian government. The Oromo are the largest ethnic group in Ethiopia and constitute nearly $90 \%$ of the population in Ethiopia's Oromia region which stretches from the southern border of Ethiopia over the centre and to the western border.

Figure II.2: Map of battle incidents

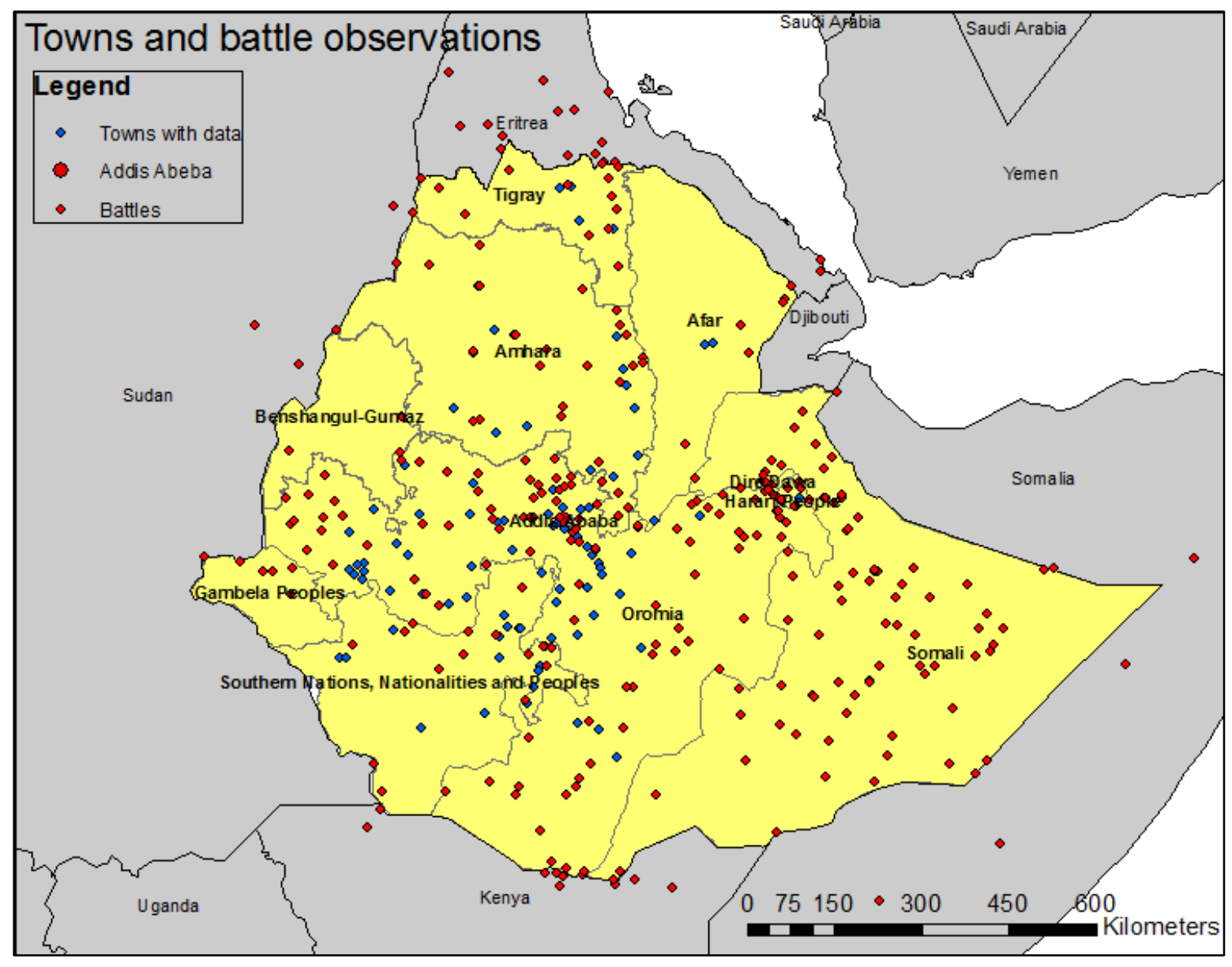

Sources: Author's calculations. Battle data: Raleigh et al. (2010); Map data for cities: UN-OCHA (2011) and National Geospatial-Intelligence Agency (2013); Map data for Ethiopia and neighbouring features: DIVA-GIS (2013).

The OLF has been declared a terrorist organization by the Ethiopian government and armed struggle is one of their core strategies (according to information provided on their own webpage). Judging from the ACLED data, the OLF was mainly active before 2003 , about $80 \%$ of the nearly 260 incidents they were involved in happened before that year. These incidents took place predominantly in the Oromia region. 
The second insurgent organization is the ONLF, who was involved in about $41 \%$ of the incidents in the database, thereby being the most important conflict party in our data. The ONLF was founded in 1984 and wants to turn the Ogaden territory, which is located in the south east of the Somali region in Ethiopia, into an independent state. The ONLF has been active over the whole period covered by our data, but especially after 2002. ACLED reports about 440 battle events the ONLF was involved in during this time. While the ONLF is mainly active in the Somali region, where we do not observe any manufacturing industry, they have had confrontations with the Ethiopian forces in many other locations across the country.

In order to generate the conflict intensity measure, the geographic location of each town from where firm observations were available, was determined. ${ }^{22}$ The GPS coordinates for the towns mainly come from a GIS dataset compiled by UN-OCHA. ${ }^{23}$ It is part of the so-called Common Operational Datasets and gives coordinates for populated places in Ethiopia. The original data comes from the CSA, the International Red Cross and the Food and Agriculture Organization of the United Nations. This data was counterchecked and complemented by a dataset of official (US-American) foreign names for Ethiopia published by the GEOnet Names Server and developed by the National Geospatial-Intelligence Agency. ${ }^{24}$ Since the ACLED data also contains the GPS-coded location of incidents, we were able to calculate the total number of events per year, of each event-type, in a specific radius around each of the towns. ${ }^{25}$ The data we mainly use in the empirical analysis, to assess the conflict intensity that a firm is exposed to in a specific year, is the count of battle events in a radius of $50 \mathrm{~km}$ around the town. Most studies that rely on the spatial identification of conflict intensity only have information about the conflict in certain administrative areas. ${ }^{26}$ Since the size of those

\footnotetext{
${ }^{22}$ The identification of the towns was not always straightforward due to different problems. The details are described in the technical notes in the appendix B.3.

${ }^{23}$ Available here: http://cod.humanitarianresponse.info/sites/default/files/towns.zip (last accessed March 14, 2013).

${ }^{24}$ The dataset is available here: http://earth-info.nga.mil/gns/html/cntyfile/et.zip last accessed March 14, 2013

${ }^{25}$ The counting was done using the Python bindings of the OGR library. The tools and techniques used to prepare the data and for the actual counting are described in more detail in the technical notes in the appendix B.3.

${ }^{26}$ Examples for this are some of the above-mentioned studies. Pshisva and Suarez (2010) have information about kidnappings and armed confrontations on the level of federal states which they relate to firm data from those states. Colombian federal states are however quite large (there are 32 states in Colombia) so there is no guarantee that the kidnappings actually happened very close to the firms that are observed. Camacho and Rodriguez (2011) rely on conflict data from Colombian municipalities. While they are much smaller than the states they can still be quite big in remote areas (more than $400 \mathrm{~km}$ from one border point to another) and they all have very different sizes. Spatial identification also becomes more problematic if the observed administrative units vary too much in size. Within a small district (small districts in Colombia only comprise a
} 
areas might differ substantially and is often quite large, it is in many cases hard to determine the actual spatial distance between the conflict and the subject under investigation. Our approach however allows for a very precise tracking of the intensity of conflict, that the firms experienced around them in each period.

\section{II.5 Empirical Strategy}

As mentioned before the violence in Ethiopia is by and large a low level conflict. Large-scale destruction of property or changes of territorial control in significant parts of the country are hardly ever observed. There are also nearly no incidents in the data indicating systematic attacks on civilians by the insurgent groups, who seem to concentrate their attacks on the Ethiopian military forces. Because of all this, we do not expect direct effects of conflict on firms involving destruction of assets or injury of employees. There is also no indication of long term disruptions in transport services due to conflict. We do however think that fighting happening in close spatial proximity would instil a sense of fear among firm owners and credit institutes, keeping them from investing too much in an insecure situation. Therefore we concentrate our analysis on investment, while we do nevertheless also check for other possible reactions of firm owners.

Addis Ababa is a special case in our data. While about 60 percent of our firm-year observations are actually from the metropolitan area, we do not expect or find an effect of conflict on firms there. Addis is the political capital and the largest city in Ethiopia. It has over 4 million inhabitants and is the seat of the African Union as well as the United Nations Economic Commission for Africa. Because of its size and international importance the city is a much safer place. While the rebel groups are certainly not small, they are no match for the Ethiopian military and no real threat to social and economic life in the capital. Because of this we do not expect firm owners in Addis to react to increased conflict as they will not feel very much threatened by it, even though there have been battles close to the city in our data. Since our sample is strongly dominated by the observations in Addis Ababa and we do not find any effect there, we split our sample into the metropolitan area of Addis and the rest of the country, to separately analyze all the firms in places where we do expect an

few square kilometers) it can be assumed that battles have happened close to the subjects that are investigated in that area, but in large district this might not be the case (the battles could have happened a few hundred kilometers away in an extreme case). So even though two districts show the same number of battles, the actual exposure to nearby conflict could be very different. 
effect. The sample without Addis is our main focus and contains about 4000 firm-year observations.

To estimate the effect of insecurity on firm behaviour, we use linear fixed-effects models, taking advantage of the panel structure of our data. This approach controls for firm specific unobserved time-invariant factors and minimizes some possible sources of endogeneity or unobserved heterogeneity. Some firms could for instance be owned by individuals who are sympathetic to the rebel movement and may not reduce their investment activities. The model is specified as follows:

$$
Y_{i j t}=\beta_{0}+\beta_{1} C_{j t}+\beta X_{i j t}+V_{i}+u_{i j t}
$$

Where $Y_{i j t}$ is our outcome variable of interest (in the main specification the investment rate). $C_{j t}$ is our time-varying insecurity measure (e.g., number of battles) at the town level, $X_{i j t}$ is a vector of firm level control variables and $V_{i}$ is the vector of firm level fixed effects. The subscript $\mathrm{i}$ denotes the individual firm, $\mathrm{j}$ the town where it is located and $t$ identifies the time period.

\section{II.5.1 A note on endogeneity}

In many empirical analyzes there are potential sources of endogeneity, which we also want to discuss for this study. We do not expect to find any reverse causality issues in our analysis. It could be claimed that a reduction in investment leads to a reduction in employment and the unemployed subsequently join the insurgent groups, leading to more violence. A first counterargument is that there would be a time lag between the firing and the workers starting to fight and more importantly, we cannot find any correlation between the employment and the conflict, so that such a theory would be implausible.

A study that uses spatial identification strategies always runs the risk of having an unobserved variable that simultaneously influences the dependent and the explanatory variable of interest. Since we use a fixed-effects approach, any time-invariant factors would be automatically eliminated from the analysis. This means, only time varying unobserved factors could cause an endogeneity problem in our setup. 
The groups mainly responsible for the conflict in Ethiopia will most likely not be affected by many factors as they fight for the liberation of certain territories or ethnic groups. The war episode with Eritrea is historically rooted and we cannot find any theory how there might be something about it that could influence investment in any other time-varying way than violence or fear of war. This conflict as well as the attacks by the insurgent groups, are focused on regions these groups are interested in (both insurgent groups and Eritrea fight for a specific territory). These regions have a higher risk of experiencing conflict which might also influence investment decisions. The territorial interest of the groups however does not change over time and so the elevated risk situation would be captured in the fixed effect.

A possibility would be local economic dynamics that cause conflict and investment reduction through localized economic downturns. This is however not plausible for our data since we do not see any connection between conflict and sales or other firm indicators. Therefore we cannot think of any factor that would influence conflict intensity and investment but leave all other indicators unaffected.

\section{II.6 Descriptive Statistics and Variable Definitions}

The summary statistics for our variables can be found in Table II.1. They refer to firm-year observations in the sample of firms outside of Addis Ababa for which we have data on investment behaviour.

As explained in the data section we use counts of different types of violent incidents, within a certain distance to the towns, as our indicators of insecurity. The most important indicator is a count of battle events which does not distinguish whether or not the battle caused a territorial change. For Ethiopia, ACLED does not provide data about casualties or any other measure to track the intensity of battles, so we simply use the number of such incidents. Looking at the battle count within $50 \mathrm{~km}$ from the town, we find a maximum of 21 battle events and a mean close to one. In about 70 percent of our firm-year observations, there were no recorded battle events and only less than 1 percent experienced more than 10 events. Increasing the distance to $100 \mathrm{~km}$, only in 43 percent of the cases there were no recorded battle and at a distance of $30 \mathrm{~km}$ this number increases to about 80 percent. Violence against civilians is less frequent just like riots and protests. 
The most important outcome variable is the investment rate which is defined as total investment spending $\left(I_{t}\right)$ minus the capital sales $\left(S_{t}\right)$ as a percentage of the lagged capital stock: $\left(I_{t}-S_{t}\right) / K_{t-1}$. In the analysis all values of investment larger than 5 are excluded as outliers (only 22 observations) and for the remaining observations the average yearly investment rate is 11 percent (as a comparison, for the firms in Addis Ababa it is about 14 percent). There are only 2 observations where the capital sales were higher than the new investment causing a negative investment rate.

Table II.1: Summary statistics

\begin{tabular}{|lrrrrr|}
\hline \multicolumn{7}{|l}{ Descriptive statistics of observations with investment } & \multicolumn{1}{r|}{ Max } \\
\hline \hline Variable & No. Obs. & Mean & Std. Dev. & Min & \\
\hline & & & & & \\
Battles 50km & 2580 & 0.943 & 2.123 & 0 & 21 \\
Battles 30km & 2580 & 0.495 & 1.396 & 0 & 16 \\
Battles 100km & 2580 & 2.324 & 3.463 & 0 & 24 \\
& & & & & \\
Riots/Protest 50km & 2580 & 0.575 & 2.014 & 0 & 13 \\
Violence against civilians 50km & 2580 & 0.768 & 1.751 & 0 & 9 \\
Total no. of incidents 50km & 2580 & 2.286 & 4.789 & 0 & 28 \\
& & & & & \\
Investment rate & 2655 & 0.116 & 0.348 & -0.359 & 4.322 \\
Profit Rate & 2344 & 0.579 & 1.081 & -2.485 & 4.965 \\
Output variance & 2493 & 0.399 & 0.317 & 0 & 1.719481 \\
Road Connection & 2575 & 1416.503 & 610.337 & 201.69 & 2900 \\
& & & & & \\
Total labour & 2522 & 148.473 & 392.995 & 0 & 4629.5 \\
Private & 2655 & 0.778 & 0.416 & 0 & 1 \\
Total sales (M. Birr) & 2655 & 16.714 & 62.764 & 0 & 1082.416 \\
Newly hired personnel & 1880 & 5.796 & 8.264 & 1 & 52 \\
\hline
\end{tabular}

One of the firm level control variables is the profit rate. The assumption is that credit constrained firms would rely on internal sources of finance for investment purposes. Similar to the investment rate, the profit rate is calculated as the value added minus wages, as a percentage of the lagged capital stock. ${ }^{27}$ Profit rates are quite high at a mean of about 60 percent despite nearly 600 observations with negative profit. Due to the lag in both, investment and profit variables, we have no information for them in the first period that a firm was observed. This along with regular missing data is a main reason why we can't use all

\footnotetext{
${ }^{27}$ Value added and wages are the values for the current period. Capital stock is evaluated at the end of the period, therefore the lagged value is the capital stock at the beginning.
} 
4000 observations in the empirical analysis. In the analysis we also use the lag of the profit variable, as described in the next section, but this brings some additional problems and has no impact on the results.

We also control for demand uncertainty or market fluctuation through the coefficient of variation of firm level sales. The coefficient of variation is calculated as the standard deviation of sales in the last three years, divided by the mean output. The private variable is a dummy indicating whether the firm is a private firm (about 80 percent of our observations). All other variables are self-explanatory.

Since public investment on infrastructure is believed to crowd-in private investment, we control for the road connectivity of the town in which the firm is located. The road connection variable measures the area accessible by road during a one hour drive using all roads passing through or close to a town. The area accessible is calculated by taking a $5 \mathrm{~km}$ buffer zone on each side of a road.

When we analyze the impact by industry, firms are divided into 'food industry' if they produce food or beverages and the 'textile industry' if they produce textiles, leather, clothing or footwear. The classification 'non-metal industry' is more heterogeneous and comprises wood, furniture, paper, chemicals, plastic and rubber. The last category is the 'metal industry' for iron, steel, metal products and light machinery.

\section{II.7 Empirical Results}

A first impression about the relationship between conflict and investment can be glanced from Figure II.3. It shows a negative association between the investment rate on the y-axis and the number of battles, within a $50 \mathrm{~km}$ distance, on the $x$-axis. ${ }^{28}$ The figure also shows a

\footnotetext{
${ }^{28}$ Since the number of battles is discrete some random noise was added to clarify the observation density (otherwise they would all be on one line). Observations with a battle count larger than ten have been excluded in the figure for scaling reasons, just like the two negative investment rates. They are however not excluded from the regressions because we are quite sure they are not cases of measurement error (even though excluding them does not change the results).
} 
simple regression line, without taking into account the panel structure of the data or any control variables.

\section{II.7.1 General results for investment}

Table II. 2 contains the results for our base regressions. The first column shows the effect of conflict on investment without any control variables, although the fixed effects will already capture the effect of time invariant firm characteristics. The advantage of this approach is that we can use the maximum number of observations since we do not face the problem of additional missing values in our control variables.

Figure II.3: Scatterplot Battles vs. Investment

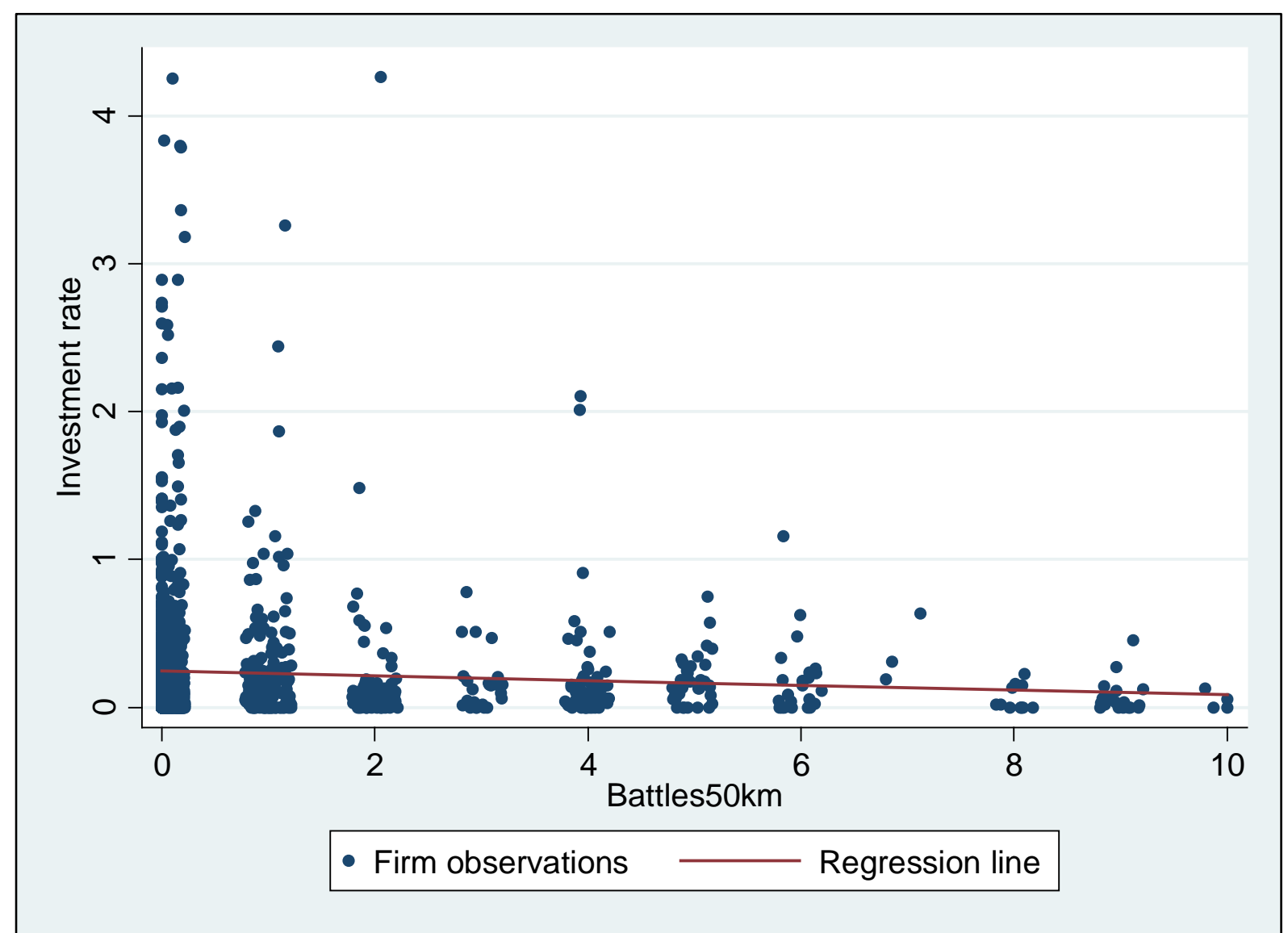

This means we can use data on 631 firms with a total of nearly 2600 firm-year observations. In this specification the battle-count within $50 \mathrm{~km}$ distance is highly significant and has a coefficient of -0.01 . This suggests that one additional incidence of battle within $50 \mathrm{~km}$ of the 
town in which the firm is located will decrease the average investment rate by 1 percentage point. This is quite a sizable effect, considering that the mean investment is only 11 percent.

When we introduce control variables in column two, the coefficient for our conflict measure decreases slightly (by 0.003), but remains significant at the one percent level. The only control variable coming out significant - using standard significance thresholds - is the profit rate, showing that owners invest more in profitable firms. Due to missing values in the control variables we only observe data from 540 firms in this specification.

Table II.2: Regression results firm investment, basic models

\begin{tabular}{|c|c|c|c|c|}
\hline \multicolumn{5}{|c|}{$\begin{array}{l}\text { Dep. Variable Investment Rate, Fixed Effects Regression } \\
\text { Basic specifications }\end{array}$} \\
\hline \multirow[t]{2}{*}{ Battles $50 \mathrm{~km}$} & $-0.010 * * *$ & $-0.007 * * *$ & $-0.006^{*}$ & $-0.007 * *$ \\
\hline & $(-3.60)$ & $(-2.72)$ & $(-1.93)$ & $(-2.19)$ \\
\hline \multirow[t]{2}{*}{ Profit rate } & & $0.044 * * *$ & & $0.043 * * *$ \\
\hline & & $(3.82)$ & & $(3.76)$ \\
\hline \multirow[t]{2}{*}{ Profit rate (lagged) } & & & $0.031 * * *$ & \\
\hline & & & $(2.66)$ & \\
\hline \multirow[t]{2}{*}{ Output variation } & & -0.019 & -0.019 & -0.019 \\
\hline & & $(-0.49)$ & $(-0.38)$ & $(-0.51)$ \\
\hline \multirow[t]{2}{*}{ log Road connection } & & 0.018 & 0.009 & 0.014 \\
\hline & & $(0.60)$ & $(0.25)$ & $(0.38)$ \\
\hline \multirow[t]{2}{*}{ Total sales } & & -0.000 & 0.000 & -0.000 \\
\hline & & $(-0.38)$ & $(0.75)$ & $(-0.45)$ \\
\hline \multirow[t]{2}{*}{ log Firmsize (Workers) } & & 0.032 & $0.062 * *$ & 0.029 \\
\hline & & $(1.55)$ & $(2.48)$ & $(1.43)$ \\
\hline Year dummies & no & no & no & yes \\
\hline No. obs. & 2581 & 2060 & 1569 & 2060 \\
\hline No. firms & 631 & 540 & 378 & 540 \\
\hline R sq. & 0.003 & 0.024 & 0.019 & 0.030 \\
\hline
\end{tabular}

Robust standard errors; t-statistics in parentheses. $* * *, * *, *$ denote significance at the $1 \%, 5 \%$, $10 \%$ level respectively.

Since it could be argued that it is not so much current profit that makes owners invest, but rather profit in the last period, we use the first lag of the profit rate in the specification in column 3. By adding another lag we reduce our analysis sample to only about 380 firms. The conflict effect remains stable and significant at nearly the 5 percent level and the coefficient for the lagged profit is highly significant as well. Since using it does not seem to have any 
further advantage, but strongly reduces observations, we stick to the current profit as the control variable for all other specifications.

The specification in column 4 is equivalent to the specification in column 2 but it adds year dummies to the regression. This allows us to control for time fixed effects such as macroeconomic developments that affects all firms in a given year (e.g., economic growth). Our results still hold although the significance of our conflict indicator is slightly reduced. The reason for this is probably a systematic correlation between the battle count and the year dummies since some years were more conflict intensive than others.

In Table B.1 we control for the robustness of the conflict effect to the use of different distance measures (up to which distance battle events are counted). We use a count of battles within $30 \mathrm{~km}$ in the first two columns and within $100 \mathrm{~km}$ in the last two columns. Using the $30 \mathrm{~km}$ measure we see a slightly higher coefficient in the model with control variables (column two) compared to the main specification. With the $100 \mathrm{~km}$ specification the coefficients are lower compared to the earlier regressions. All effects are statistically significant. This table could be interpreted as the conflict effect being stronger, the closer the conflict is to the firm's location.

An important aspect of the investment reduction is whether the effect is lasting and whether the investment is completely cancelled or merely postponed. In order to get more information about this, we use the lagged conflict experience instead of the current one. The results for this can be found in Table B.2. The first column shows the original model as a baseline. In the second column we use the first lag of conflict because of which we lose some observations. The coefficient is negative, low and statistically insignificant. Adding control variables it turns significant, but further checks show that this is probably not due to the control variables, but rather to the different sample. The different sample is generated by the missing values in the control variables and from this we conclude that there is no robust relationship. ${ }^{29}$ There are no significant results for the second lag either as can be seen in columns 3 and 4 . The lack of any significant effects implies two things. First, it appears that there is no long-term effect of conflict on investment. It really seems to be the current

\footnotetext{
${ }^{29}$ To check this we perform a regression without control variables on the same reduced sample and find the same negative significant effect. Including the current conflict alongside the lags (not reported) also turns the negative effect in column 3 insignificant but has no big effect on the other regressions.
} 
insecurity keeping people from investing during the same period. Second, if the investment was delayed by one or two periods, we might find a positive effect of the lagged conflict on investment. We do not find any evidence for such a delay in investment. This is however not conclusive, as most likely different firms would delay their investment for different time periods and then it would not show up clearly in the data.

\section{II.7.2 Differential effects of conflict on investment}

To gain more insight into the processes behind the investment reduction and to analyze who might be most affected by it, we interact the conflict variable with dummy variables that identify private firms, capital intensive firms and the industry it belongs to. ${ }^{30}$

For the regressions reported in Table II.3, we classified a firm as capital intensive if the capital stock per worker was larger than 50,000 Birr. While this is an arbitrary value we have tried the same with other values (e.g., the median value) with the same results. 50,000 Birr per worker is about the 70th percentile of the distribution in our data and a little bit more than twice the median value. With this definition of capital intensive firms, we find that the effect of battle is nearly twice as large as in the base specifications and highly significant as reported in column 1 . The interaction term between the high capital dummy and the battle count, which can be interpreted as the effect of conflict on firms with high capital intensity, is also highly significant and the coefficient is 0.015 . Therefore the negative effect of conflict would be nearly offset for capital intensive firms or it would at least be significantly smaller (only about -0.004). Adding control variables lowers the absolute values of both coefficients and their significance but the tendencies remain unchanged. This implies that it is mainly the labour intensive firms that reduce their investment, while in general, firms with a high capital share in their production process react much less to increased insecurity around them.

Capital intensive firms are larger (on average they have twice as many employees), which could mean that they are better able to cope with risks. We do control whether larger firms are less affected by an interaction term between the conflict variable and firm size but it

\footnotetext{
${ }^{30}$ The dummy variables are time invariant and hence cannot be separately included in the fixed effects regression. Therefore the main effect of the dummies is not visible but, due to the time invariance, it is captured by the fixed effect, allowing for the regular interpretation of the interaction term.
} 
does not turn out significant at conventional levels (regression results not reported). ${ }^{31}$ When introducing this interaction along with the capital intensity interaction nothing changes, the latter remains significant (at similar magnitude) and the former is not. So size cannot explain the differential effect of conflict on capital intensive firms.

Table II.3: Regression results firm investment for capital intensive and private firms

\begin{tabular}{|c|c|c|c|c|c|}
\hline \multicolumn{6}{|c|}{$\begin{array}{l}\text { Dep. Variable Investment Rate, Fixed Effects Regression } \\
\text { Control for differential effects on capital intensive or private firms }\end{array}$} \\
\hline Battles 50km & $\begin{array}{l}-0.019 * * * \\
(-4.51)\end{array}$ & $\begin{array}{l}-0.013 * * * \\
(-3.32)\end{array}$ & $\begin{array}{l}-0.012^{* *} \\
(-2.39)\end{array}$ & $\begin{array}{l}-0.012^{* *} \\
(-2.37)\end{array}$ & $\begin{array}{l}-0.020^{* * *} \\
(-3.32)\end{array}$ \\
\hline Cap.Int.*Battles & $\begin{array}{l}0.015^{* * *} \\
(2.95)\end{array}$ & $\begin{array}{l}0.009 * \\
(1.67)\end{array}$ & & & $\begin{array}{l}0.011^{* *} \\
(2.04)\end{array}$ \\
\hline Private*Battles & & & $\begin{array}{l}0.003 \\
(0.52)\end{array}$ & $\begin{array}{l}0.007 \\
(1.12)\end{array}$ & $\begin{array}{l}0.010 \\
(1.60)\end{array}$ \\
\hline Profit rate & & $\begin{array}{l}0.044^{* * *} \\
(3.84)\end{array}$ & & $\begin{array}{l}0.044^{* * *} \\
(3.82)\end{array}$ & $\begin{array}{l}0.044^{* * *} \\
(3.85)\end{array}$ \\
\hline Output variation & & $\begin{array}{l}-0.019 \\
(-0.48)\end{array}$ & & $\begin{array}{l}-0.021 \\
(-0.53)\end{array}$ & $\begin{array}{l}-0.021 \\
(-0.53)\end{array}$ \\
\hline Road connection & & $\begin{array}{l}0.016 \\
(0.51)\end{array}$ & & $\begin{array}{l}0.016 \\
(0.54)\end{array}$ & $\begin{array}{l}0.012 \\
(0.40)\end{array}$ \\
\hline Total sales & & $\begin{array}{l}-0.000 \\
(-0.37)\end{array}$ & & $\begin{array}{l}-0.000 \\
(-0.30)\end{array}$ & $\begin{array}{l}-0.000 \\
(-0.26)\end{array}$ \\
\hline log Firmsize (Workers) & & $\begin{array}{l}0.032 \\
(1.54)\end{array}$ & & $\begin{array}{l}0.033 \\
(1.56)\end{array}$ & $\begin{array}{l}0.033 \\
(1.57)\end{array}$ \\
\hline No. obs. & 2581 & 2060 & 2581 & 2060 & 2060 \\
\hline No. firms & 631 & 540 & 631 & 540 & 540 \\
\hline R sq. & 0.005 & 0.025 & 0.003 & 0.024 & 0.026 \\
\hline
\end{tabular}

Robust standard errors; t-statistics in parentheses. $* * * * * *$ denote significance at the $1 \%, 5 \%, 10 \%$ level respectively.

A possible explanation could be different risk attitudes between owners of capital intensive and labour intensive firms. Firm owners with a relatively large capital stock are most likely less risk-averse. A risk-averse person would probably rely on more labour intensive production processes in the first place, because workers are only paid per month and represent no more cost when fired if the firm terminates production. A large part of the capital investment on the other hand would be lost in such a case.

\footnotetext{
${ }^{31}$ Since the distribution of firms' size is skewed to the right we try the same with the logarithm of the number of employees but the results are not significant either.
} 
If the investment reduction is due to fear, then risk-averse firm owners will react more strongly as we suggest in our theory. So if the above assumption is correct then the result of a much stronger reaction for less capital intensive firms is what we would expect.

Another aspect could be that reducing the investment too much might cause major disruptions in a capital intensive firm. Capital intensive firms rely more heavily on capital goods as production factors and those might need a regular minimum investment for repair and replacement in order to continue operation. So the potential loss from not investing might outweigh the perceived risk from conflict.

As already mentioned in the theory section, not only firm owners but also their employees might react to greater perceived risk, e.g., by reducing their work hours. If this is the case it might also explain why more labour intensive firms show a stronger reaction to conflict. Additionally, employees in capital intensive firms would receive higher wages and richer households are better able to insure against insecurity, which might make them react less strongly.

We also control for differences between public and private firms by including an interaction between conflict intensity and the private dummy. The interaction term for private companies is - as reported in columns three and four - positive, suggesting that they are less affected than public firms but it is not significant. In column five we include both interaction terms in the regression and the interaction with the private dummy nearly reaches the 10 percent significance level. When adding up the coefficients for both interaction terms we would find that a capital intensive, private firm would not lower investment due to increased conflict in their environment.

In the regressions reported in Table II.4, we control for the different industries by interacting each industry dummy with the conflict intensity measure. We leave out the interaction term with the food industry, which means that the non-interacted conflict measure represents the effect of conflict on this sector and the interaction terms represent differences to this main term for the other industries.

In column one we see a strong and highly significant effect of conflict on the food industry and no significant differences with the other sectors (the interaction term for the textile industry is however almost significant). When adding control variables in column two, the 
effect on the food industry increases. At the same time, the interaction effects for the textile and non-metal sectors turn significantly positive. For the textile sector, the interaction term's coefficient is so high, that it completely offsets the negative main effect. This means that the textile industry would not be affected by conflict.

Table II.4: Regression results firm investment by industry

\begin{tabular}{|c|c|c|c|c|c|}
\hline \multicolumn{6}{|c|}{$\begin{array}{l}\text { Dep. Variable Investment Rate, Fixed Effects Regression } \\
\text { Control for differential effects by industry }\end{array}$} \\
\hline Battles $50 \mathrm{~km}$ & $\begin{array}{l}-0.015^{* * *} \\
(-2.95)\end{array}$ & $\begin{array}{l}-0.016^{* * *} \\
(-3.07)\end{array}$ & $\begin{array}{l}-0.022^{* * *} \\
(-4.51)\end{array}$ & $\begin{array}{l}-0.018^{* *} \\
(-2.52)\end{array}$ & $\begin{array}{l}-0.028 * * * \\
(-3.66)\end{array}$ \\
\hline Textile ind.*Battles & $\begin{array}{l}0.017 \\
(1.59)\end{array}$ & $\begin{array}{l}0.019 * \\
(1.80)\end{array}$ & $\begin{array}{l}0.013 \\
(1.18)\end{array}$ & $\begin{array}{l}0.019 \\
(1.57)\end{array}$ & $\begin{array}{l}0.020^{*} \\
(1.66)\end{array}$ \\
\hline Non-metal ind*Battle & $\begin{array}{l}0.005 \\
(0.85)\end{array}$ & $\begin{array}{l}0.010^{*} \\
(1.75)\end{array}$ & $\begin{array}{l}0.004 \\
(0.69)\end{array}$ & $\begin{array}{l}0.004 \\
(0.74)\end{array}$ & $\begin{array}{l}0.008 \\
(1.45)\end{array}$ \\
\hline Metal ind.*Battle & $\begin{array}{l}0.005 \\
(0.63)\end{array}$ & $\begin{array}{l}0.009 \\
(0.78)\end{array}$ & $\begin{array}{l}0.004 \\
(0.45)\end{array}$ & $\begin{array}{l}0.004 \\
(0.47)\end{array}$ & $\begin{array}{l}0.005 \\
(0.42)\end{array}$ \\
\hline Cap.Int.*Battles & & & $\begin{array}{l}0.014^{* * *} \\
(2.74)\end{array}$ & & $\begin{array}{l}0.010^{*} \\
(1.85)\end{array}$ \\
\hline Private*Battles & & & & $\begin{array}{l}0.005 \\
(0.77)\end{array}$ & $\begin{array}{l}0.011 \\
(1.52)\end{array}$ \\
\hline Profit rate & & $\begin{array}{l}0.044^{* * *} \\
(3.83)\end{array}$ & & & $\begin{array}{l}0.044^{* * *} \\
(3.86)\end{array}$ \\
\hline Output variation & & $\begin{array}{l}-0.018 \\
(-0.47)\end{array}$ & & & $\begin{array}{l}-0.020 \\
(-0.51)\end{array}$ \\
\hline Road connection & & $\begin{array}{l}0.015 \\
(0.50)\end{array}$ & & & $\begin{array}{l}0.009 \\
(0.30)\end{array}$ \\
\hline Total sales & & $\begin{array}{l}-0.000 \\
(-0.40)\end{array}$ & & & $\begin{array}{l}-0.000 \\
(-0.27)\end{array}$ \\
\hline log Firmsize (Workers) & & $\begin{array}{l}0.032 \\
(1.55) \\
\end{array}$ & & & $\begin{array}{l}0.033 \\
(1.57) \\
\end{array}$ \\
\hline No. obs. & 2581 & 2060 & 2581 & 2581 & 2060 \\
\hline No. firms & 631 & 540 & 631 & 631 & 540 \\
\hline R sq. & 0.004 & 0.026 & 0.006 & 0.004 & 0.028 \\
\hline
\end{tabular}

Robust standard errors; t-statistics in parentheses. $* * * * *, *$ denote significance at the $1 \%, 5 \%, 10 \%$ level respectively.

Since the capital intensity seems to be a very important determinant it was added to the model. When controlling for it, by using the interaction term with conflict, it shows up positive and significant as in the earlier models. Without the other control variables however all industry interactions remain insignificant (again with the textile industry interaction having by far the highest t-value). With all control variables included the interaction terms for high capital intensity and textile industry show up significant and positive. 
While the results are not completely robust they do suggest that the textile industry is less affected than all the others but we cannot directly explain why.

\section{II.7.3 Other measures of insecurity}

In addition to battles, we want to check for the effects of other measures of insecurity which we can derive from the ACLED data. This concerns the already mentioned incident categories 'Riots and Protests' and 'Violence against civilians', as well as the sum of all recorded incidents. The results are reported in Table B.3 and there is no significant effect of any of those indicators on firm investment. This is not surprising for riots and protests as this is a rather vague category also comprising by definition non-violent protests. Practically all violence against civilians in our data was perpetrated by either the Ethiopian military or police forces. This however does not seem to create much insecurity among the firm owners and causes no investment reactions. In general we conclude that only high-level violence representing or resembling actual warfare has an effect on businesses.

\section{II.7.4 Conflict effects on other firm behaviour}

In order to see whether the exposure to conflict also has more effects on firms besides the investment reduction, we use other firm indicators as dependent variables in our regression framework. Table B.4 reports the results for the effect of conflict on the number of new workers hired by a company, the same indicator but relative to the labour stock already in place, the total sales of a firm, the total number of workers (firm size) and the profit rate. The battle count variable only shows a significant and negative effect on the number on new workers hired. This result does however not hold if we take the number of newly hired employees as a percentage of the total workforce in the firm (column two).

The sales, firm size and profit variables are a good way to check for actual effects of conflict. If the conflict had an effect on the local markets we would expect a reduction of sales, which we do not find. If the battles in Ethiopia destroyed firms on a large scale we would most likely see a reduction in their size. If the conflict situation caused high additional costs, we would expect lower profits. In the data we do not see any such effect, supporting our 
argument that it is not so much actual conflict effects but the fear of insecurity itself causing the effect on investment.

Camacho and Rodriguez (2011) find that higher conflict intensity increases the probability of firm exit in that municipality in Colombia. They perform their analysis on the firm level and the dependent variable is a dummy whether or not the firm exits. To this setup they apply a linear probability model with fixed effects.

Table II.5: Regression results firm exit and entry

\begin{tabular}{|c|c|c|c|c|c|c|}
\hline \multicolumn{7}{|c|}{ Negative Binomial Regression with Fixed Effects } \\
\hline Dep. Var. On town level: & No. Exits & No. Exits & No. Entries & No. Entries & No. Entries & No. Entries \\
\hline \multirow[t]{2}{*}{ Battles 50km } & 0.032 & 0.020 & 0.023 & 0.020 & & \\
\hline & $(1.27)$ & $(0.76)$ & $(0.96)$ & $(0.85)$ & & \\
\hline \multirow[t]{2}{*}{ Battles lag 1} & & & & & -0.027 & -0.041 \\
\hline & & & & & $(-0.96)$ & $(-1.40)$ \\
\hline \multirow[t]{2}{*}{ log Road connection } & -0.071 & -0.016 & $0.472 * *$ & 0.042 & 0.353 & -0.089 \\
\hline & $(-0.24)$ & $(-0.04)$ & $(2.20)$ & $(0.16)$ & (1.59) & $(-0.33)$ \\
\hline Year Dummies & no & yes & no & yes & no & yes \\
\hline No. obs. & 663 & 663 & 648 & 648 & 569 & 569 \\
\hline No. towns & 76 & 76 & 75 & 75 & 71 & 71 \\
\hline
\end{tabular}

t-statistics in parentheses. ${ }^{* * *}, * *, *$ denote significance at the $1 \%, 5 \%, 10 \%$ level respectively.

To check whether we find any effect on firm exit or entry in our data, we use a simpler setup. We calculate the entry and exit rates for each town and since we are dealing with count data in this case, we use a negative binomial regression with fixed effects on the town level to see whether we find an effect. The results are reported in Table II.5. In the first two columns we look at the number of exits per town. Our only additional control variable is the road connection as an indicator for infrastructure, making a town more or less attractive for businesses. Column one reports the result without and column two with year dummies. We use data on 76 different towns (some towns are dropped by the regression because there were no observed exits during the time period observed and therefore no variation in the dependent variable) and find no effect of conflict on firm exit. This is in line with our theory that in a low level conflict, firm owners would not react so strongly that they completely terminate their business.

A more plausible scenario would be that entrepreneurs are less inclined to establish a new business in an insecure environment affecting the number of entrants. This model is shown in column three and four, again with and without year dummies. When not taking year dummies into account, it seems that an improved infrastructure motivates people to 
establish a new firm, but we find no impact of conflict. One might argue that founding a firm is a time consuming process, and the decision to do so will be taken some time before. To control for this we use the lagged conflict in our analysis but the results remain insignificant.

\section{II.7.5 The case of Addis Ababa}

As we stated at the beginning Addis Ababa is excluded from our analysis because we do not expect or see an effect of conflict there. The results for the regression with the Addis sample can be found in Table B.5. The battle count variable is insignificant in all specifications. When merging both samples, we do not see any effect either because the data from Addis strongly dominates the sample.

\section{II.8 Conclusions}

This chapter deals with the impact of conflict on firms, by applying a very precise spatial identification strategy that has hardly been used until now. With this we hope to make a useful contribution to a still very small literature.

Our results show that even a low level conflict like the one in Ethiopia can have important consequences for investment behaviour. Especially in such conflicts the firms will suffer much more from foregone investment opportunities than from losses directly caused by the conflict. We provide various explanations why this could be the case and believe that it is mainly increased insecurity causing firm owners to hesitate with investments. Credit constraints are a possibility as well, but in our data we cannot identify the exact causal channel.

We find that especially labour intensive firms suffer from the investment reduction. We suppose this has something to do with more risk-averse owners of such establishments and an anticipation of potential reactions to conflict from the workforce which would be less severe if the production process relied more on capital goods.

We cannot assess the overall economic cost connected to the investment reduction we observe, but do not believe it will be overwhelming considering that the firms in Addis Ababa, which is the largest industrial centre of Ethiopia, are not affected. The main 
contribution of this research is to show that even a very low intensity conflict has impacts on the investment behaviour of firms. If this result was generalized it could imply an enormous problem for more conflict affected regions in the world, where a stronger reduction of investment might, additionally to possible direct destruction, erode the existing capital stock over time. 


\title{
Chapter 3
}

\section{Determinants of the duration and ending of terrorist and other non-state armed groups}

\begin{abstract}
:
This chapter empirically investigates the impact of group characteristics and host country conditions on the duration and the ending of terrorist organizations and rebel groups. The empirical analysis relies on data for more than 600 armed groups from the Terrorist Organization Profiles, collected by the MIPT, and employs discrete time duration models with unobserved heterogeneity and its application to a setting with competing risks. It is found that organizations stabilize over time and face the highest risk of failure at the beginning. Factors that motivate members play an important role, as does support from other countries. Rich states are more likely to defeat armed groups and there is no evidence found that a restriction of civil rights decreases the duration of armed groups or increases the likelihood of capturing them.
\end{abstract}

\section{Acknowledgements}

I would like to thank Stephan Klasen, Axel Dreher and the participants of the Ph.D. student seminar of the Economics department at the University of Göttingen for helpful comments and discussion contributions. Financial support by the German Research Foundation (DFG) through the CRC-PEG is gratefully acknowledged. 


\section{III.1 Introduction}

This chapter empirically investigates the life-span or duration of non-state armed organizations and identifies factors which lead to these groups' cessation, considering the different ways in which such a group can end. Terrorism and civil conflict have strong negative effects on the economy, society and each individual in the affected country or region. There has been a large increase in literature regarding both terrorism and civil war in the last two decades. While both topics have much in common, the contributions in the literature have, in most cases, treated them more or less separately. Empirical research so far, has mainly focused on the explanation of the onset and duration of civil war or incidences of acts of terrorism in a country. A comprehensive overview over the civil war literature can be found in Blattman and Miguel (2010) and most strands of the terrorism literature are surveyed in Schneider et al. (2011a/b). An overview over the comprehensive research literature, that relates incidents of terrorism to country characteristics, can be found in Gassebner and Luechinger (2011).

The importance of armed groups - and therefore the importance of investigating them - is clear, because they form the organizational unit for terroristic attacks and insurgency. Without them, there is no civil conflict and only few terrorist attacks are committed by individuals alone. The main questions about those organizations are therefore, why they form, how they work, why they either succeed in reaching their goal or fail in their fight and how long they exist. The duration of terrorist organizations is very unequal. While many organizations dissolve after only one attack or short campaigns of violence, others persist for decades. It is therefore important to assess what factors do contribute to the duration of such organizations.

Despite their importance, empirical research of factors leading to the creation and ending of organizations behind such violent acts is very scarce. The purpose and contribution of this chapter is to investigate how long armed groups exist, what factors influence their duration and in which way they end, by using a large dataset of terrorist and rebel organizations. The dataset is mainly based on the 'Terrorist Organization Profiles' (TOP), originally collected by 
the Memorial Institute for the Prevention of Terrorism (MIPT). The goal of this study is not to explain why such groups form or when and how often they attack.

The issues of duration and ending type are directly related and can be empirically assessed using econometric duration models. Specifically, this study uses discrete time duration models, controlling for unobserved heterogeneity, and applies this to a setting of competing risks. To the author's knowledge there are no empirical studies about the duration of terrorist organizations, with the exception of Blomberg et al. (2010), who focus on transnational terrorists.

Some of the main findings of the empirical analysis are that groups in general are least stable at the beginning, nationalist and separatist groups are somewhat more lasting than others, more powerful states are much more likely to defeat the groups and the restriction of civil liberties does not help to defeat terrorists.

\section{III.2 Definitions and Classifications}

While everyone has an idea of what civil war and terrorism are, exact definitions can be quite controversial. A common definition for civil war, in economic and political research, is a conflict within a country between its government and at least one more party that causes more than a certain threshold number of deaths either per year or accumulated. ${ }^{32}$ The nonstate actors in such a conflict are usually referred to as rebels, guerrillas or insurgents.

In contrast to this, there are countless different definitions for terrorism or terroristic attacks. Some of the most common definitions stem from the US State Department, the European Union, the UN Security Council and more from the research community. ${ }^{33}$ The most important goal of those definitions is to separate terrorism from criminal acts.

\footnotetext{
${ }^{32}$ There are two major datasets for civil war, the Correlates of War project (COW) and UCDP/PRIO. The COW requires a civil war to be military action internal to the state system, active participation of the government, effective resistance on both sides and at least 1000 battle related fatalities per year. For more details see Sarkees (2010) and Sarkess and Waymand (2010). The UCDP/PRIO dataset sets the number of deaths per year at the much lower level of 25 for what they classify as civil conflict and also at 1000 for civil war. For details see Gledtisch et al. (2002).

${ }^{33}$ US Department of State definition: Office of the Law Revision Counsel of the U.S. House of Representatives (2011): United States Code, Title 22 Section 2656f(d). EU definition: European Union (2002). For an overview over UN Security Council definitions see Saul (2005) and as one example: UN Security Council (2004). Example for a common definition in the research community: Enders and Sandler (2006) p. 3.
} 
Therefore, researchers and policy makers usually require the violence or threat of violence, to be associated with some form of political goal and the intention to influence a government, the public or another organization to behave in a certain way, by spreading fear or panic. The definition of a political goal is usually rather broad, but important for the separation from regular crimes, where the motivations are mostly profit and personal/emotional issues. One important difference between the definitions is whether or not the victims are required to be non-combatants and violence against state agents - such as the police or the military - is counted as terrorism. While the US Department of State does not count violence against the military as terrorism many other definitions do. ${ }^{34} \mathrm{~A}$ frequent requirement is also that the terrorists are trying to spread fear beyond the actual target group.

It is in many cases very difficult to distinguish between terrorists and insurgents: "The line between rebel and terrorist groups is blurry" (Blattman and Miguel, 2010). Both employ violence as a means to pursue political goals, mostly but not necessarily, against the state. While rebel groups engage in open battle and guerrilla warfare, they also use terrorist attacks as an additional tactic. Wide parts of guerrilla warfare are technically terrorist attacks according to many definitions. A 'classic' terrorist organization will however not engage in open battle. Under the presence of a rebel army, the state usually does not have full control over all of its territory, while this is not necessarily the case under the presence of a terrorist organization. This finding is in line with the common view that the difference mainly lies in the strength of the organization, relative to the strength of the state the organization is operating against. In a strong state, such organizations stay small and rely only on terrorist attacks, while in weaker states they may grow and become an insurgent army (e.g., Sanchez Cuenca and de la Calle (2009), p.32). In the public debate, the categorization of different armed groups is also unclear, since now many organizations that earlier were called rebel groups, are listed as terrorist organizations, e.g., the Revolutionary Armed Forces of Colombia (FARC) which have been declared terrorists by the U.S. Department of State and the EU.

Due to the close relationship between rebel and terrorist groups and the difficulties of distinction, both organization types are pooled in this study and jointly investigated. The

\footnotetext{
${ }^{34}$ For a short discussion of victims see Ender and Sandler (2006), p.3.
} 
organizations of interest here are at least loosely organized groups, comprising more than one individual, that have relied on violence or were actively planning to do $\mathrm{so}^{35}$ and pursue a political goal.

When looking at the influences of group characteristics and conditions however, one has to acknowledge the differences between guerrillas and terrorists. Guerrillas are large in size and therefore require more resources and support. As stated by Collier and Hoeffler (2004) "rebellion needs [...] opportunity" (p.563). Since rebels are normally weaker than the state in military terms, they require areas to retreat to and to hide. Such safe havens could be provided by mountainous or wooded terrain. For the same reason, large countries with low population densities are also more advantageous to the survival of a rebel army. Large organizations need to supply their troops, which implies a large financial and logistical effort and thereby a need to generate or extract income. Depending on how well they are able to do this, they might need support from the population. Weinstein (2007) provides interesting case studies of how rebel armies behave towards the population also depending on the ability to secure sufficient resources with or without them.

Small terrorist groups on the other side, are often urban-based and operate secretly. They do not depend on terrain and the interaction with the population is different. Since it is much easier to support small groups, they can persist with significantly fewer resources. The individual members - since they are not full day soldiers - might just support themselves or will rely on small support networks, which do not have to be based in their country of operation.

Another broad categorization of terrorist organizations could be made according to their relationship with the local population, because not all arguments about group duration may apply in the same fashion to all categories. A proposal for a simple distinction could be two categories: Ideological and representing groups. As stated by Crenshaw (1981) terrorism is a tool of small elites. A distinctive feature is therefore whether or not the group represents larger parts of the population, a specific region or ethnicity.

In ethno-nationalist or secessionist conflicts, or rebellions against autocratic regimes, the groups tend to represent a significant share of the population. These groups often enjoy

\footnotetext{
${ }^{35}$ In some cases the organizations were discovered before they had been able to execute their first attack.
} 
much support and can potentially grow into large rebellion movements, working towards a regime change or autonomy. These are classified as representing groups and even though they might have some ideological foundation, the contact to and support from the surrounding population are of greatest importance. In contrast, the ideological groups do care much less about the population. They tend to be much smaller groups of ideological radicals (political or religious), who even operate without support and against the will of the population (often claiming to know what is best for the population even though it does not share this view).

Such ideological groups are the most common form of terrorist groups in democratic countries. They are usually small and do not enjoy much support from the general public (the public does not share their political goals). This implies that they do not have the possibility to use the democratic process for their usually quite radical purpose, but still try to reach their goal in other ways. Examples would be leftist groups fighting for a socialist revolution in Western democracies during the 1970's, which definitely was not the popular opinion among the population.

\section{III.3 Literature Review}

Duration analysis has been used in the conflict literature to identify the factors influencing the duration of civil wars (see, e.g., Collier et al., 2004 and Buhaug et al., 2009). The subject of investigation in this study is obviously different, as it assesses the duration of organizations and not conflicts per se. In the case of smaller terrorist organization, the threshold number of deaths for a civil war is usually not reached. When looking at large rebel groups, whose fight is classified as a civil war, the end of one group does not necessarily represent the end of the conflict, as there might be more parties involved. The end of the conflict on the other hand, might not be the end of the group, since they might continue, e.g., on a smaller scale. This implies that the above-mentioned literature can only give limited insight into the topic of interest here. The outcomes of civil wars have been one subject of study in DeRouen and Sobek (2004). They specifically mention the bias in the data, due to the exclusion of small groups that never start an open war with the government. 
There is hardly any literature that deals with the duration and ending of terrorist or insurgent groups. The exceptions are Jones and Libicki (2008), Cronin (2009) and Blomberg et al. (2010). Jones and Libicki (2008) compile a list of 648 terrorist organizations from the RAND-MIPT Terrorism Incident database and add the start and end year and more characteristics of each group. Their data is one of the main sources used in this study. ${ }^{36}$ The by far largest part of their research consists of comparative case studies while the empirical analysis remains very short and shows no results probably also due to methodological issues.

Relying on qualitative case studies and descriptive statistics, Cronin (2009) studies six different types of endings for terrorist organizations and discusses reasons and processes triggering these endings. Her data is a reduced sample of the 'Terrorist Organization Profiles' from the MIPT 'Terrorism Knowledge Base'. She excludes all groups that have exclusively targeted property or military targets without hurting civilians and groups that have only carried out one or one series of attacks. Cronin (2009) argues that an organization or its campaign will endure, as long as it can maintain what she calls momentum. This can be kept up by the actions of the groups or by the reactions of their opponents. 'Overreactions' or 'overly repressive law enforcement campaigns can add to the momentum of terrorists. She concludes that capturing terrorists or terrorist leaders, is much more effective than killing them, because it demystifies them, taking away the momentum. She considers negotiation as a slow process, which only in very few cases leads to the desired outcome. A common end for groups is the implosion or marginalization, especially when groups loose support from the population, often due to their own tactics.

The study with the most similar approach to this one is Blomberg et al. (2010). It looks at the impact of target country characteristics on the duration of transnational terrorist organizations using survival analysis techniques, specifically Weibull regressions. They find a negative duration dependence, which means that the risk of ending for an organization decreases over time and that the probability of survival of a groups increases with the income and population of targeted countries. The empirical analysis has however some major shortcomings. Blomberg et al. (2010) rely on the 'International terrorism: attributes of terrorist events' (ITERATE) database. The ITERATE database records what it defines as international terrorism events. Sanchez-Cuenca and de la Calle (2009) give some reasons,

\footnotetext{
${ }^{36}$ The data can be found as a table in the appendix of their study.
} 
why this definition, as well as its implications are problematic, especially considering that international terrorism represents only a very small share of the overall terrorist activities in the world. The duration time of an organization in the Blomberg study is determined by setting the start point at the first attack and looking at the continuation of attacks by the groups, where it is effectively considered as ended if no further attacks occur. The most problematic point about this setup is that one group may carry out attacks that are classified as international and others that are not. So a group might exist for decades but if it only carries out one attack - which happens to be classified as international - it will appear in the dataset as a group with a one-year duration. Because of the definition of international attacks, such a scenario is not unlikely. It may be observable for a purely domestic terrorist group that once kills, e.g., by chance, a tourist in a bombing attack. Furthermore, the formation of a group does not necessarily coincide with the year of its first attack. Instead, considerable time might pass between the foundation of an organization and the planning and execution of an attack. Because of this the determination of the duration time of a terrorist group is highly problematic.

The covariates of the analysis in Blomberg et al. (2010) do not contain information about the individual groups, but only about the target country. Since by definition the terrorists do not come from the target country, it is questionable whether the conditions in that country are the most important determinants for the survival of the organization. The only information related to the individual groups is the number of attacks and number of victims of those attacks. Both numbers - again due to the definition of international attacks - will only reflect a small portion of the groups' real activity. One example of this is the Colombian FARC which was founded in the 1960's and is still active. In the Blomberg data - which covers 1968 to 2007 - it is however recorded with a duration of only 29 years, instead of the full 39 and only 67 attacks are listed. In the observed time, the FARC has without doubt executed thousands of attacks, but those are not recorded, because they did not involve foreigners or foreign territory. As a consequence, the data only provides information about the international activities of the organization, while excluding information about the organization itself or the conditions in the country. As a last problem, the data contains groups that are no actual groups, but rather general categories for possibly many unidentified groups. Examples are Arab and Palestinian guerrillas, Colombian guerrillas, German right wing guerrillas and 
Somalian guerrillas (all of which are reported in the table of the groups with the highest incidences of attacks).

To the author's knowledge, there has been no empirical investigation of the duration of terrorist and rebel organizations, except for the study by Blomberg et al. (2010). This study therefore tries to provide a quantitative analysis improving their approach and complementing the qualitative and comparative analysis by Jones and Libicki (2008) and Cronin (2009). It uses a dataset much more suitable for the subject of investigation, adding data about the groups' characteristics and about the country where they are actually based. The econometric techniques used are also more appropriate for the data structure and offer some more flexibility.

\section{III.4 Hypotheses and Theoretical Considerations}

\section{III.4.1 Decision framework}

The theoretical framework of this analysis is based on what is sometimes referred to as the strategic model of terrorism. Even though it is usually not applied to rebel organizations, the theory can easily be extended to account for these groups as well. A similar framework is, e.g., used by Collier and Hoeffler (2004) to explain the onset of rebellions. The following points are mostly taken from McCormick (2003) who provides a review of the literature on the strategic framework for terrorism. Terrorist organizations in the strategic framework are considered to be rational actors with rather stable preferences who consider terrorism as the optimal strategy choice to pursue their goals. This implies that the organization is seen as a collective with common preferences and can be treated like an individual. While this is of course a simplification, it is not unreasonable. The organization has a common goal which they try to achieve and dissent among members is resolved within the group. If the preferences of members differ too much, the groups will most likely disintegrate or split. If they are rational actors, they will view all possible alternative strategies for achieving their goal and will choose the optimum, considering the expected political returns and the cost of each strategy. In reality, the concept of bounded rationality might apply, where the decision- 
makers face incomplete information or mental restrictions. This means that they could later discover that their initial assessment of the situation is no longer or was never correct.

Terrorism or any form of political violence is therefore a strategy or tool to achieve a desired political outcome. Conditions leading to violence as the optimal choice are described by Crenshaw (1981). There must be a grievance among at least a small part of the population and the goal of the groups must be to end it. As a motivation for violence, Crenshaw (1981) sees the "lack of opportunity for political participation" (p. 383). Furthermore, she views terrorism as the "result of elite disaffection" (p.384). This elite might, or might not represent larger parts of the population. If the group was strong enough they would openly rebel or stage a coup d'état. So again, the difference between terrorism and rebellion is mainly seen as a matter of relative strength. Regarding the lack of political participation, a common counterargument is that there is quite a lot of terrorism in democratic countries with a wide range of participation possibilities. A better formulation might therefore be to say that the goal is nearly impossible to achieve using regular political activities.

\section{III.4.2 The imperative of continuation}

Kydd and Walter (2006) argue that terrorists are not able to reach their objective militarily but try to alter 'the audience's beliefs about such matters, as the terrorist's ability to impose costs and their degree of commitment to their cause' (p.50). If terrorist organizations do not have the means to defeat their enemy they can only hope to achieve their goal if they make the intended audience believe that the cost of fighting them is too high to not make any concessions. This course of action requires if possible high profile attacks and the expectation of the continuation of attacks. If the audience expects the terrorist group to not continue there is no reason to make concessions. Kydd and Walter (2006) define this as the attrition strategy. Terrorism in this context can be seen as a costly signalling process showing the resolve of the groups to impose costs on others at a cost for themselves. So once violence has been chosen as a strategy, continuation becomes imperative to maintain the credible threat if they hope to convince their audience. McCormick (2003) refers to the need to continue in order to 'hold their audience'. This also shows that terrorism and its continuation are necessary to keep the perceived grievance on the media's agenda, which is 
an argument also supported by Rohner and Frey (2007) who set up a model where the media coverage acts as a multiplier for the benefits terrorists derive from their action creating a "mutually beneficial relationship [...]" where the media profits from spectacular terrorist attacks. So if they are rational actors they will continue until they have reached their goal, or continuation has becomes impossible. Looking at larger rebel organizations similar strategic considerations apply. Even though they might be able to win by force, this is only a quick way if they are much more powerful than the ruling regime which is nearly never the case. So if they are not able to overpower the regime in a quick coup d'état (which is usually not staged by rebel groups but by the military itself) they will have to fight until they succeed, or are able to secure enough concessions from the state or cannot continue, just like the smaller terrorist groups.

\section{III.4.3 Rational choice and terrorism duration}

If the continuation of terrorism is imperative, it must be part of the initial decision. If terrorism is a rational choice, there has to be a cost-benefit calculation that leads to the decision to use terrorism in the first place. Only if the benefits the terrorists have from fighting are larger than the cost they face, they will use terrorism. They will continue to do so until this condition is not fulfilled anymore, they are not able to continue, have found a more promising alternative way or have reached their goal.

Terrorism is a costly action for the terrorists. It imposes costs on the members of the terrorist organization and on the organization itself. The costs for the members are mainly non-monetary. By engaging in terrorism they face strongly increased risk in their life, namely the risk of being detected and consequently arrested or killed. Stress and trauma can also be considered part of this, as well as the disruption of family life and possibly restricted mobility. In addition they have opportunity costs through foregone earnings.

The organization itself faces more direct costs. They need recruits, material and financial resources in order to continue their activities.

How large the costs of terrorism are, is mainly determined by the state. If detection and defeat are more likely because of a powerful regime with a good law enforcement and 
military infrastructure, the cost for a single terrorist is higher, as it is for the organization which will need more resources for their fight. Important factors contributing to this are the anti-terrorism policies of the state and the political system. In a liberal democratic state, terrorism might be easier because the law also protects the civil rights of terrorists.

Since the costs for the members are, except for the forgone earnings, mainly non-financial, the terrorists need compensation beyond regular pay, which could be motivation and the expectance of victory. Only if the group can sufficiently motivate their fighters they will continue and the group will be able to find new recruits. A possible source of motivation can be religion as it promises future benefits and might help to find recruits in religious circles.

When the costs for the organization members become higher than the benefits, e.g., the motivation, they will stop and the group disappears. This also happens if members realize that terrorism was not the optimal choice for reaching their goal. Anything that increases the cost or reduces the motivation will make this ending more likely. A lack of motivational tools of the organization and, e.g., higher probability of detection under more oppressive or stronger regimes will have this effect. If the organization cannot create agreement between the members and motivate them to work together, another consequence can be for the organization to splinter into factions. This could happen if, e.g., at least a part of the organization sees alternatives to fighting.

For the organization, it will only be possible to continue terrorist actions, if the costs can at least be covered. This requires the organization to gain sufficient support (financially and maybe logistically). Reliance on future gains, as is sometimes assumed for rebellions, is only an option if the organization has the possibility to borrow. This will only be possible for the largest organizations in specific situations and so in general it can be assumed that organizations without enough support cease to exist.

Support can be local or international. Cronin (2009) argues that groups "cannot survive without either active or passive support from a surrounding population." Active refers to financial and material support and especially the provision with new recruits, while passive support means, e.g., to accept or ignore the presence or operation of such a group. Phillips (2011) presents a theoretical model that emphasizes the importance of such "grassroots support" for the duration of terrorist groups and expects this support to be greater in ethno- 
nationalist conflicts. Abrahams (2008) gives an overview over an increasing literature that has found people to join terrorist organizations, because of the contact with other members in their social environment. Since it can be assumed that those networks are stronger in ethno-nationalist conflicts, recruitment is expected to be easier in such situations and duration to be consequently higher. Support from the outside can be just as important. It is a well known fact that many terrorist organizations have been and are still backed and supplied by foreign governments. This can happen through training or hiding possibilities in other countries, or the direct supply with money and material. All of this should greatly increase the duration of the organizations.

The lack of support can lead to the disappearance of the group or make its defeat more likely. Without passive support they can be more easily detected and maybe not avoid state forces by retreating into foreign territory. Without active support (training and material) the military defeat is easier. If all, or a significant part of the members of the organization, have been captured or killed the continuation of terrorism is simply impossible. Such an event is more likely if the state is relatively stronger characterized by its financial and military/police resources. A common assumption is also that regimes with less civil rights have more possibilities to monitor the general public, facilitating the capture of terrorists.

Disappearance and defeat are involuntary endings of terrorist groups from their perspective (even though splintering/disappearance is voluntary from the perspective of at least a part of the members). Armed groups could however also end in different ways.

An ending due to a political process might be a negotiated ceasefire, a peace agreement or a change in the situation that rectifies the original grievance leading to the fight. Negotiations require willingness on both sides. The higher the benefit from fighting and a possible victory (i.e., the higher the motivation of the members) the less likely it will be that an organization negotiates. A stronger state will probably be less likely to negotiate, as it sees the terrorists or rebels as a smaller threat. On the other hand, democratic regimes might be more willing to negotiate because the political settlement of conflicts is an integral part of democracy. The general public, which is usually the target audience that terrorists want to impress, also has a greater influence on a democratic government and might therefore more easily motivate it to negotiate, in order to end the violence, even if this includes making concessions to the terrorists. A last point is that negotiation is more likely if the terrorist's 
goal is not too extreme. Governments will not easily accept a regime change or giving up a part of their territory, but a change in policy might be more negotiable.

If however the state is too weak and the group has enough support, they might be able to successfully implement their goals, in which case a continuation of terrorist activity becomes unnecessary.

\section{III.4.4 The effect of time (duration dependence)}

Looking at the duration of anything involves investigating the time dependence of processes. The probability of survival or continuation of terrorist organizations will probably change over time. In general the risk of failure for an organization should be highest at the beginning and then decrease over time. The beginning involves the first steps of recruitment, organization setup and generation of support and is therefore the most risky and unstable period. Over time, experience increases, the organizations can grow, become better known and attract more recruits and establish a larger support base, which will increase their probability of survival.

A major problem is the distinction whether this duration dependence comes from unobserved factors or is really correlated with time. Unobserved factors are, e.g., the skills of the group's leadership. Less talented or intelligent leaders or group founders might not be able to keep groups together for a long time, or are quickly captured. This implies an early ending but is not an effect of time. The learning effects mentioned above however do happen over time. To better distinguish between these scenarios (besides empirical strategies that try to account for unobserved heterogeneity) the specific endings of the organizations can provide some insights.

Organizations that end by splintering or disintegration will probably end quickly and follow the above pattern quite closely. If the organization is not able to motivate their members they will leave and the organization collapses. The same applies when members first come to realize the cost of terrorism, which is probably at the beginning, and change their mind. Therefore, splintering and especially disintegration will be most likely at the beginning and then become less likely over time. Much of this should be attributed to the unobserved factors, because the realization of having made a wrong decision implies less talented leaders or members who did not have the mental capacity to fully anticipate the 
consequences of their decisions. In the case of defeat the risk will be somewhat higher at the beginning as the organization did not have much time to grow and build up strength (this could be in part attributed to the unobserved factors). However if the organization continues its activity over time, the government might have a bigger interest in defeating them and will devote more resources to the fight. Negotiation is a process that will usually not start in the beginning, but rather after a longer duration of the conflict. If neither side is making significant progress, they will have a stronger motivation to find another solution. Therefore a solution of the conflict through negotiation will be less likely at the beginning and increase over time. The probability of victory will also probably increase over time when the organization has had the opportunity to grow stronger. In both cases this should rather be a true effect of time than of unobserved factors.

\section{III.4.5 Hypotheses}

From this, the following hypotheses are derived, to be tested in the empirical analysis:

- H1: Ethnic/secessionist movements increase the duration of terrorist organizations as they provide more support.

- $\quad \mathrm{H} 2$ : Internationally operating organizations last longer because of the possibilities of support and hiding in and from other countries and the necessity for coordinated efforts to defeat them.

- H3: Motivation increases the duration of terrorist organizations and will decrease the likelihood of negotiation.

- H4: More powerful states will decrease the duration of terrorist organizations because of their ability to defeat them and because in such states the cost of terrorism is higher. Powerful states are also less likely to negotiate.

- H5: More oppressive regimes will decrease the duration of terrorist organizations as they will more easily detect terrorists. More oppression also increase the likelihood of disappearance or splintering of the group, by increasing the cost of terrorism.

- H6: Democratic regimes will be more likely to negotiate as they face more pressure from the public to end violence and negotiation is an integral part of democracy.

- H7: Negotiation is more likely if the goal is less comprehensive (e.g., a change in a single policy). 
- H8: Terrorist organizations generally are more likely to fail in the beginning than in later periods when they have had more time to organize and establish themselves; they are especially less likely to splinter or disappear.

- H9: Victory and negotiation are more likely to happen after longer durations of conflict.

\section{III.5 Data}

The main data source for information about terrorist and other armed groups that is used here, are the Terrorist Organization Profiles (TOP) from the Terrorist Knowledge Database (TKB), collected by the Memorial Institute for the Prevention of Terrorism (MIPT). This database - the same that is used by Cronin (2009) - was updated until 2008 when the project ceased to exist. To this point, the organization profiles of more than 860 organizations are made available from the website of the 'National Consortium for the Study of Terrorism and Responses to Terrorism' (START) but they are not maintained, checked or updated. These profiles were matched with the data from Jones and Libicki (2008), from whom especially the end dates were used. ${ }^{37}$ Determining when a terrorist organization started and when it ended is not always straightforward. For most groups some information is available from media accounts, group statements or experts. Jones and Libicki (2008) use as start year the "first indication that the group existed and was dedicated to the use of violence. The end year of a terrorist group was assigned based on the earliest evidence that the group no longer existed or that the group no longer used terrorism to achieve its goals" (p. 5). Their data does not cover all organizations contained in the TOP (only about 650) so the same standards were used to determine the end year of the remaining groups, in case they were no longer active (the start year is reported in the TOP). If there was no information about the current status of an organization available and there was no indication of activity in the last five years from online news searches, the Global Terrorism Database or the RAND/MIPT Terrorist Incidents Database, the group was assumed to have ended. An important aspect of

\footnotetext{
${ }^{37}$ More information about how the data was obtained and subsequently modified can be found in the technical notes in the appendix C.2.
} 
this is that only the time as a terrorist group is counted. Any time that the group existed before or after but was not using, planning or supporting violence is not considered.

The type of ending and the organization's goals were also taken from their data but have been partially recoded to fit the categories described below. The political orientation recorded in their data was compared to the data from the TOP and also recoded.

Both TOP and Jones and Libicki (2008) report the countries where the groups where active. This information was compared and if more than one country was listed it was determined which country was the main base of operations for the group, usually from the text descriptions in the TOP. For this method, there are of course unclear cases where the groups have their bases in border regions or have changed their base in the course of their existence. In this case the region where they had spent most of their time was chosen.

The majority of the resulting data entries about the organizations, after the compilation, were checked manually. Some codings from the database were revised if additional information suggested that the coding was incorrect or outdated and missing data was added if possible. For all groups that were still considered active, it was checked whether there was any indication that they had ended in the meantime or that they were still active in 2011. The main sources of information for the addition and revision of data were the TOP text descriptions, the Global Terrorism Database, the RAND/MIPT Terrorist Incidents Database, the 'Violent Extremism Knowledge Base' (VKB) of the Institute for the Study of Violent Groups (ISVG), the research project 'Mapping Militant Organizations' from Stanford University, the 'South Asia Terrorism Portal' and internet news searches. A future extension could be to add new organizations which has however not been done in the present study.

Not all organizations listed in the data are used for the final analysis. More than 200 entries have been excluded leaving 645 organizations for the empirical analysis. Groups were excluded for various reasons. Since the TOP data focuses on groups that have been active since the 1960's, we exclude all groups that were founded before the year 1960, since only longer lasting organizations founded before would be observed. Some groups are large political parties where only a very small fraction of the members has contact with terrorist activities. Some are the political arm of another terrorist organization that is listed as well and including both would mean double counting. A few groups are known or strongly 
suspected to be cover names for other organizations (e.g., 'Arab Revolutionary Brigades' for 'Al-Fatah') and in some cases there was never a real organization but just a single terrorist who claimed to be an organization. Purely criminal organizations were also removed from the analysis (e.g., Mara Salvatruchas, a street gang from El Salvador). Quite many organizations listed in the TOP data, are Greek anarchists who usually just commit one attack and disappear. These are not considered to be real organizations. In very few cases, organizations were excluded if there was too little reliable information available and it was questionable whether the organization ever existed.

Using, checking and modifying the above data sources, the following information about the organizations was obtained: Start and end year, political orientation, goal, approximate peak size, financial sources (only in a few cases), whether it can be categorized as a religious group and whether the groups' operations or bases were located in more than one country. Only very few of these characteristics are likely to change over time (mainly the size) but for those there are no observations over time.

The idea of this chapter is not only to analyze the duration of the organizations and the factors that led to their cessation but also in which way they ended. The possible endings have been coded in 4 categories as outlined in the theory section: The first is 'Policing/Military defeat' which refers to cases where either the whole group or at least an important part of it was either captured or killed by the police or military, thus effectively ending the organizations' ability to continue their struggle. The second category is 'Splintering or Disappearance'. This definition refers to all cases where the group split into various factions or when organizations just disappeared for unknown reasons. The third ending refers to political processes like peace agreements or permanent ceasefires. The same coding was used if the organization refrained from any future use of violence and, e.g., started to pursue its goals on the political stage. A small fraction of groups abandoned their fight because the situation in the country changed so that the original goal was not existent anymore. An example for the latter is the 'Manuel Rodriguez Patriotic Front' (El Frente Patriotico Manuel Rodriguez) in Chile which intended to bring down the Pinochet regime. After the regime's fall (not due to the organizations activities otherwise it would have been a victory) there was effectively no reason for them to continue. A follow up organization with the same name (but obviously different goals) split off from the original group. In the data 
however they are coded as separate organizations. These cases are not investigated as a category of their own (because there are too few) but especially for them it is a fine line to the last ending category: 'Victory' which is used if the organization successfully implemented their goal. There are only very few observations in the data where this has happened which makes the separate analysis of this outcome practically impossible.

Organizations where classified by their type and by their goal. The classifications are based on the categories in the TOP and in the Jones and Libicki data. The different types are 'Nationalist or Separatist', 'Left-Wing', 'Right-Wing' and 'Anarchist'. The most general category here is probably the 'Left-Wing' since it is coded to also contain militant environmentalists or animal rights or anti globalization activists. Anarchists are the smallest category.

The possible goals of organizations are classified as 'Territorial Change' which can refer to expansive or separatist movements, 'Regime Change' if the organization wants to end the government or whole political system (e.g., wanting to turn a democracy into socialism), 'Policy change' if the goal is more specific (e.g., a change in one law or a change in foreign policy) and the 'Status Quo' if the groups wants to stop a reform or other processes of change.

An extra variable identifies whether or not the organization has a religious background. The aspect of religion has not been used as a category of its own, because in most cases organizations are not just religious. As a characteristic it can be combined with all the above types and goals.

Table III.1 provides an idea about the distribution of organization characteristics in the data. Most of the organizations are classified as either Nationalist/Separatist (50\%) or Left Wing (26\%), Anarchists being the smallest category. The non-political organizations are mostly religious ones but there are also many religious groups with a political orientation. In total, about $30 \%$ of the organizations in the data have a religious orientation. The actual separatist movements can be more easily identified by their goal which is coded as territorial change. They account for a little more than $30 \%$ of the sample. The most common goal is a regime change (46\%). Of the listed organizations, $30 \%$ are classified as still active while about $30 \%$ ended due to splintering or disappeared without information. Another common ending is 
police or military action (22\%). Only very few organizations were coded as having achieved victory (3\%). Most organizations are small with less than 100 members (55\%) and only $16 \%$ are coded as large organizations (more than 1000 members). The organizations where mostly located in the MENA countries, Europe and South and South East Asia (each about $20 \%)$.

Table III.1: Summary statistics

\begin{tabular}{|c|c|c|c|c|c|c|c|c|}
\hline \multicolumn{9}{|c|}{ Descriptive Statistics for duration of ended organizations } \\
\hline \multicolumn{2}{|r|}{ Category } & $\begin{array}{l}\text { Total } \\
\text { count }\end{array}$ & $\begin{array}{l}\text { Total } \\
\text { percent }\end{array}$ & $\begin{array}{l}\text { Count } \\
\text { ended }\end{array}$ & $\begin{array}{l}\text { Mean } \\
\text { Duration }\end{array}$ & $\begin{array}{l}\text { Std. } \\
\text { Dev. }\end{array}$ & Min. & Max. \\
\hline All Organizations & - & 645 & - & 435 & 7.27 & 8.85 & 1 & 42 \\
\hline \multirow{4}{*}{ By: Goal of Organization } & Regime change & 299 & 46.36 & 208 & 7.75 & 8.79 & 1 & 37 \\
\hline & Territorial change & 205 & 31.78 & 112 & 8.80 & 10.15 & 1 & 39 \\
\hline & Policy change & 121 & 18.76 & 99 & 4.06 & 5.38 & 1 & 30 \\
\hline & Status Quo & 20 & 3.1 & 16 & 10.19 & 12.29 & 1 & 42 \\
\hline \multirow{5}{*}{ By: Political Orientation } & No political orientation & 107 & 16.59 & 57 & 4.42 & 6.89 & 1 & 30 \\
\hline & Nationalist/Separatist & 316 & 48.99 & 200 & 7.71 & 9.69 & 1 & 42 \\
\hline & Left-Wing & 170 & 26.36 & 135 & 8.79 & 8.82 & 1 & 37 \\
\hline & Right-Wing & 31 & 4.81 & 25 & 5.20 & 6.10 & 1 & 26 \\
\hline & Anarchist & 21 & 3.26 & 18 & 2.89 & 1.81 & 1 & 7 \\
\hline \multirow{2}{*}{ By: Religiousness } & Non-religious & 451 & 69.92 & 345 & 7.73 & 9.11 & 1 & 42 \\
\hline & Religious & 194 & 30.08 & 90 & 5.50 & 7.57 & 1 & 31 \\
\hline \multirow{5}{*}{ By: Ending Type } & Still Active & 209 & 32.4 & - & - & - & - & \\
\hline & Policing/Military defeat & 146 & 22.79 & - & 8.03 & 8.19 & 1 & 34 \\
\hline & Splintering/Disappearance & 198 & 30.7 & - & 3.95 & 6.36 & 1 & 36 \\
\hline & Politics (Ceasefire/other) & 71 & 11.01 & - & 12.79 & 11.22 & 1 & 42 \\
\hline & Victory & 20 & 3.1 & - & 15.00 & 9.89 & 1 & 32 \\
\hline \multirow{4}{*}{ By: Size of Organization } & $<100$ & 365 & 56.59 & 290 & 3.60 & 5.19 & 1 & 32 \\
\hline & $<1000$ & 183 & 28.37 & 93 & 12.09 & 8.98 & 1 & 39 \\
\hline & $<10000$ & 72 & 11.16 & 32 & 18.53 & 10.62 & 6 & 42 \\
\hline & $>10000$ & 25 & 3.88 & 20 & 20.05 & 9.99 & 4 & 37 \\
\hline \multirow{8}{*}{ By: Region } & USA \& Canada & 43 & 6.67 & 39 & 5.77 & 6.03 & 1 & 26 \\
\hline & Latin America \& Caribbean & 95 & 14.73 & 79 & 8.65 & 8.08 & 1 & 35 \\
\hline & Middle East \& North Africa & 152 & 23.57 & 95 & 5.49 & 8.04 & 1 & 33 \\
\hline & Sub-Saharan Africa & 40 & 6.2 & 28 & 15.86 & 11.51 & 1 & 39 \\
\hline & Europe & 142 & 22.02 & 119 & 5.54 & 8.34 & 1 & 42 \\
\hline & South \& South East Asia & 126 & 19.53 & 48 & 9.10 & 9.88 & 1 & 36 \\
\hline & East Asia \& Oceania & 12 & 1.86 & 7 & 8.43 & 11.86 & 1 & 32 \\
\hline & Central Asia & 35 & 5.43 & 20 & 6.65 & 7.56 & 1 & 29 \\
\hline
\end{tabular}

Since the conditions in the country where the organization is based undoubtedly will have strong effects on its survival, socio-economic indicators of the countries have been compiled and added to the group data as yearly country observations. As a first remark, the West Bank and Gaza are treated as a country in this study and the respective indicators were used for the groups based in these regions. The income indicator for the countries is the GDP per capita, measured in thousands of 2005 International Dollars PPP and taken from the Penn 
World Tables (Heston et al., 2011). Additional income data for West Bank and Gaza were taken from the World Development Indicators (World Bank, 2012). This is also the source of the population-density measure (people per square kilometre). The measure for civil rights is the index of civil liberties published by Freedom House (2012). The index ranges from 1 to 7 where 7 is the lowest level of civil liberties or the highest level of oppression. The index is based on information about the freedom of expression, belief, association, the rule of law, personal autonomy and individual rights. Democracy is measured as a dummy variable based on the dataset by Cheibub et al. (2010). They distinguish between 3 different types of democracies and dictatorships respectively, based on indicators about executive selection, legislative selection, legality and existence of political parties etc. This study uses all 3 democracy classifications to identify democratic countries. There are many proposals for measures concerning ethnic concentration, polarization and fractionalization. Behind them are different assumptions of how ethnic composition fuels conflict. This analysis uses a very simple indicator, which is just the size of the second largest ethnic group in the country (as a share of the whole population). This serves as a measure of whether there is a large minority in a country. The measure is far from perfect, but that is true for most others and this one is easily available for most countries and years from Ellingsen (2000). Since the ethnic composition in countries is rather stable (especially this indicator) there is hardly any variation over time. Whether or not the use of such an ethnicity indicator is necessary or appropriate is questionable anyway, because many organizations in the data have no ethnic background at all.

\section{III.6 Empirical Model}

The common approach for estimating any kind of duration or spell data is the use of survival analysis techniques. The interest lies in the estimation of the hazard rate, which is the conditional probability of leaving a spell at a specific time, which in this case refers to the probability for a terrorist organization to cease to exist (this is often referred to as 'failure'). To this end, a proportional hazard model for discrete time duration data is employed, taking into account possible unobserved heterogeneity and the possibility of different outcomes or endings. 
A general formulation of proportional hazard $(\mathrm{PH})$ models or 'multiplicative hazard' models is the following:

$$
h_{i}(t, X)=h_{0}(t) \exp \left(\beta^{\prime} X_{i t}\right)
$$

Where $h_{i}$ is the hazard of failure for individual i during time interval $t$, depending on additional characteristics. $h_{0}(t)$ is the so-called baseline hazard that varies only with time but is identical for all individuals and $\exp \left(\beta^{\prime} X_{i t}\right)$ is a non-negative function of individual specific time-varying or time constant covariates $\left(X_{i t}\right)$ that scale the baseline hazard. A PH model assumes that there is some kind of duration dependence for all individuals represented by the baseline hazard and this is then multiplicatively modified or scaled by the individual specific covariates. PH models can be used in a continuous or discrete time setting. The analysis of Blomberg et al. (2010) employs continuous time models. In their data as well as ours, however time is observed in discrete intervals (years) and the typical duration amounts to only a few periods. This means that a $\mathrm{PH}$ model for discrete time intervals (and not a continuous time model like the Weibull model) seems more appropriate. Such a model is presented by Prentice and Gloeckler (1978). The discrete time hazard is given by:

$$
h(j, X)=1-\exp \left[-\exp \left(\beta^{\prime} X_{i t}+\gamma_{j}\right)\right]
$$

Where $\mathrm{j}$ refers to the observed time interval and $\gamma_{j}$ is the interval-specific baseline hazard rate. This is the hazard for an organization to end during a specific time interval (period or year), given that it has survived until the beginning of this interval.

Additional to the observed covariates there might be unobserved characteristics causing heterogeneity which is usually referred to as 'frailty' in the survival literature. Meyer (1990) proposes a model with an unobservable random individual effect that enters the hazard multiplicatively and has a gamma distribution. This is often referred to as a 'mixed proportional hazard' model and gives the following hazard:

$$
h(j, X)=1-\exp \left[-\exp \left(\beta^{\prime} X_{i t}+\gamma_{j}+\ln (v)\right)\right]
$$


Where $v$ is the unobserved random effect. ${ }^{38}$

While the general model uses any ending of a terrorist organization, more insights can likely be gained by also taking into account that organizations can end in different ways and that the influences of the covariates might affect different outcomes in different ways. The various endings are usually called competing risks, because any outcome prevents any other outcome from ever happening. Under the assumption of independence between the risks, one can estimate a single risk model for each risk, with the above methods, by simply treating all organizations that ended in any other way as right-censored. Even though this is a strong assumption it is the common approach and will be used here as well. Discrete time duration models with competing risks and unobserved heterogeneity have so far been mainly used for the investigation of the duration of unemployment (for the application of a very similar approach as above to unemployment see, e.g., Böheim and Taylor, 2002).

One other important assumption these models make, is that the hazards are actually proportional, meaning that the relative difference in hazards between two organizations due to different characteristics should not vary over time. One problem is that in the data the approximate size of the organization is observed only at its peak and not at every point in time. Since it takes time for an organization to grow to a certain size, it is clear that a large organization needs to have survived for a certain time in order to have become large. This implies that the peak size, as a covariate, would most likely violate the proportionality assumption, because the survival probability of a large organization must be higher in the beginning. Tests confirm this and the variable is not used in the regression.

As a last point there are different possibilities to model the baseline hazard. This study uses a so-called semi-parametric model that estimates a baseline hazard for specific intervals of time. This approach is more flexible than, e.g., the Weibull model used by Blomberg et al. (2010). The Weibull model uses a fully parametric baseline hazard, the shape of which is restricted to forms determined by an estimated shape parameter. Estimating the semiparametric baseline is only possible if there are enough observed failures in each of the intervals. Since this is not always the case for each year in the data, especially in the

\footnotetext{
${ }^{38}$ This model is estimated in STATA using the pgmhaz8 procedure by Stephen Jenkins as described in Jenkins (1997). Under the assumption of no unobserved heterogeneity, the model is estimated with a complementary log-log regression (cloglog).
} 
competing risks setting, intervals are grouped, trying to keep the baseline as flexible as possible. ${ }^{39}$ The estimation of this baseline allows to get a closer look at the suspected duration dependence patterns outlined above.

\section{III.7 Empirical Analysis}

Looking at the descriptive statistics for the average duration by organization type can give a first idea about the hypotheses. Table III.1 shows the total number of organizations and the number of those that have already ended, by categories. For the organizations that have been classified as ended, the average duration time is given as well. Still active groups are not counted for these averages. This of course causes a bias in the averages but including active organizations does as well, because it is only known how long they have lasted already, but their future duration is unknown. This can be partially illustrated by Figure III.1, which is a histogram, showing how many organizations lasted for a particular number of years. It includes those groups that have ended already and the ones that have not. From this figure it can be seen that most terrorist organizations last a rather short time. Table III.1 shows that duration is highest for separatist movements and those seeking to maintain the status quo. As is quite logical, larger organizations last longer (as already mentioned they will need time to become large in the first place). An interesting aspect is that the groups that ended victorious or through politics lasted much longer than the others. Possible explanations might be that victory is hard to achieve and that a political end might take so long, because negotiations become a more attractive option for both sides, when they realize, after a long time, that neither side is able to win and that the general population is tired of fighting. In these simple statistics the religious groups have a much shorter lifespan than the others. The main problem with this is that the majority of religious groups in the data is still active and so the long lasting ones are not part of the calculated means.

While some of the hypotheses include directly observable characteristics, other factors cannot be directly observed or characteristics could be interpreted in different ways. One of those is the ability of organizations to motivate their members. There are no straightforward proxies for this, so it is assumed that motivation is highest and most lasting, if the

\footnotetext{
${ }^{39}$ The groups are: year 1 , year 2, years 3-5, years 6-10, years 11-15, years $16-25$ and years $26-40$.
} 
organization members expect a difficult fight from the beginning, which is the case if the goal pursued is very difficult to achieve. This could, e.g., be an intended regime change since this naturally is what every system tries hardest to prevent. If the goal is less difficult, e.g., a policy change, the members might expect a shorter fight and loose motivation if the goal is not achieved quickly. Religion is also assumed to be very strong motivational tool and religiousness is observed in the data.

Figure III.1: Histogram organization duration

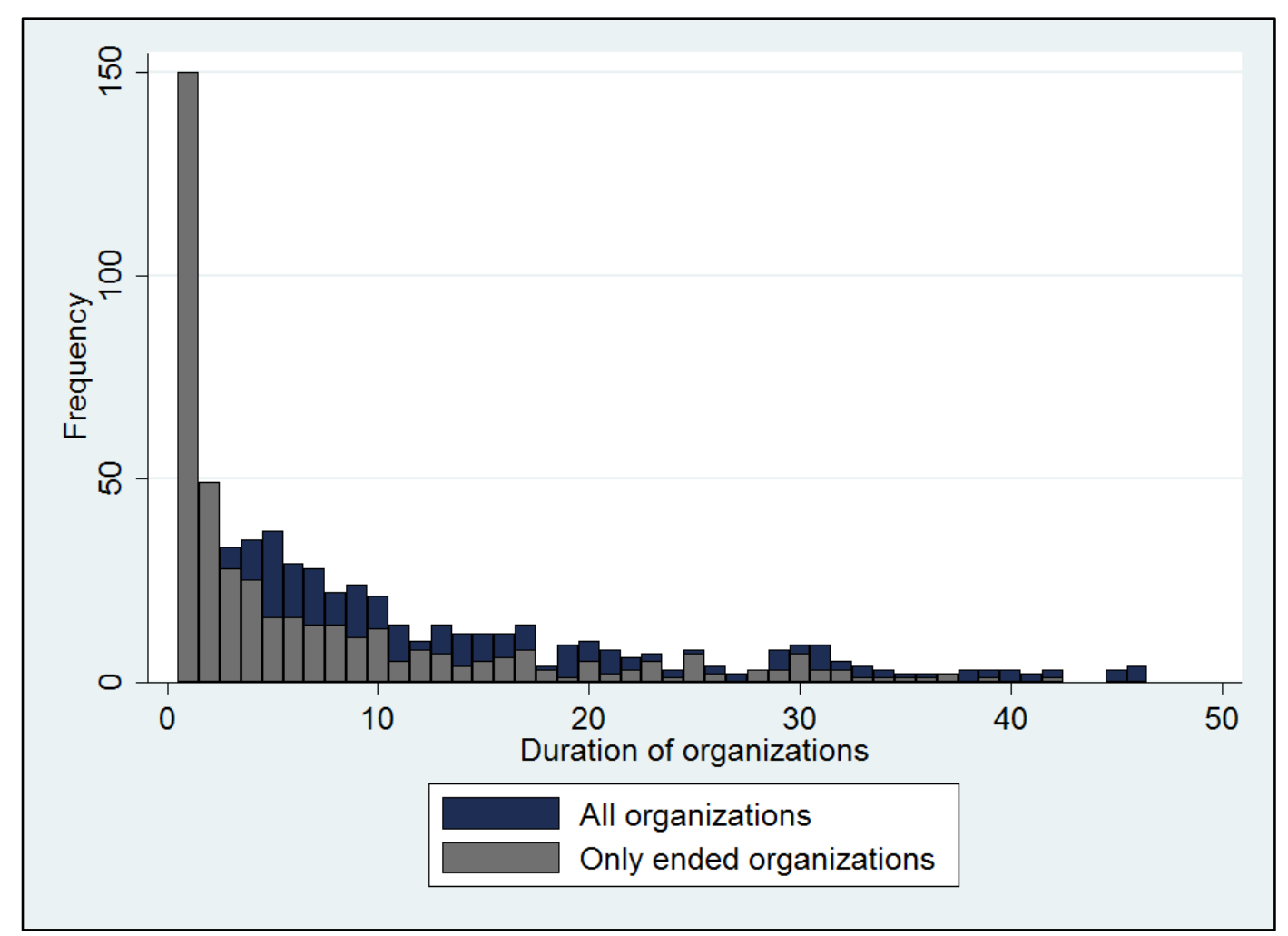

Actual support is only known for a small fraction of the organizations and is therefore not included. As already stated in the hypotheses, local support will be most likely in the case of secessionist and nationalist movements, which is therefore interpreted in this way. A hint towards international support could be if the organization maintains bases in more than one country. ${ }^{40}$ While this does not necessarily mean that the group is directly supported by another country, which is however often the case, at least it hints towards passive support, meaning that the choice of maintaining bases in more than one country will probably have

\footnotetext{
${ }^{40}$ In the data such groups are coded as international organizations. This is not to be confused with the use of international in the literature of transnational terrorism. Staging attacks in other countries or merely attacking foreign nationals in their own country does not qualify a group as international in this data. They are only international if the group or significant parts of it are based in different countries or move between them.
} 
something to do with unequal prosecution across the countries. ${ }^{41}$ International operation however also suggests a more flexible and maybe better organization structure, so it offers itself to more than one interpretation.

\section{III.7.1 Regression results}

The regression tables report the estimation results of the different specifications using the discrete time proportional hazard model with an unobserved individual effect. However in nearly no regression the likelihood ratio test can reject the null hypothesis that there is no unobserved heterogeneity. This implies that either there actually is no heterogeneity, or the method used cannot account for it and it will mainly be captured by the baseline. Using the competing risks and hypotheses, it should however be possible to gain some insights into the underlying processes. All tables containing estimation results, report hazard ratios instead of estimation coefficients. This allows for an easier quantification of the effects since a hazard ratio of 1.08 can be interpreted as an 8 percent higher risk of failure (i.e., end of the organization) and a ratio of 0.97 as a 3 percent lower risk. The estimation results for the time intervals representing the baseline hazard are not reported instead they are presented graphically in Figures III.2-III.5. Estimates that do not meet the 10 percent significance threshold are considered insignificant in this study.

Table III.2 reports the results for the general duration model where the focus is not on a specific type of ending, but any ending is considered. The first column reports the simplest model containing only the group characteristics. The model in column 2 adds region fixed effects to this, in order to account for different background conditions for the organizations. ${ }^{42}$ Both models contain the full estimation sample and the coefficients do not show very large differences between the specifications. The reference category for the organizations' goals is the territorial change, since separatist movements are expected to be the most stable ones. Estimations confirm that organizations with different goals generally face a higher risk of failure in any given period but the estimates are not always significant at the 10 percent level. While the risk for groups that fight for a regime change, and which are

\footnotetext{
${ }^{41}$ Groups in the Palestinian-Israeli conflict tend to have more than one base country because they are prosecuted in Israel but not in neighbouring countries. Colombian guerrillas are known to retreat into Ecuador and Venezuela to avoid confrontations with the military forces.

${ }^{42}$ Country fixed effects are not possible as there are not enough observations of ended groups across all countries.
} 
also expected to be rather long lasting, is somewhat higher (15-45\%), the estimate of the risk of failure is up to more than twice as high for groups which want a policy change. Religious groups as expected, and contrary to the descriptive statistics, are less likely to fail (by about $30 \%)$, as are also the internationally operating groups (more than $40 \%$ less likely).

Table III.2: Regression results for organization duration, general models

\begin{tabular}{|c|c|c|c|c|}
\hline \multicolumn{5}{|c|}{ Duration of Terrorist Organizations } \\
\hline \multirow[t]{2}{*}{ Polit. Change } & $2.629 * * *$ & $2.426 * * *$ & $1.749 * * *$ & $1.692 * * *$ \\
\hline & $(4.58)$ & $(3.88)$ & $(2.95)$ & $(2.72)$ \\
\hline \multirow[t]{2}{*}{ Regime Change } & $1.441 * * *$ & 1.230 & $1.268^{*}$ & 1.161 \\
\hline & $(2.62)$ & $(1.30)$ & (1.69) & (0.99) \\
\hline \multirow[t]{2}{*}{ StatusQuo } & 1.633 & 1.248 & 1.238 & 1.084 \\
\hline & $(1.54)$ & $(0.65)$ & $(0.69)$ & $(0.25)$ \\
\hline \multirow[t]{2}{*}{ Religious } & $0.639 * * *$ & $0.729 *$ & $0.686 * * *$ & $0.715^{* *}$ \\
\hline & $(-3.26)$ & $(-1.85)$ & $(-2.66)$ & $(-2.07)$ \\
\hline \multirow[t]{2}{*}{ Int. operations } & $0.569 * * *$ & $0.536 * * *$ & $0.628 * * *$ & $0.608 * * *$ \\
\hline & $(-3.18)$ & $(-3.44)$ & $(-2.76)$ & $(-2.90)$ \\
\hline \multirow[t]{2}{*}{ State oppression } & & & 0.996 & 0.971 \\
\hline & & & $(-0.07)$ & $(-0.40)$ \\
\hline \multirow[t]{2}{*}{ GDP p.c. 1000 's Int.\$ } & & & $1.036 * * *$ & $1.029 * *$ \\
\hline & & & $(3.46)$ & $(2.26)$ \\
\hline \multirow[t]{2}{*}{ Pop. Density } & & & $0.999 *$ & 1.000 \\
\hline & & & $(-1.67)$ & $(-0.55)$ \\
\hline \multirow[t]{2}{*}{ Size 2nd ethnicity } & & & 0.995 & 0.998 \\
\hline & & & $(-0.69)$ & $(-0.24)$ \\
\hline \multirow[t]{2}{*}{ Democracy } & & & $0.722 *$ & 0.890 \\
\hline & & & $(-1.76)$ & $(-0.57)$ \\
\hline No. Subjects & 645 & 645 & 612 & 612 \\
\hline No. Failures & 435 & 435 & 402 & 402 \\
\hline No. Obs. & 6985 & 6985 & 5800 & 5800 \\
\hline Region fixed effects & no & yes & no & yes \\
\hline
\end{tabular}

Columns 3 and 4 show the full model, including time-varying country indicators to give a better understanding of how the conditions in their base country influence the duration of the armed groups. Since these country indicators are not available for all relevant countries, a few groups are lost and for the others there are less observation periods. Column 3 shows the model without and column 4 the model with region fixed effects. Both results are similar to the first models additionally showing a higher risk of failure in countries with a higher 
GDP. Although the effect might seem small, it is the effect of an increase by only $\$ 1000$. Population density and democracy show up significant at the 10 percent level and reduce the risk of failure, suggesting that terrorist groups exist longer in democracies. These results turn insignificant when region fixed effects are added to the model in column 4 , while the other results remain stable. The measures for civil liberties and ethnic composition are insignificant in these specifications.

These results for the general model give some support to the hypotheses. Secessionist movements seem to be somewhat more stable than others as stated in $\mathrm{H} 1$. The same is true for internationally operating groups as stated in $\mathrm{H} 2$. Religious groups last longer and in richer states groups face a higher risk of failure which is claimed in $\mathrm{H} 3$ and $\mathrm{H} 4$. $\mathrm{H} 5$ however finds no support from these models as civil liberties have no statistically significant effect on the risk of group ending.

A problem with the introduction of region dummies is that there is a systematic correlation between, e.g., GDP and the religious indicator and the regions because richer countries or religious groups are very unevenly distributed among the regions. This strongly increases the standard errors of some of the indicators.

Figure III.2 shows the baseline hazard over time, at the mean of all covariates, for the full model without region fixed effects (point estimates and smoothed). The risk of failure is quite high in the first year (nearly 25\%) and then quickly decreases. After about 15 years the risk increases again slightly. As there are fewer and fewer observations of failures in later periods the estimations become likely less accurate and for the model to be more easily estimated the flexibility of the baseline is strongly restricted after 15 years, leading to the flat portions at the end. The general pattern however supports Hypothesis 8 that the risk is highest in the beginning and then decreases over time.

The organizations' political orientations are not used in these first models. The theoretical framework presented does not suggest that groups with a certain political orientation should last longer than others, with the exception of Nationalist and Separatist groups. Nationalist and separatist groups are however quite well captured by the territorial change goal (the correlation between both indicators is about 0.6). Additionally, there are more high 
correlations, e.g., between the non-political category and the religious indicator (correlation also about 0.6).

Figure III.2: Baseline hazard, model with all endings

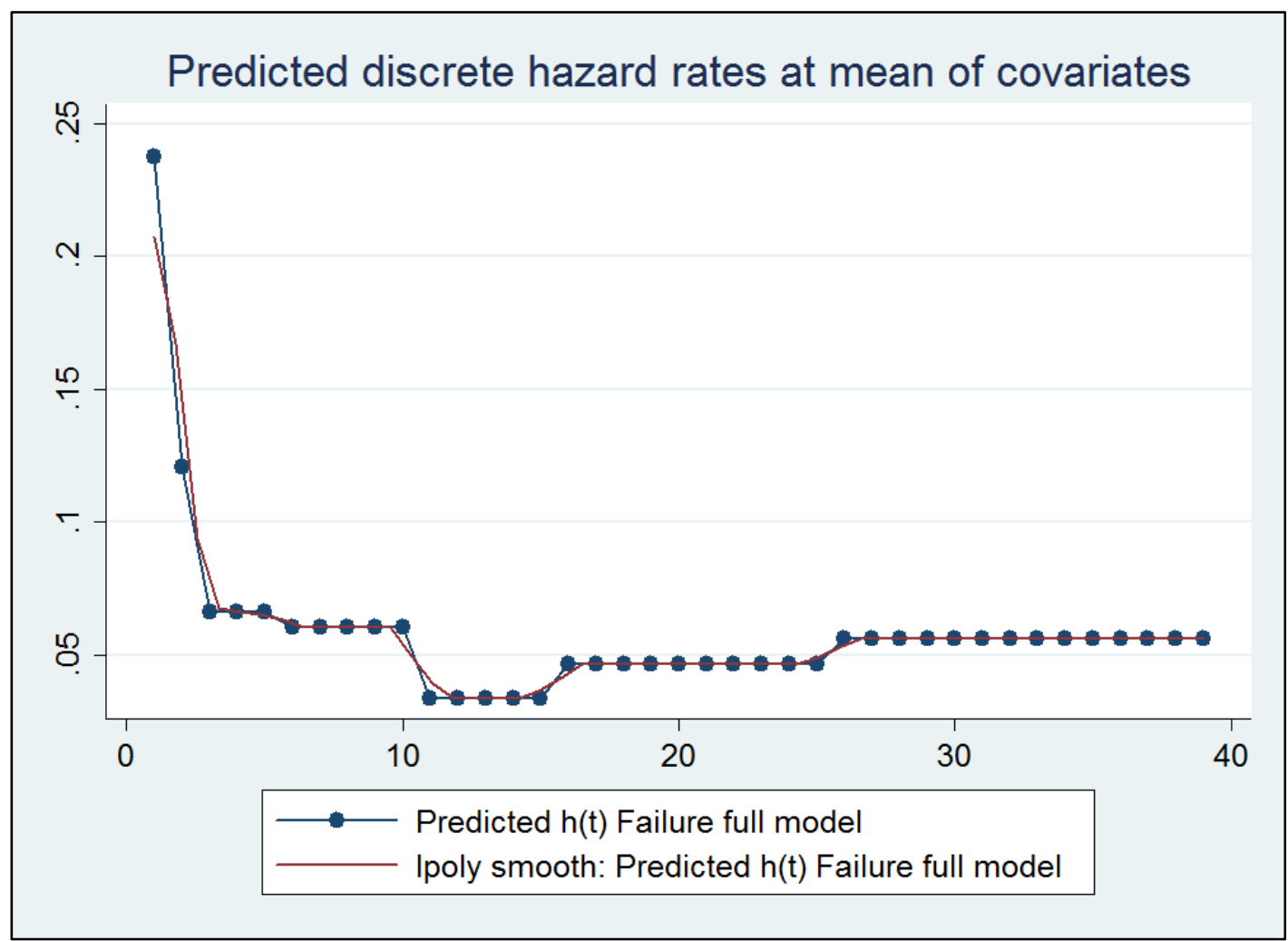

Table C.1 shows results for general duration if political orientations are incorporated. Column 1 presents the results if goals are left out and without country characteristics. Here Nationalist and Left-Wing groups have a lower risk of failure compared to the reference category (no political orientation). If the goals are added (column 2) only the Left-Wing indicator remains significant and if country characteristics are controlled for, they do not seem to have any additional explanatory power. All other indicators are similar to the models without political orientation, the main difference is that the religious dummy has a higher significance level and the democracy indicator remains significant at the 10 percent level, even if region fixed effects are added. Since they do not seem to add very much to the model, the indicators of political orientation are left out in all other models. 


\section{III.7.2 Competing risk regression}

Using the model for each specific competing risk, it is possible to estimate the impact of the variables, not only on the general duration, but on the likelihood for the organizations to end in one of the ways described above. As mentioned before, any group that ended in another way than the one specifically investigated in a model, is treated as right censored. The other model specifications are the same as above. A major problem with this approach is that the number of groups that are observed to end in a specific way is of course much lower than in the above model. The investigation of different endings should however be able to give a better insight into the channels of how the observed characteristics impact the duration of armed groups.

Table III.3 presents the models for organizations ending by police or military intervention. In the full model this was the ending of nearly 140 of the groups in the data. Table III.4 gives results for 'Splintering' which happened to 185 of the observed cases and Table III.5 shows estimations for political endings, which only happened about 60 times. The columns are organized as in Table III.2, each model (with and without country indicators) is presented first without and then with region fixed effects. Victory and political endings where the situation changed were not analyzed, because there are too few observations of such cases.

Looking at the results for groups with different goals, it is found that groups who want a policy change face a much higher risk of failure in the general model. While there is not much evidence that they are defeated more often they seem to have a significant and much higher risk to either splinter or disappear or end in a political process. This gives support to $\mathrm{H} 3$ that a less comprehensive goal is less motivating and will more easily lead to the disintegration of the groups, as well as to $\mathrm{H} 7$ showing that negotiation about such goals seems easier. For groups who want a regime change there is a higher risk in the general model (except for one specification) but practically no evidence in the competing risk models. Organizations whose interest is the perpetuation of the status quo seem to be more willing to negotiate, which might reflect the fact that negotiation over this might be easier for a ruling regime.

Religion as a proxy for motivation lowers the risk of failure for groups in the general model. There is no significant evidence that it reduces the probability of splintering and 
disintegration (the hazard ratio is however below one and in most specifications close to the 10 percent significance level). This does not fit hypothesis 3 about the effect of motivation. There is however some evidence that religious groups are less likely to negotiate or end politically even though this is only significant in the models without region dummies (maybe due to the correlation between region and religion).

Table III.3: Regression results for risk of defeat

\begin{tabular}{|c|c|c|c|c|}
\hline \multicolumn{5}{|l|}{ End by defeat } \\
\hline \multirow[t]{2}{*}{ Polit. Change } & $2.553 * * *$ & 1.436 & 1.565 & 1.257 \\
\hline & $(2.64)$ & (1.04) & (1.27) & (0.64) \\
\hline \multirow[t]{2}{*}{ Regime Change } & $1.700 * *$ & 1.207 & 1.239 & 1.168 \\
\hline & $(2.37)$ & $(0.77)$ & $(0.77)$ & $(0.55)$ \\
\hline \multirow[t]{2}{*}{ StatusQuo } & 1.423 & 0.900 & 0.699 & 0.693 \\
\hline & $(0.61)$ & $(-0.19)$ & $(-0.49)$ & $(-0.53)$ \\
\hline \multirow[t]{2}{*}{ Religious } & 0.723 & 0.938 & 1.045 & 1.029 \\
\hline & $(-1.52)$ & $(-0.24)$ & $(0.16)$ & (0.09) \\
\hline \multirow[t]{2}{*}{ Int. operations } & $0.591 * *$ & $0.663^{*}$ & $0.599 *$ & 0.674 \\
\hline & $(-2.05)$ & $(-1.71)$ & $(-1.71)$ & $(-1.36)$ \\
\hline \multirow[t]{2}{*}{ State oppression } & & & 0.821 & 0.907 \\
\hline & & & $(-1.60)$ & $(-0.73)$ \\
\hline \multirow[t]{2}{*}{ GDP p.c. 1000 's Int.\$ } & & & $1.084 * * *$ & $1.091 * * *$ \\
\hline & & & $(4.37)$ & $(3.84)$ \\
\hline \multirow[t]{2}{*}{ Pop. Density } & & & $0.998^{*}$ & 1.000 \\
\hline & & & $(-1.80)$ & $(-0.24)$ \\
\hline \multirow[t]{2}{*}{ Size 2nd ethnicity } & & & 1.019 & 0.996 \\
\hline & & & $(1.36)$ & $(-0.26)$ \\
\hline \multirow[t]{2}{*}{ Democracy } & & & $0.398 * *$ & $0.466^{* *}$ \\
\hline & & & $(-2.48)$ & $(-2.04)$ \\
\hline No. Subjects & 645 & 645 & 612 & 612 \\
\hline No. Failures & 146 & 146 & 134 & 134 \\
\hline No. Obs. & 6985 & 6985 & 5800 & 5800 \\
\hline Region fixed effects & no & yes & no & yes \\
\hline
\end{tabular}

Hazard ratios reported; t-statistics in parentheses. $* * *, * * *$ denote significance at the $1 \%, 5 \%, 10 \%$ level respectively.

Internationally operating groups are much less likely to fail in the general model. Hypothesis 2 attributes this to the possibility of hiding in other countries (the unequal prosecution across different countries) and maybe even getting support from them. Both should especially reduce the risk of defeat which is confirmed by nearly all specifications. Only in 
the full model with region fixed effects is the hazard ratio insignificant (but below 1). The variable also shows a strong effect reducing the likelihood of disintegration and splintering, which might be a hint towards the importance of foreign support to maintain operations which is also part of $\mathrm{H} 2$.

Table III.4: Regression results for risk of splintering/disappearance

\begin{tabular}{|lllll|}
\hline \multicolumn{5}{l}{ End by Splintering / Disappearance } \\
\hline Polit. Change & $4.609^{* *}$ & $2.391^{* * *}$ & $1.557^{* *}$ & $1.808^{* *}$ \\
Regime Change & $(2.08)$ & $(3.17)$ & $(2.00)$ & $(2.51)$ \\
& 1.399 & 1.299 & 1.334 & 1.266 \\
StatusQuo & $(0.87)$ & $(1.28)$ & $(1.57)$ & $(1.21)$ \\
& 0.602 & 0.629 & 0.546 & 0.543 \\
Religious & $(-0.51)$ & $(-0.74)$ & $(-1.00)$ & $(-1.00)$ \\
& 0.845 & 0.717 & 0.741 & 0.709 \\
Int. operations & $(-0.46)$ & $(-1.56)$ & $(-1.61)$ & $(-1.60)$ \\
& $0.206^{* *}$ & $0.487^{* * *}$ & $0.624^{* *}$ & $0.582^{* *}$ \\
State oppression & $(-1.98)$ & $(-2.84)$ & $(-2.15)$ & $(-2.37)$ \\
& & & $1.251^{* * *}$ & 1.130 \\
GDP p.c. 1000's Int.\$ & & & $(2.80)$ & $(1.28)$ \\
& & & $1.043^{* * *}$ & 1.020 \\
Pop. Density & & & $(4.11)$ & $(1.31)$ \\
& & & 1.000 & 1.000 \\
Size 2nd ethnicity & & & $(0.31)$ & $(0.13)$ \\
& & & $0.979^{* *}$ & 1.003 \\
Democracy & & & $(-2.25)$ & $(0.25)$ \\
& & & 1.055 & 1.417 \\
No. Subjects & & & $(0.22)$ & $(1.10)$ \\
No. Failures & 645 & 6985 & 185 & 612 \\
No. Obs. & 198 & 5800 & 185 \\
Region fixed effects & no & & no & yes \\
\hline
\end{tabular}

Hazard ratios reported; t-statistics in parentheses. $* * *, * *, *$ denote significance at the $1 \%, 5 \%, 10 \%$ level respectively.

When it comes to the importance of the environment in which the organizations operate, the civil liberties variable (a higher index value means less civil liberties) does not show up significant in the general model. The main argument for restricting civil liberties, as also stated in $\mathrm{H} 5$, is that, e.g., the facilitation of the intrusion into people's privacy helps uncovering and ultimately defeating or policing such groups. This does not show up in the analysis. When it comes to the probability of defeat, the variable is insignificant and the hazard ratio is even smaller than one, indicating that more oppression (reduction of civil 
liberties) reduces the risk of failure (in the specification without region dummies this is even nearly significant at the 10 percent level). There is however some evidence (significance in one of two models) that less civil liberties increases the likelihood of disintegration of groups which could be connected to the increased costs of terrorists in such an environment.

Table III.5: Regression results for risk of political ending

\begin{tabular}{|c|c|c|c|c|}
\hline Political Ending & & & & \\
\hline Polit. Change & 1.842 & $2.498 * *$ & $2.654^{* *}$ & $2.503^{*}$ \\
\hline & $(1.52)$ & (1.99) & $(2.20)$ & (1.89) \\
\hline Regime Change & 0.997 & 0.960 & 1.180 & 0.983 \\
\hline & $(-0.01)$ & $(-0.10)$ & $(0.45)$ & $(-0.04)$ \\
\hline StatusQuo & $4.342 * * *$ & $4.339 * * *$ & $6.069 * * *$ & $4.337^{* *}$ \\
\hline & $(3.03)$ & $(2.66)$ & $(3.40)$ & $(2.55)$ \\
\hline Religious & $0.466 * *$ & 0.501 & $0.492^{*}$ & 0.592 \\
\hline & $(-1.96)$ & $(-1.56)$ & $(-1.76)$ & $(-1.13)$ \\
\hline Int. operations & 0.687 & 0.698 & 0.817 & 0.717 \\
\hline & $(-1.18)$ & $(-1.07)$ & $(-0.57)$ & $(-0.88)$ \\
\hline State oppression & & & 0.956 & 0.928 \\
\hline & & & $(-0.28)$ & $(-0.43)$ \\
\hline GDP p.c. 1000 's Int.\$ & & & $0.950 * *$ & 0.957 \\
\hline & & & $(-2.12)$ & $(-1.05)$ \\
\hline Pop. Density & & & 1.000 & 1.000 \\
\hline & & & $(-0.12)$ & $(0.44)$ \\
\hline Size 2nd ethnicity & & & 0.994 & 0.996 \\
\hline & & & $(-0.37)$ & $(-0.23)$ \\
\hline Democracy & & & 1.402 & 2.015 \\
\hline & & & $(0.73)$ & $(1.29)$ \\
\hline No. Subjects & 645 & 590 & 612 & 560 \\
\hline No. Failures & 56 & 56 & 52 & 52 \\
\hline No. Obs. & 6985 & 6451 & 5800 & 5332 \\
\hline Region fixed effects & no & yes & no & yes \\
\hline
\end{tabular}

Richer and thereby more powerful states (measured by the GDP per capita variable) strongly increase the likelihood of failure of terrorist organizations. H5 states that this is because of the increased capabilities of the state to fight and defeat them. This result from the general model is backed up by the results of the defeat model, in which the hazard ratios are even much higher and highly significant. GDP also shows up significant in the context of splintering (only without region fixed effects), which might hint towards the higher cost for terrorists, due to the increased probability of detection. There is also some evidence that 
richer states are less likely to negotiate with terrorists, as they probably pose less of a threat to them (again only significant without region dummies).

Population density as a proxy for terrain only shows up significant in the general and one specification of the defeat model implying that a higher population density reduces the likelihood of failure, which does not fit the hypotheses.

The ethnicity measure only shows up significant once, when it comes to splintering or disappearance of groups and would indicate that this is less likely to happen if there is a large ethnic minority in a country. The data does not suggest that such larger minorities, in general, play a big role for the duration of terrorists, this can however be attributed to the fact that it would only matter in conflicts that do have some ethnic component.

There is some evidence of democracy increasing the lifespan of armed groups. Specifically, it seems that democracies are much less likely to defeat them. $\mathrm{H} 6$ is not supported by the data since democracies do not appear to be more willing to negotiate than others regimes.

Figure III.3: Baseline hazard, model for defeat

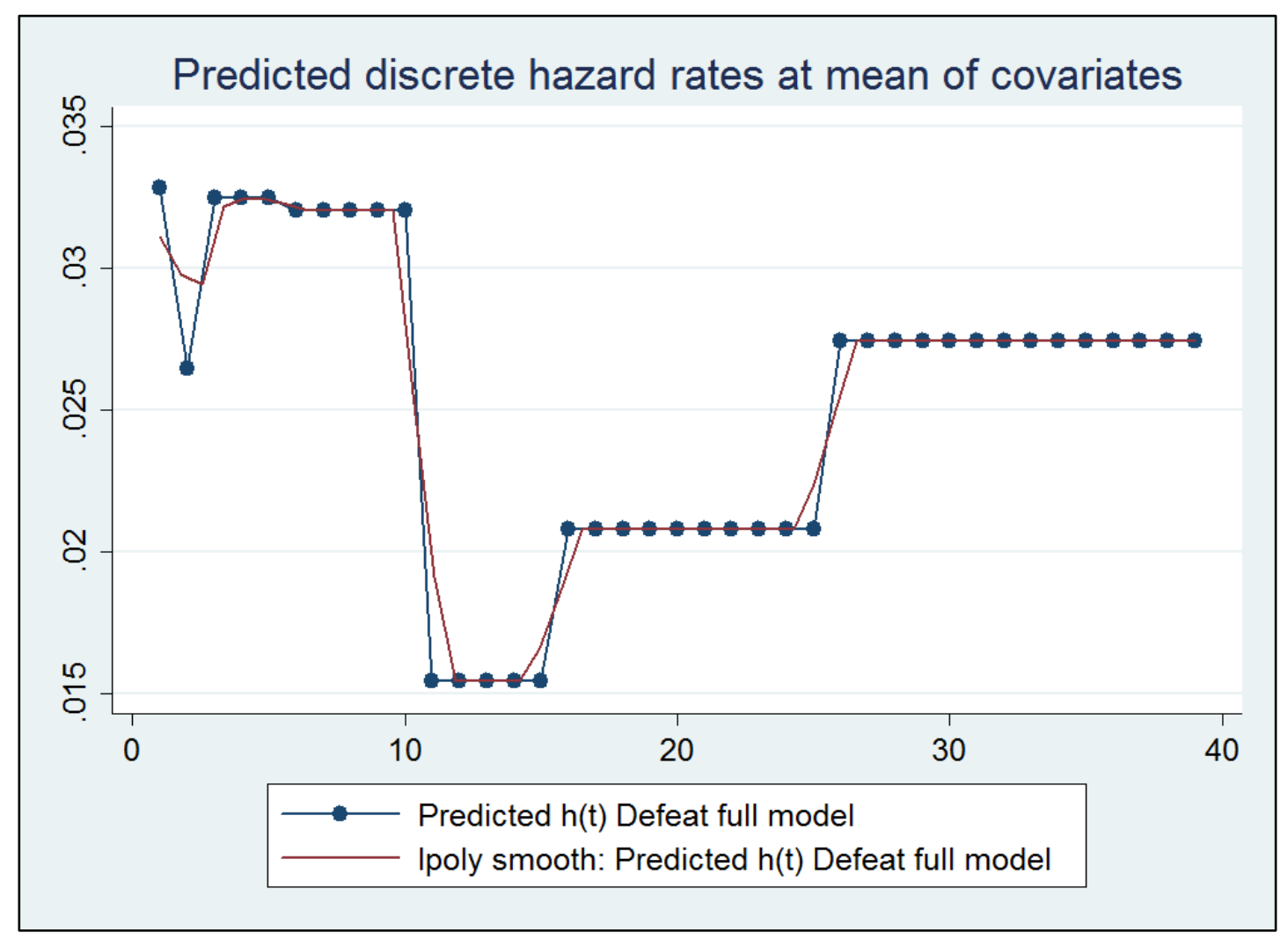


Figure III.3 shows the calculated baseline hazard for defeat supporting the idea that the risk for defeat is highest at the beginning and then decreases. It does however seem to increase again later which could indicate a higher effort of the state to fight long-lasting groups.

Figure III.4 gives the baseline results for splintering or disintegration showing a very high risk at the beginning with a strong decrease afterwards. Since there are hardly any observations of groups that failed in this way after more than 10 years, those results are probably not too reliable. This result gives support to hypothesis 8 .

Figure III.5 confirms hypothesis 9 that negotiation is unlikely in the early years of a group's existence (with the exception of year 1 ) but becomes more likely over time.

Figure III.4: Baseline hazard, model for splintering/disappearance

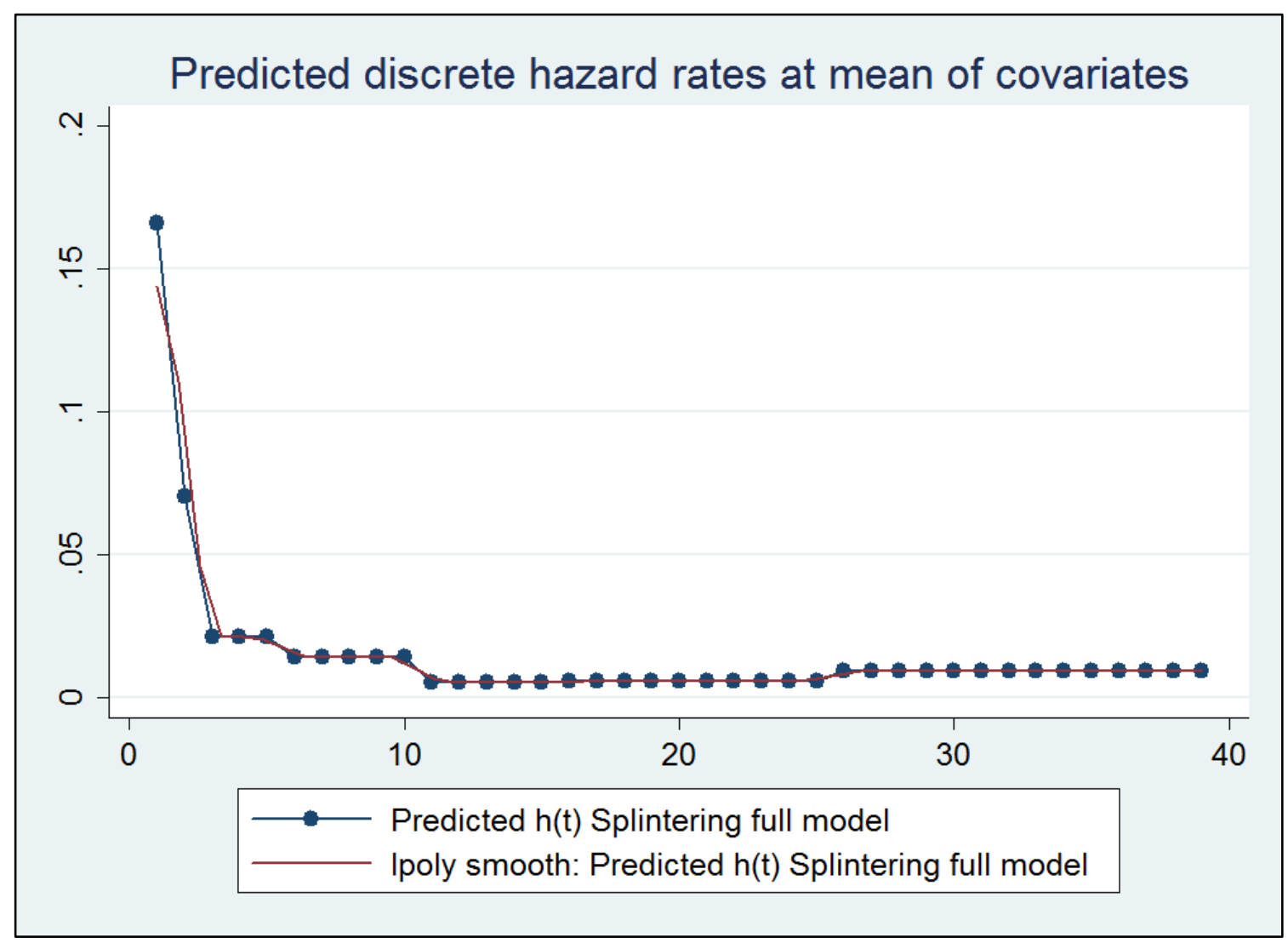


Figure III.5: Baseline hazard, model for political ending

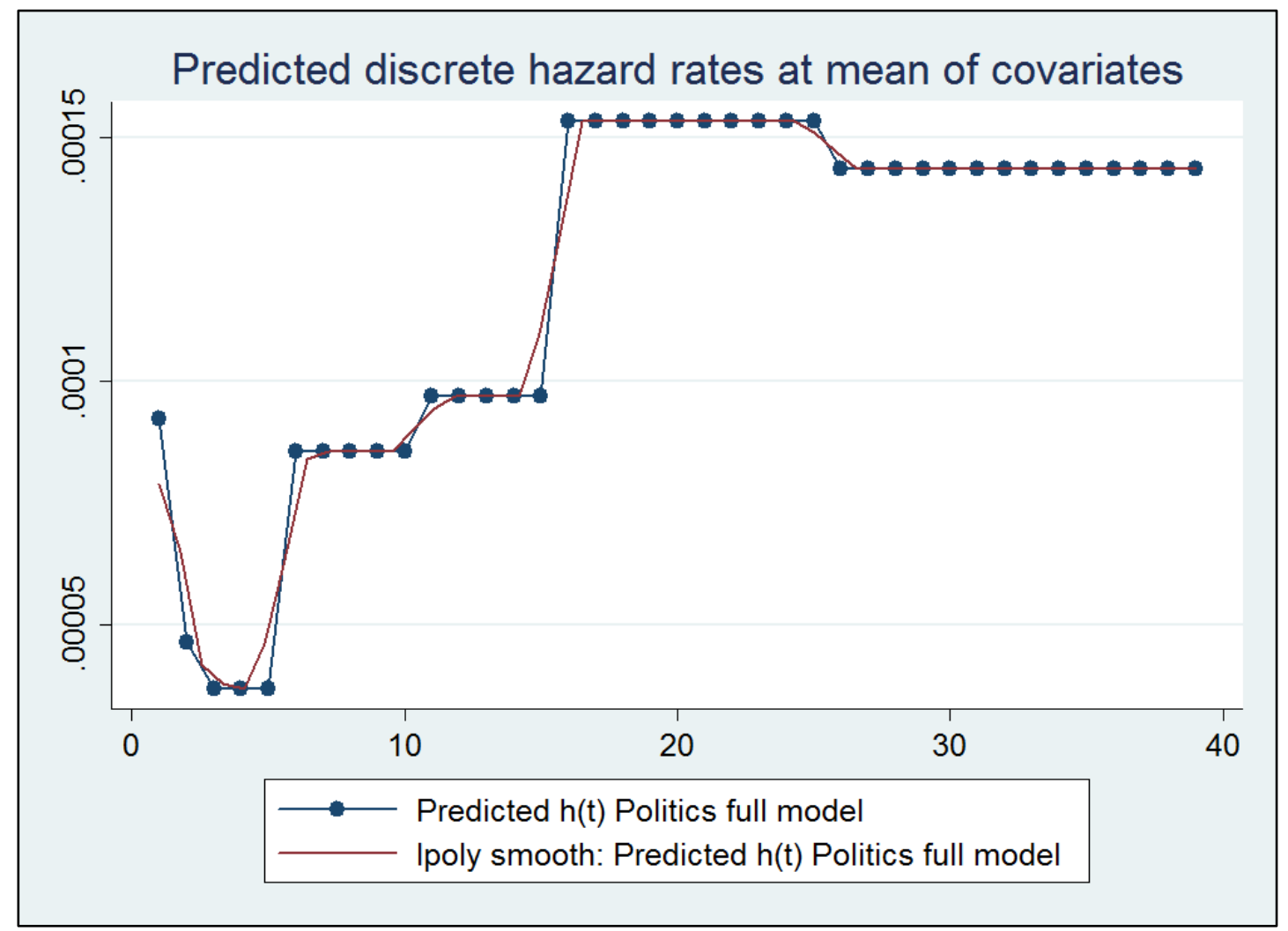

\section{III.8 Findings Overview and Conclusions}

This study uses discrete time duration models to estimate the effect of different factors on the duration and ending type of non-state armed groups. It is the first time a comprehensive dataset about terrorist and rebel groups has been used for such a purpose, giving the possibility to include group characteristics, country characteristics and duration dependence into the estimation. The data used is much more suitable to investigate duration than data about terrorist attacks which does not give very much information about the groups behind them. The methodology is also more appropriate for this kind of data - where the observed intervals are rather long compared to the average duration - than the continuous time models used before.

Since there is no empirical literature about this topic there is no strict focus on the effect of a single factor on groups duration, but a whole array of hypotheses are tested. 
Some of the conclusions are that motivational factors as, e.g., religious motivation are very important to keep a terrorist group together by offering the members a compensation for the cost they incur from participating in an armed campaign. There is also evidence that such groups tend to not negotiate, maybe out of greater dedication to their cause or because they know that most of their demands will not be met.

Maintaining bases in more than one country seems an important factor for explaining longer durations of groups. Hiding and evasion of state forces are likely to be behind this and it can also be a hint towards support from other countries (letting groups hide could be seen as passive support anyway). This result shows how important cooperation between countries is if terrorist groups are to be defeated.

Local support - proxied by nationalist and separatist groups - seems to increase the duration of armed groups as well. This should be expected, as without the necessary means it is impossible to continue a fight.

It is also not surprising that a higher income allows countries to set up and maintain much better police forces and military systems and enables them to detect and defeat armed groups more easily, which also increases the cost for terrorists and thereby seems to also contribute to the disintegration of such organizations.

This study cannot find any evidence implying that a restriction of civil rights helps to fight and defeat armed groups. There is some indication that groups are more likely to disappear under such circumstances, but the effect on policing is, if anything, negative. There is also no hint that regimes with less civil liberties shorten the duration of terrorist organizations in general.

Armed groups - mainly those with simpler goals or those who seek to maintain the status quo - are more likely to negotiate and negotiation is a process that usually starts at later periods of the organization's existence, probably because after a long fight this option becomes more attractive for all sides.

In general, organizations seem to fail mainly at the beginning and if they make it to get through the starting phase their chances of survival increase very much. From this it could 
also be concluded that anti-terrorism efforts should be most effective shortly after a group has been founded.

This study relies mainly on the interpretation of proxy variables, which is a major shortcoming. There is however no data the author is aware of, that would allow a more exact approach. Currently there are not many publicly accessible, free databases of terrorist organizations that are maintained and updated regularly (there are some large databases maintained by private firms like IHS Jane's and TRAC). Exceptions are the Institute for the Study of Violent Groups (ISVG), the research project 'Mapping Militant Organizations' at the Stanford University and the group profiles of the 'South Asia Terrorism Portal' (all of which were used to check some of the information in the data). All these give very detailed, mainly qualitative information, but only for rather few groups (and in the last case only for a specific region). For any empirical investigation the number of groups would probably have to be extended and especially the information coded. The compilation and generation of better data about terrorist organizations and a continuation of their investigation should therefore be an interesting and promising field of future research. Especially interesting could be the thorough investigation of financial sources and group structures, for which however much more information would be needed. 


\section{References}

Abadie, Alberto and Javier Gardeazabal (2003) 'The Economic Costs of Conflict: A Case Study of the Basque Country', The American Economic Review, 93 (1), 113-132.

Abrahams, Max (2008) 'What Terrorists Really Want: Terrorist Motives and Counterterrorism Strategy', International Security, 32 (4), 78-105.

Adelman, Madelaine (2003) 'The Military, Militarism, and the Militarization of Domestic Violence', Violence against Women, 9 (9), 1118 - 1152.

Aizer, Anna (2010) 'The Gender Wage Gap and Domestic Violence', American Economic Review, 100 (4), 1847-1859.

Alesina, Alberto and Roberto Perotti (1996) 'Income distribution, political instability, and investment', European Economic Review, 40 (6), 1203-28.

Barro, Robert (1991) 'Economic growth in a cross-section of countries', The Quarterly Journal of Economics, 106 (2), 407-443.

Bigsten, Arne, Paul Collier, Stefan Dercon, Marcel Fafchamps, Bernard Gauthier, Jan Willem Gunning, Abena Oduro, Remco Oostendorp, Catherine Pattillo, Måns Söderbom, Francis Teal and Albert Zeufack (1999) 'Adjustment Costs, Irreversibility and Investment Patterns in African Manufacturing', IMF Working Papers 99/99, International Monetary Fund.

Bjørkhaug, Ingunn (2010) 'Child Soldiers in Colombia: The Recruitment of Children into Nonstate Violent Armed Groups', MICROCON Research Working Paper, 27.

Blattman, Christopher (2009) 'From Violence to Voting: War and political participation in Uganda', American Political Science Review, 103 (2), 231-247.

Blattman, Christopher and Edward Miguel (2010) 'Civil War', Journal of Economic Literature, 48 (1), 3-57. 
Blomberg, S. Brock, Rozlyn C. Engel and Reid Sawyer (2010) 'On the duration and Sustainability of Transnational Terrorist Organizations', Journal of Conflict Resolution, 54 (2), 303-330.

Böheim, René and Mark P.Taylor (2002) 'The Search for Success: Do the Unemployed find stable employment', Labour Economics 9, 717-735.

Brett, Sebastian (2003) 'You'll Learn Not to Cry: Child Combatants in Colombia', Human Rights Watch.

Brubaker, Rogers and David D. Laitin (1998) 'Ethnic and Nationalist Violence', Annual Review of Sociology, 24, 423-52.

Bueno de Mesquita, Ethan (2008) 'The Political Economy of Terrorism: A Selective Overview of Recent Work', The Political Economist, 10 (1), 1-12.

Buhaug, Halvard, Scott Gates and Päivi Lujala (2009) 'Geography, Rebel Capability, and the Duration of Civil Conflict', Journal of Conflict Resolution, 53 (4), 544-569.

Bundervoet, Tom (2010) 'Assets, Activity Choices, and Civil War: Evidence from Burundi', World Development, 38 (7), 955-965.

Calderón, Valentina, Margarita Gáfaro and Ana María Ibáñez (2010) 'Forced Migration, Female Labor Force Participation, and Intra-household Bargaining: Does Conflict Empower Women?' Households in Conflict Network Seminar paper.

Camacho, Adriana and Catherine Rodriguez (2011) 'Firm Exit and Armed Conflict in Colombia', Mimeo, available at: http://www.esrc.ac.uk/my-esrc/grants/RES-167-250593/outputs/Download/ec188bfa-6fd3-4986-877c-fe2b1b76159f ; last accessed March 19, 2013.

Central Statistical Agency (CSA) of Ethiopia (2007) 'Annual Manufacturing Survey', 19962007.

Cheibub, José Antonio, Jennifer Gandhi and James Raymond Vreeland (2010) 'Democracy and Dictatorship Revisited', Public Choice, 143, 67-101. 
Chirinko, Robert S. (1993) 'Business Fixed Investment Spending: Modeling Strategies, Empirical Results, and Policy Implications', Journal of Economic Literature, 31 (4), 1875-1911.

Cohen Silver, Roxane, E. Alison Holman, Daniel N. McIntosh, Michael Poulin, Virginia GilRivas (2002) 'Nationwide Longitudinal Study of Psychological Responses to September 11', The Journal of the American Medical Association, 288 (10), 1235 1244.

Collier, Paul (1999) 'On the Economic Consequences of Civil war', Oxford Economic Papers, 51, 168-183.

Collier, Paul and Anke Hoeffler, (2004) 'Greed and Grievance in Civil War', Oxford Economic Papers, 56, 563-595.

Collier, Paul, Anke Hoeffler and Måns Söderbom (2004) 'On the Duration of Civil War', Journal of Peace Research, 41 (3), 253-273.

Collier, Paul and Marguerite Dupchonel (2010) 'The Economic Legacy of Civil War: Firm Level Evidence from Sierra Leone, UNU-WIDER, Working Paper No. 2010/90.

Crenshaw, Martha (1981) 'The Causes of Terrorism', Comparative Politics, 13 (4), 379-399.

Cronin, Audrey K. (2009) 'How Terrorism Ends', Princeton University Press, Princeton.

Deininger, Klaus (2003) 'Causes and Consequences of Civil Strife: Micro-Level Evidence from Uganda', Oxford Economic Papers, 55, 579-606.

DeRouen, Karl R. and David Sobek (2004) 'The Dynamics of Civil War Duration and Outcome', Journal of Peace Research ,41 (3), 303-320.

DIVA-GIS (2013) Spatial Data, available at: http://www.diva-gis.org/Data, last accessed June 13, 2013.

Dixit, Avinash K. and Robert S. Pindyck (1994) 'Investment under Uncertainty', Princeton University Press.

Doms, Mark E. and Timothy Dunne (1998) 'Capital Adjustment Patterns in Manufacturing Plants', Review of Economic Dynamics, 1 (2), 409-429. 
Durevall, Dick and Annika Lindskog (2013) 'Intimate Partner Violence and HIV in Sub-Saharan Africa', Scandinavian Working Papers in Economics, 563, Department of Economics, University of Gothenburg.

Ellingsen, Tanja (2000), 'Colorful Community or Ethnic Witches' Brew? Multiethnicity and Domestic Conflict during and after the Cold War', Journal of Conflict Resolution, 44 (2), 228-249.

Enders, Walter and Todd Sandler (2006). 'The Political Economy of Terrorism', Cambridge University Press, Cambrige.

European Union (2002) 'Council Framework Decision of 13 June 2002 on Combating Terrorism', Official Journal of the European Communities, 45, L 164/3

Farmer, Amy and Jill Tiefenthaler (1997) 'An Economic analysis of Domestic Violence', Review of Social Economy, 55 (3), $337-358$.

Fearon, James D. and David D. Laitin (2003) 'Ethnicity, Insurgency, and Civil War', American Political Science Review, 97 (1), 75-90.

Fine, Jason P. and Robert J. Gray (1999) 'A Proportional Hazards Model for the Subdistribution of a Competing Risk', Journal of the American Statistical Association, 94, 496-509.

Fonagy, Peter (1999) 'Male perpetrators of violence against women: An attachment theory perspective', Journal of Applied Psychoanalytic Studies, 1 (1), 7-27.

Food and Agriculture Organization of the United Nations (2000) 'Global Forest Resources Assessment 2000 (FRA 2000)', available at: http://www.fao.org/forestry/32203/en/, last accessed June 13, 2013.

Freedom House (2012) 'Freedom in the World', Country Ratings and Territory Ratings 19722012.

Gallegos, José V. and Italo A. Gutierrez (2011) 'The Effect of Civil Conflict on Domestic Violence: the Case of Peru', SSRN Working Paper Series. 
Garces, Laura (2005). Colombia: the link between drugs and terror. Journal of Drug Issues, 35 (1), 83-105.

García-Moreno, Claudia, Henrica A.F.M. Jansen, Mary Ellsberg, Lori Heise, Charlotte Watts (2005) 'WHO multi-country study on women's health and domestic violence against women: initial results on prevalence, health outcomes and women's responses.' WHO Press, World Health Organization, Geneva.

Gassebner, Martin and Simon Luechinger, (2011) 'Lock, stock and barrel: a comprehensive assessment of the determinants of terror', Public Choice, 149, 235-261.

Gleditsch, Nils Petter, Peter Wallensteen, Mikael Eriksson, Margareta Sollenberg and Håvard Strand (2002) 'Armed Conflict 1946-2001: A New Dataset', Journal of Peace Research 39 (5), 615-637.

Guidolin, Massimo and Eliana La Ferrara (2007) 'Diamonds Are Forever, Wars Are Not: Is Conflict Bad for Private Firms?', The American Economic Review, 97 (5), 1978-1993.

Gutiérrez Sanín, Francisco (2008) 'Telling the Difference: Guerrillas and Paramilitaries in the Colombian War', Politics Society 36 (1), 3-34.

Hammermesh, Daniel S. (1999) 'Crime and the Timing of Work', Journal of Urban Economics, $45,311-330$

Heston, Alan, Robert Summers and Bettina Aten (2011) 'Penn World Table Version 7.0', Center for International Comparisons of Production, Income and Prices at the University of Pennsylvania.

Institute for the Study of Violent Groups (ISVG) (2012) 'Violent Extremism Knowledge Base'

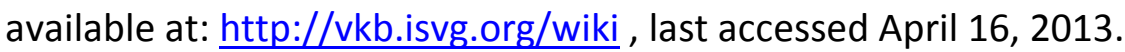

International Center for Tropical Agriculture (CIAT) '90m SRTM Data', available at: http://srtm.csi.cgiar.org/, last accessed June 13, 2013.

Jenkins, Stephen P. (1997) 'sbe17 Discrete Time Proportional Hazards Regression', Stata Technical Bulletin 39, 22-32. 
Jones, Seth G. and Martin C. Libicki (2008) 'How Terrorist Groups End: Lessons for Countering al Qa'ida', RAND Corporation Monograph Series.

Jorgenson, Dale (1967) 'The Theory of Investment Behavior', in: Ferber, Robert (Ed.)

'Determinants of Investment Behavior', National Bureau of Economic Research, Columbia University Press, New York, 129-188.

Justino, Patricia (2009). Poverty and Violent Conflict: A Micro-Level Perspective on the Causes and Duration of Warfare. Journal of Peace Research, 46, 315-333.

Karnofsky, Eva (2005) ,Familiäre Gewalt und Kindesmißbrauch in Kolumbien', Brennpunkt Lateinamerika, 4, 37-44.

Koenig, Michael A., Rob Stephenson, Saifuddin Ahmed, Shireen J. Jejeebhoy and Jacquelyn Campbell (2006) 'Individual and Contextual Determinants of Domestic Violence in North India', American Journal of Public Health, 96 (1), 132-138.

Krieger, Tim and Daniel Meierrieks (2011) 'What Causes Terrorism', Public Choice, 147 (1), 327.

Krkoska, Libor and Katrin Robeck (2009) 'Crime, Business Conduct and Investment Decisions: Enterprise Survey Evidence from 34 Countries in Europe and Asia', Review of Law and Economics, 5 (1), 493-516.

Kydd, Andrew H. and Barbara F. Walter (2006) 'The Strategies of Terrorism', International Security, 31 (1), 49-80.

Lia, Brynar (2005). 'Globalization and the Future of Terrorism', Routledge, London.

Marshall, Monty G., Keith Jaggers and Ted Robert Gurr (2010) 'POLITY IV PROJECT: Political Regime Characteristics and Transitions, 1800-2010', Center for Systemic Peace.

McDonald, Kerri (2008) 'The Impact of Crime on Small Businesses in South Africa', SBP Johannesburg, South Africa.

McCormick, Gordon H. (2003) 'Terrorist Decision Making', Annual Review of Political Science, 6, 473-507. 
Mejia, Daniel and Pascual Restrepo (2008) 'The War on Illegal Drug Production and Trafficking: An Economic Evaluation of Plan Colombia', Households in Conflict Network Working Papers, 53.

Memorial Institute for the Prevention of Terrorism (2008) 'Terrorist Organization Profiles', Terrorist Knowledge Base, now hosted by START at: http://www.start.umd.edu/start/data_collections/tops/ , last accessed March 23, 2013.

Meyer, Bruce D. (1990) ‘Unemployment Insurance and Unemployment Spells’, Econometrica $58(4), 757-782$.

Miguel, Edward, Sebastián M. Saiegh and Shanker Satyanath (2011) 'Civil War Exposure and Violence', Economics \& Politics, 23 (1), 59 - 73.

Montalvo, Jose G. and Marta Reynal-Querol (2005) 'Ethnic Polarization, Potential Conflict, and Civil Wars', American Economic Review, 95 (3), 796-816.

National Geospatial-Intelligence Agency (2013) Foreign geographic names data for Ethiopia, Geographic Names for Geopolitical Areas from GNS (ISO/IEC 10646 [Unicode UTF-8], available at: http://earth-info.nga.mil/gns/html/namefiles.htm ; last accessed March $19,2013$.

Office of the Law Revision Counsel of the U.S. House of Representatives (2011) 'United States Code' available at: http://www.gpo.gov/fdsys/browse/collectionUScode.action?collectionCode=USCODE , last accessed April 16, 2013.

Ojeda, Gabriel, Myriam Ordóñez, Luis Hernando Ochoa (2005) 'Salud Sexual y Reproductiva: Resultados Encuesta Nacional de Demografía y Salud 2005', Macro International/DHS+ Program, Maryland. Available at: http://www.measuredhs.com/publications/publication-FR172-DHS-FinalReports.cfm, last accessed June 13, 2013. 
Pineda, Carolina (2005) 'Plan Colombia - A Political, Economic, and Cultural Analysis of Coca and Poppy Eradication Projects in Putumayo, Colombia', Totem: The University of Western Ontario Journal of Anthropology, 13 (1), $72-80$.

Pollak, Robert A. (2004) 'An intergenerational model of domestic violence', Journal of Population Economics, 17 (3), 311 - 329.

Prentice, R.L. and L.A. Gloeckler (1978) 'Regression Analysis of Grouped Survival Data with Application to Breast Cancer Data', Biometrics 34 (1), 57-67.

Profamilia (2005) 'Encuesta Nacional de Demografía y Salud 2005’, Bogotá. Available at: http://www.measuredhs.com/what-we-do/survey/survey-display-255.cfm, last accessed June 13, 2013.

Programa Presidencial de Derechos Humanos y Derecho Internacional Humanitario (2010) Observatorio Derechos Humanos (DDHH) y Derecho Internacional Humanitario (DIH): Diagnósticos Estadísticos por Departamento, available at: http://www.derechoshumanos.gov.co/Observatorio/Paginas/DiagnosticosDepartam ento.aspx, downloaded April 2010, last accessed June 13, 2013.

Pshisva, Rony and Gustavo A. Suarez (2010) 'Capital Crimes: Kidnappings and Corporate Investment in Colombia', in: Di Tella, Rafael, Sebastian Edwards and Ernesto Schargrodsky: 'The Economics of Crime: Lessons for and from Latin America', University of Chicago Press, 63-97.

Raleigh, Clionadh, Andrew Linke, Håvard Hegre and Joakim Karlsen (2010) 'Introducing ACLED-Armed Conflict Location and Event Data', Journal of Peace Research, 47 (5), 110.

Rettberg Beil, Beatriz Angelika (2008) 'Explorando el Dividendo de la Paz: Impactos del Conflicto Armado en el Sector Privado Colombiano, Resultados de una Encuesta Nacional', Bogotá: Universidad de los Andes.

Richani, Nazih (1997) 'The Political Economy of Violence: The War-System in Colombia', Journal of Interamerican Studies and World Affairs, 39 (2), 37-81. 
Rockmore, Marc (2011) 'The Cost of Fear: The Welfare Effects of the Risk of Violence in Northern Uganda', HiCN Working Paper 109, Households in Conflict Network.

Rockmore, Marc (2012) 'Living Within Conflicts: Risk of Violence and Livelihood Portfolios', HiCN Working Paper 121, Households in Conflict Network.

Rohner, Dominic and Bruno S. Frey (2007) 'Blood and Ink! The common-interest game between terrorists and the media', Public Choice 133, 129-145.

Sánchez-Cuenca, Ignacio and Luis de la Calle (2009) 'Domestic Terrorism: The Hidden Side of Political Violence', Annual Review of Political Science, 12, 31-49.

Sarkess, Meredith Reid (2010) 'The COW Typology of War: Defining and Categorizing Wars (Version 4 of the Data)', available at: http://www.correlatesofwar.org/COW2\%20Data/WarData NEW/COW\%20Website\% 20-\%20Typology\%20of\%20war.pdf.

Sarkees, Meredith Reid and Frank Wayman (2010) 'Resort to War: 1816 - 2007', CQ Press.

Saul, Ben (2005) 'Definition of "Terrorism" in the UN Security Council: 1985-2004', Chinese Journal of International Law, 4 (1), 141-166.

Schneider, Friedrich, Tilman Brück and Daniel Meierrieks (2011a). 'The Economics of Terrorism and Counter-Terrorism: A Survey (Part I)', Economics of Security Working Paper 44.

Schneider, Friedrich, Tilman Brück and Daniel Meierrieks (2011b). 'The Economics of Terrorism and Counter-Terrorism: A Survey (Part II)', Economics of Security Working Paper 45.

Sherman, Michelle D., Fred Sautter, M. Hope Jackson, Judy A. Lyons, Xiaotong Han (2006) 'Domestic Violence in Veterans with posttraumatic stress disorder who seek couples therapy', Journal of Marital and Family Therapy, 32 (4), 479 - 490.

SIG-OT (2013) Sistema de Información Geográfica para la Planeación y el Ordenamiento Territorial Nacional, at: http://sigotn.igac.gov.co/sigotn/, last accessed June 13, 2013. 
Siqueira, Kevin and Todd Sandler (2010) 'Terrorist Networks, Support, and Delegation', Public Choice, 142, 237-253.

Solow, Robert M. (1956) 'A Contribution to the Theory of Economic Growth', Quarterly Journal of Economics, 70, 65-94.

South Asia Terrorism Portal (2013) at: http://www.satp.org/ , last accessed April 16, 2013.

Stanford University (2013) 'Mapping Militant Organizations' at:

http://www.stanford.edu/group/mappingmilitants/cgi-bin/ , last accessed April 16, 2013.

Steele, Abbey (2007) 'Massive Civilian Displacement in Civil War: Assessing Variation in Colombia', Households in Conflict Network Working Paper, 29.

Straus, Murray A. (1993) 'Physical Assaults by Wives: A Major Social Problem', in: Gelles, Richard J. and Donileen R. Loseke (Eds.) 'Current Controversies on Family Violence', 67-87.

Tauchen, Helen V., Ann D. Witte and Sharon K. Long (1991) 'Domestic Violence: A nonrandom Affair', National Bureau of Economic Research Working Paper Series, 1665.

Tobin, James (1969) 'A general equilibrium approach to monetary theory', Journal of Money Credit and Banking, 1 (1), 15-29.

UN-OCHA (2011) Ethiopia Populated Places: Towns, GIS-Dataset. Common Operational Datasets. Available at: http://cod.humanitarianresponse.info/countryregion/ethiopia.

UN Security Council (2004) 'Security Council Resolution 1566: Concerning Threats to International Peace and Security Caused by Terrorism', S/RES/1566 (2004), available at: http://www.refworld.org/docid/42c39b6d4.html , last accessed April 16, 2013.

Voors, Maarten J., Eleonora E. M. Nillesen, Philip Verwimp, Erwin H. Bulte, Robert Lensink and Daan P. Van Soest (2012) 'Violent Conflict and Behavior: A Field Experiment in Burundi', American Economic Review, 102 (2), 941-964. 
Waldmann, Peter (2007) 'Is there a Culture of Violence in Colombia?', International Journal of Conflict and Violence, 1 (1), 61-75.

Weinstein, Jeremy M. (2007) 'Inside Rebellion: The Politics of Insurgent Violence ', Cambridge University Press, Cambridge.

Winkel, Frans Willem (2007) 'Post traumatic anger: Missing link in the wheel of misfortune', Intervict, Tilburg University.

Wood, Elisabeth Jean (2008) 'The Social Processes of Civil War: The Wartime Transformation of Social Networks', Annual Review of Political Science, 11, 539 - 561.

World Bank (2011) 'World Development Report 2011: Conflict, Security, and Development', The International Bank for Reconstruction and Development / The World Bank, Washington.

World Bank (2012) 'World Development Indicators 2012', The International Bank for Reconstruction and Development / The World Bank, Washington. 


\section{Appendix A}

\section{A.1 Additional Tables}

Table A.1: Different measures of domestic violence

\begin{tabular}{|lccc|}
\hline Domestic violence: Definitions & & & \\
\hline Form of violence & violence & threats & combined \\
\hline push / shake & & & \\
hit with hand & $x$ & - & $\mathrm{x}$ \\
hit with object & $\mathrm{x}$ & - & $\mathrm{x}$ \\
bite & $\mathrm{x}$ & - & $\mathrm{x}$ \\
kick/ drag & $\mathrm{x}$ & - & $\mathrm{x}$ \\
threaten with knife, gun other weapon & $\mathrm{x}$ & - & $\mathrm{x}$ \\
attack with knife, gun other weapon & $\mathrm{x}$ & $\mathrm{x}$ & $\mathrm{x}$ \\
try to strangle, burn & $\mathrm{x}$ & - & $\mathrm{x}$ \\
physically force for unwanted sex act & $\mathrm{x}$ & - & $\mathrm{x}$ \\
& $\mathrm{x}$ & - & $\mathrm{x}$ \\
threatened with abandoning her & & & $\mathrm{x}$ \\
threatened to take away children & - & $\mathrm{x}$ & $\mathrm{x}$ \\
threatened to withdray economic support & - & $\mathrm{x}$ & $\mathrm{x}$ \\
& - & $\mathrm{x}$ & \\
used expressions like you are good for nothing & - & - & - \\
didn't allow to see friends & - & - & - \\
limited contact with family & - & - & - \\
wanted to know where she was all the time & - & - & - \\
\hline
\end{tabular}


Table A.2: Regression results for different measures of domestic violence

\begin{tabular}{|c|c|c|c|c|}
\hline \multicolumn{5}{|c|}{ Probit regression; Alternative dependent variables } \\
\hline & \multicolumn{2}{|c|}{ Threats } & \multicolumn{2}{|c|}{ Threats and physical vio. } \\
\hline & Living together & All women & Living together & All women \\
\hline \multirow[t]{2}{*}{ No. armed confrontations $03 / 04$} & $0.0015 * *$ & $0.0021 * *$ & $0.0016^{* *}$ & $0.0023^{*}$ \\
\hline & $(2.38)$ & $(2.13)$ & $(2.08)$ & $(1.83)$ \\
\hline \multirow[t]{2}{*}{ Age respondent } & $-0.0020 * * *$ & $-0.0029 * * *$ & $-0.0032 * * *$ & $-0.0050 * * *$ \\
\hline & $(-3.58)$ & $(-6.26)$ & $(-5.49)$ & $(-9.95)$ \\
\hline \multirow[t]{2}{*}{ Resp. primary edu. } & $-0.0250 *$ & $-0.0374 * * *$ & -0.0207 & $-0.0308^{*}$ \\
\hline & $(-1.79)$ & $(-2.61)$ & $(-1.20)$ & $(-1.83)$ \\
\hline \multirow[t]{2}{*}{ Resp. secondary edu. } & $-0.0462 * * *$ & $-0.0534 * * *$ & $-0.0459 * * *$ & $-0.0481 * * *$ \\
\hline & $(-3.05)$ & $(-3.45)$ & $(-2.61)$ & $(-2.82)$ \\
\hline \multirow[t]{2}{*}{ Resp. higher edu. } & $-0.0658 * * *$ & $-0.0706 * * *$ & $-0.0769 * * *$ & $-0.0736 * * *$ \\
\hline & $(-3.20)$ & $(-3.67)$ & $(-3.30)$ & $(-3.31)$ \\
\hline \multirow[t]{2}{*}{ Resp. currently working } & $0.0271 * * *$ & $0.0541 * * *$ & $0.0333 * * *$ & $0.0575 * * *$ \\
\hline & $(4.93)$ & $(8.53)$ & $(5.06)$ & $(7.86)$ \\
\hline \multirow[t]{2}{*}{ Sign. share of $\mathrm{HH}$ earnings } & $-0.0138 *$ & -0.0002 & -0.0122 & 0.0024 \\
\hline & $(-1.94)$ & $(-0.03)$ & $(-1.46)$ & $(0.27)$ \\
\hline \multirow[t]{2}{*}{ Min. 6 months pregnant } & $-0.0392 * *$ & $-0.0448 * *$ & $-0.0583 * * *$ & $-0.0646 * * *$ \\
\hline & $(-2.14)$ & $(-2.52)$ & $(-2.70)$ & $(-3.10)$ \\
\hline \multirow[t]{2}{*}{ Exp. of violence in past } & $0.0510 * * *$ & $0.0519 * * *$ & $0.0677^{* * *}$ & $0.0711^{* * *}$ \\
\hline & (6.04) & $(6.55)$ & $(6.87)$ & $(7.35)$ \\
\hline \multirow[t]{2}{*}{ Partner's age } & $-0.0008 *$ & & $-0.0019 * * *$ & \\
\hline & $(-1.92)$ & & $(-4.07)$ & \\
\hline \multirow[t]{2}{*}{ Part. primary edu. } & -0.0129 & $-0.0236 * *$ & -0.0072 & -0.0173 \\
\hline & $(-0.98)$ & $(-2.21)$ & $(-0.46)$ & $(-1.41)$ \\
\hline \multirow[t]{2}{*}{ Part. secondary edu. } & $-0.0279 *$ & $-0.0366 * * *$ & -0.0180 & $-0.0243 *$ \\
\hline & $(-1.92)$ & $(-3.11)$ & $(-1.14)$ & $(-1.79)$ \\
\hline \multirow[t]{2}{*}{ Part. higher edu. } & $-0.0727 * * *$ & $-0.0813 * * *$ & $-0.0783 * * *$ & $-0.0855 * * *$ \\
\hline & $(-3.91)$ & $(-4.90)$ & $(-3.71)$ & $(-4.30)$ \\
\hline \multirow[t]{2}{*}{ Income category 2} & 0.0022 & -0.0062 & 0.0021 & -0.0057 \\
\hline & $(0.21)$ & $(-0.51)$ & $(0.18)$ & $(-0.46)$ \\
\hline \multirow[t]{2}{*}{ Income category 3} & $-0.0204^{*}$ & $-0.0303 *$ & -0.0175 & $-0.0286^{*}$ \\
\hline & $(-1.69)$ & $(-1.93)$ & $(-1.26)$ & $(-1.84)$ \\
\hline \multirow[t]{2}{*}{ Income category 4} & $-0.0486 * * *$ & $-0.0569 * * *$ & $-0.0671 * * *$ & $-0.0705^{* * *}$ \\
\hline & $(-3.49)$ & $(-3.24)$ & $(-3.97)$ & $(-3.81)$ \\
\hline \multirow[t]{2}{*}{ Income category 5} & $-0.0739 * * *$ & $-0.1016 * * *$ & $-0.0777 * * *$ & $-0.1033^{* * *}$ \\
\hline & $(-4.65)$ & $(-5.06)$ & $(-4.14)$ & $(-5.13)$ \\
\hline \multirow[t]{2}{*}{ Rural area } & $-0.0590 * * *$ & $-0.0603 * * *$ & $-0.0677 * * *$ & $-0.0660 * * *$ \\
\hline & $(-5.73)$ & $(-4.76)$ & $(-5.72)$ & $(-4.89)$ \\
\hline \multirow[t]{2}{*}{ No. children } & $0.0147^{* * *}$ & & $0.0143 * * *$ & \\
\hline & $(6.70)$ & & $(5.80)$ & \\
\hline \multirow[t]{2}{*}{ No. female adults in $\mathrm{HH}$} & $-0.0144 * * *$ & & $-0.0234 * * *$ & \\
\hline & $(-3.03)$ & & $(-3.89)$ & \\
\hline Pseudo $\mathrm{R}^{2}$ & 0.030 & 0.021 & 0.033 & 0.024 \\
\hline $\mathrm{N}$ & 17319 & 21636 & 17319 & 21636 \\
\hline
\end{tabular}

Average marginal effects reported, standard errors are clustered at municipality level; t-statistics in parentheses; asterisks denote the following significance levels: ${ }^{*} p<0.10,{ }^{* *} p<0.05,{ }^{* * *} p<0.01$. 
Table A.3: Regression results for armed confrontations per district

\begin{tabular}{|c|c|c|c|}
\hline \multicolumn{4}{|c|}{ Negative Binomial regression; Dep. var. No. armed confrontations 2003/04 } \\
\hline & $\begin{array}{l}\text { First stage of two- } \\
\text { stage model }\end{array}$ & \multicolumn{2}{|c|}{ Alternative instruments } \\
\hline \multirow[t]{2}{*}{ Elevation range } & $0.0004 * * *$ & $0.0005 * * *$ & $0.0005 * * *$ \\
\hline & $(4.47)$ & $(11.22)$ & $(10.83)$ \\
\hline \multirow[t]{2}{*}{ Oil region } & $0.7438 * * *$ & $0.8220 * * *$ & $0.8063 * * *$ \\
\hline & $(3.54)$ & $(7.30)$ & (6.97) \\
\hline \multirow[t]{2}{*}{ Area km2 } & & $0.0001^{* * *}$ & $0.0001 * * *$ \\
\hline & & (3.55) & (3.31) \\
\hline \multirow[t]{2}{*}{ Perc. area with coca cultivation } & & $2.0294 * * *$ & $2.0379 * * *$ \\
\hline & & $(5.00)$ & $(4.97)$ \\
\hline \multirow[t]{2}{*}{ Perc. area forest covered } & & $1.5742 * * *$ & $1.6556 * * *$ \\
\hline & & $(7.53)$ & $(7.75)$ \\
\hline \multirow[t]{2}{*}{ National highway } & & $0.2080^{*}$ & 0.1877 \\
\hline & & $(1.82)$ & $(1.62)$ \\
\hline \multirow[t]{2}{*}{ Oil refinery } & & 0.3460 & 0.2616 \\
\hline & & $(1.16)$ & $(0.88)$ \\
\hline \multirow[t]{2}{*}{ Telephone coverage 2005} & & $0.0147 * * *$ & $0.0142 * * *$ \\
\hline & & $(4.64)$ & $(3.63)$ \\
\hline \multirow[t]{2}{*}{ Population density 2005} & & & 0.0000 \\
\hline & & & $(0.37)$ \\
\hline \multirow[t]{2}{*}{ Oil pipeline } & & & 0.0815 \\
\hline & & & $(0.66)$ \\
\hline \multirow[t]{2}{*}{ Mean distance to larger town } & & & $-0.0017 *$ \\
\hline & & & $(-1.78)$ \\
\hline \multirow[t]{2}{*}{ Mean distance to next army base } & & & $0.0037^{*}$ \\
\hline & & & $(1.65)$ \\
\hline \multirow[t]{2}{*}{-cons } & -0.0818 & $-1.8333 * * *$ & $-1.9289 * * *$ \\
\hline & $(-0.41)$ & $(-10.85)$ & $(-9.15)$ \\
\hline Pseudo $\mathrm{R}^{2}$ & 0.0356 & 0.0711 & 0.0724 \\
\hline
\end{tabular}

t-statistics in parentheses; asterisks denote the following significance levels: $* p<0.10, * * p<0.05$, $* * * \mathrm{p}<0.01$. 


\section{A.2 Technical Notes}

All the data used in this research was obtained before the first draft of this study in May 2010. Since the first draft did not contain geographical instruments the data for those was downloaded and generated within a few months later. In these notes we do however provide links to where the data can be obtained now (June 2013).

All Colombian districts have a unique 5 digit identification number which consist of a two digit identifier for the federal state and then a 3 digit identifier for the municipality. These identifiers are assigned by the Colombian national statistics department (Departamento Administrativo Nacional de Estadística - DANE) in the codification of the political administrative division (Codificación de la división político administrativa - DIVIPOLA).

The data on armed confrontations was extracted from documents published by the 'Observatorio del Programa Presidencial de DDHH y DIH' of the 'Programa Presidencial de Derechos Humanos y Derecho Internacional Humanitario'. The documents are called the 'Statistical Diagnostics' (Diagnóstico Estadístico) and they are published separately for every federal state and are available at:

http://www.derechoshumanos.gov.co/Observatorio/Paginas/DiagnosticosDepartamento.as px, last accessed June 13, 2013.

Originally the data was gathered from the daily updates of the Administrative Security Department (DAS). The document versions used here, were downloaded in 2010 and contain among other things the number of armed confrontations for each municipality between 2003 and 2008. The information on armed confrontations was merged with the DHS data (Profamilia, 2005), based on the identification number of the municipality.

The creation of the geographical instruments used in the endogeneity check, was somewhat more complex and time consuming. For all GIS related tasks, ArcGIS version 9 was used. The basis of all GIS based data collection and data generation, is a map of Colombia downloaded as a polygon shapefile in the ESRI Shapefile format from SIG-OT (2013). SIG-OT stands for Geographic information system for national, territorial planning and ordering (Sistema de Información Geográfica para la Planeación y el Ordenamiento Territorial Nacional). It is a joint project of different Colombian institutions like the DANE and the Geographic institute Agustín Codazzi (IGAC). It provides access to geo-referenced information of different kinds 
through a web-interface. From this interface the data can be downloaded in different formats. (http://sigotn.igac.gov.co/sigotn/frames pagina.aspx, last accessed June 13, 2013)

Many indicators were constructed by determining whether the features of interest were located in or overlap with the municipalities. The information on highways was obtained by downloading a line shapefile of the highway network from SIG-OT, calculating a $5 \mathrm{~km}$ bufferzone around it and coding the municipalities that overlap with this buffer-zone. In much the same way the information on pipelines is available as a line shapefile and the location of refineries as points. A polygon shapefile indicating oil regions is directly downloadable to determine the overlaps.

Most of the other information on municipalities like population density, telephone coverage and the unsatisfied basic needs index can be downloaded as shapefiles. For this however, merging the data on the basis of spatial location was not necessary, because the information contained in the database file inside the shapefile (dbase format) could be directly merged based on the municipality identifier.

The elevation and forest coverage statistics for each municipality were calculated using the Zonal Statistics from the Spatial Analyst tools contained in ArcGIS. The elevation data is a raster-dataset obtained from the CGIAR CSIConsortium for Spatial Information (data downloadable here: http://srtm.csi.cgiar.org/Index.asp, last accessed June 13, 2013) with a $90 \mathrm{~m}$ resolution (Data provided by CIAT). The statistics like the maximum, minimum and average value of the raster points, were calculated (using the zonal statistics) within the boundaries of the municipalities as they appear in the dataset from SIG-OT. The forest data comes from the Global Forest Resources Assessment 2000 (FRA 2000) conducted by the Food and Agriculture Organization of the United Nations and is also a raster dataset. For later assessments the original GIS data is not downloadable therefore the year 2000 was used (downloadable here: http://www.fao.org/forestry/32203/en/, last accessed June 13, 2013). The calculation followed the same pattern as for the elevation data.

The location of military bases was determined on the town level. On their webpage the Colombian National Army presents each brigade with information in which town each of their battalions is based (http://www.ejercito.mil.co/?idcategoria=239185, last accessed June 13, 2013). The GPS coordinates of the towns where military bases were located, was 
then determined using the dataset of official (US-American) foreign names for Colombia published by the GEOnet Names Server and developed by the National GeospatialIntelligence Agency. The data is a text-file containing the name, type and some more information about each listed location as well as the GPS coordinates (http://earthinfo.nga.mil/gns/html/cntyfile/co.zip, last accessed June 13, 2013). The coordinates were then checked for consistency and plausibility. The distance to the next base is then calculated as the average distance from every point in the municipality to the closest base. For this, a raster dataset was calculated, where the value of each raster point is the distance to the nearest military base. The average of those raster point values, within one municipality, was then determined with the same procedure as for the elevation data.

The same principle was used in the indicator distance to metropolitan area, except that there are only five metropolitan areas: Barranquilla, Bogota, Bucaramanga, Cali, Cartagena, and Medellin. 


\section{Appendix B}

\section{B.1 Additional Figures}

Figure B.1: Map of battle incidents by group

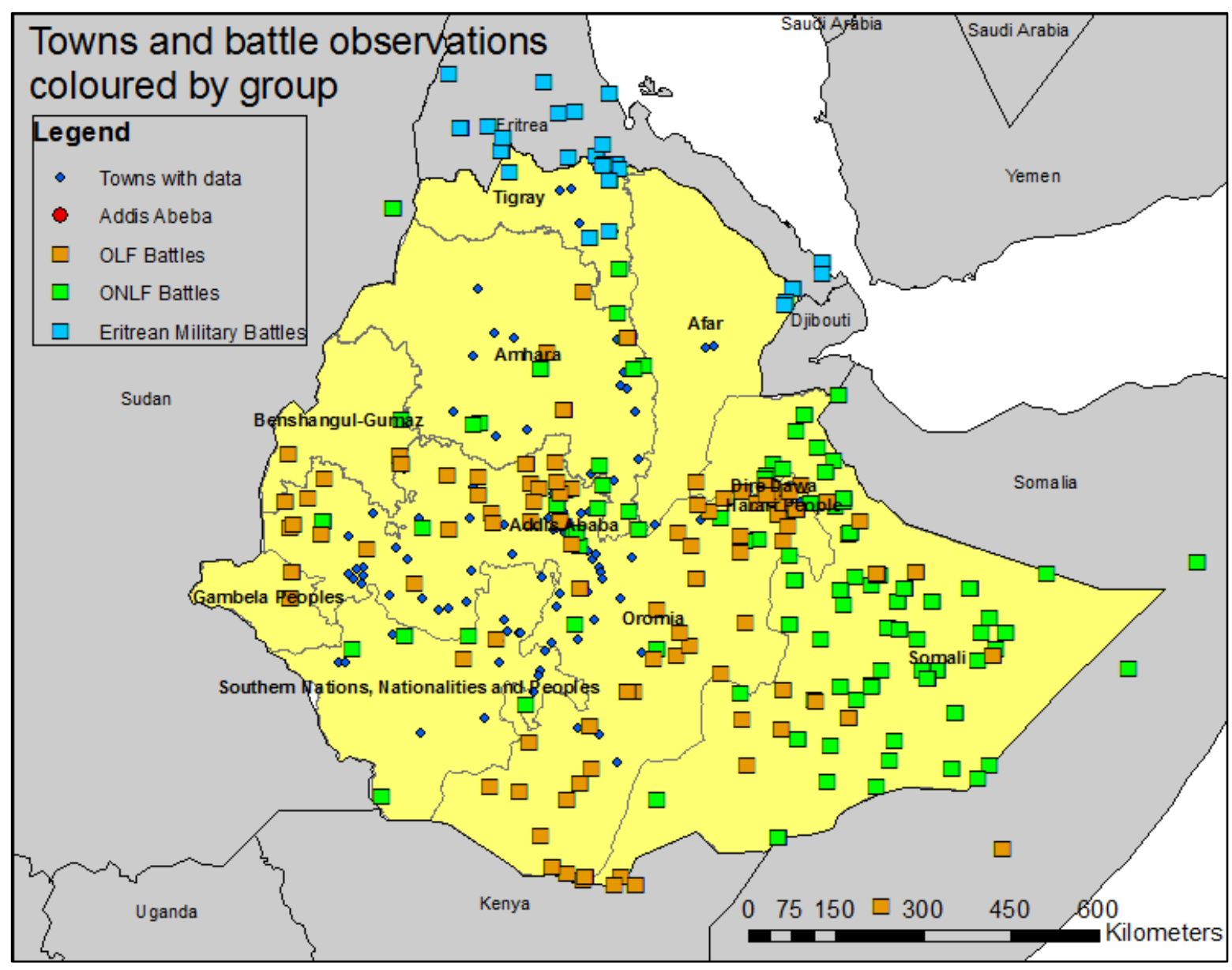

Sources: Author's calculations. Battle data: Raleigh et al. (2010); Map data for cities: UN-OCHA (2011) and National Geospatial-Intelligence Agency (2013); Map data for Ethiopia and neighbouring features: DIVA-GIS (2013). 


\section{B.2 Additional Tables}

Table B.1: Regression results firm investment, different conflict buffer sizes

\begin{tabular}{|c|c|c|c|c|}
\hline \multicolumn{5}{|c|}{ Dep. Variable Investment Rate, Fixed Effects Regression } \\
\hline Different Buffer sizes & $30 \mathrm{~km}$ & $30 \mathrm{~km}$ & $100 \mathrm{~km}$ & $100 \mathrm{~km}$ \\
\hline \multirow[t]{2}{*}{ allbattle30km } & $-0.010 * *$ & $-0.008 *$ & & \\
\hline & $(-2.57)$ & $(-1.75)$ & & \\
\hline \multirow[t]{2}{*}{ allbattle100km } & & & $-0.005^{* * *}$ & $-0.004 * *$ \\
\hline & & & $(-2.91)$ & $(-2.03)$ \\
\hline \multirow[t]{2}{*}{ Profit rate } & & $0.044 * * *$ & & $0.044^{* * *}$ \\
\hline & & (3.77) & & (3.85) \\
\hline \multirow[t]{2}{*}{ Output variation } & & -0.018 & & -0.018 \\
\hline & & $(-0.47)$ & & $(-0.47)$ \\
\hline \multirow[t]{2}{*}{ Road connection } & & 0.016 & & 0.013 \\
\hline & & $(0.52)$ & & $(0.45)$ \\
\hline \multirow[t]{2}{*}{ Total sales } & & -0.000 & & -0.000 \\
\hline & & $(-0.42)$ & & $(-0.55)$ \\
\hline \multirow[t]{2}{*}{ log Firmsize (Workers) } & & 0.033 & & 0.032 \\
\hline & & $(1.59)$ & & $(1.52)$ \\
\hline No. obs. & 2581 & 2060 & 2581 & 2060 \\
\hline No. firms & 631 & 540 & 631 & 540 \\
\hline R sq. & 0.002 & 0.022 & 0.003 & 0.023 \\
\hline
\end{tabular}

Robust standard errors; t-statistics in parentheses. ${ }^{* * *}, * *, *$ denote significance at the $1 \%, 5 \%, 10 \%$ level respectively.

Table B.2 : Regression results firm investment, lagged conflict measures

\begin{tabular}{|c|c|c|c|c|c|}
\hline \multicolumn{6}{|c|}{$\begin{array}{l}\text { Dep. Variable Investment Rate, Fixed Effects Regression } \\
\text { Using lagged conflict intensity }\end{array}$} \\
\hline Battles 50km & $\begin{array}{l}-0.010 * * * \\
(-3.60)\end{array}$ & & & & \\
\hline Battles lag 1 & & $\begin{array}{l}-0.002 \\
(-0.69)\end{array}$ & $\begin{array}{l}-0.004^{*} \\
(-1.85)\end{array}$ & & \\
\hline Battles lag 2 & & & & $\begin{array}{l}-0.000 \\
(-0.02)\end{array}$ & $\begin{array}{l}0.000 \\
(0.05)\end{array}$ \\
\hline Profit rate & & & $\begin{array}{l}0.043^{* * *} \\
(3.74)\end{array}$ & & $\begin{array}{l}0.042^{* * *} \\
(3.65)\end{array}$ \\
\hline Output variation & & & $\begin{array}{l}-0.017 \\
(-0.43)\end{array}$ & & $\begin{array}{l}-0.015 \\
(-0.36)\end{array}$ \\
\hline log Road connection & & & $\begin{array}{l}0.016 \\
(0.52)\end{array}$ & & $\begin{array}{l}0.016 \\
(0.52)\end{array}$ \\
\hline Total sales & & & $\begin{array}{l}-0.000 \\
(-0.36)\end{array}$ & & $\begin{array}{l}-0.000 \\
(-0.33)\end{array}$ \\
\hline log Firmsize (Workers) & & & $\begin{array}{l}0.033 \\
(1.56)\end{array}$ & & $\begin{array}{l}0.047^{* *} \\
(2.24)\end{array}$ \\
\hline No. obs. & 2581 & 2431 & 2060 & 2266 & 1921 \\
\hline No. firms & 631 & 606 & 540 & 591 & 528 \\
\hline R sq. & 0.003 & 0.000 & 0.022 & 0.000 & 0.023 \\
\hline
\end{tabular}

Robust standard errors; t-statistics in parentheses. ${ }^{* * *}, * *, *$ denote significance at the $1 \%, 5 \%$, $10 \%$ level respectively. 
Table B.3: Regression results firm investment, different insecurity measures

\begin{tabular}{|c|c|c|c|c|c|c|}
\hline \multicolumn{7}{|c|}{$\begin{array}{l}\text { Dep. Variable Investment Rate, Fixed Effects Regression } \\
\text { Effects of other insecurity indicators }\end{array}$} \\
\hline \multirow[t]{2}{*}{ Riots/Protests } & 0.003 & 0.004 & & & & \\
\hline & $(0.75)$ & $(1.12)$ & & & & \\
\hline \multirow[t]{2}{*}{ Violence agains Civilians } & & & 0.001 & 0.000 & & \\
\hline & & & $(0.25)$ & $(0.03)$ & & \\
\hline \multirow[t]{2}{*}{ No. Total Incidents } & & & & & -0.001 & -0.001 \\
\hline & & & & & $(-0.77)$ & $(-0.51)$ \\
\hline \multirow[t]{2}{*}{ Profit rate } & & $0.044 * * *$ & & $0.044 * * *$ & & $0.044 * * *$ \\
\hline & & $(5.24)$ & & $(5.26)$ & & $(5.27)$ \\
\hline \multirow[t]{2}{*}{ Output variation } & & -0.017 & & -0.018 & & -0.018 \\
\hline & & $(-0.58)$ & & $(-0.60)$ & & $(-0.62)$ \\
\hline \multirow[t]{2}{*}{ Road connection } & & 0.005 & & 0.014 & & 0.017 \\
\hline & & $(0.13)$ & & $(0.36)$ & & $(0.46)$ \\
\hline \multirow[t]{2}{*}{ Total sales } & & -0.000 & & -0.000 & & -0.000 \\
\hline & & $(-0.20)$ & & $(-0.16)$ & & $(-0.15)$ \\
\hline \multirow[t]{2}{*}{ log Firmsize (Workers) } & & $0.032^{*}$ & & $0.033^{*}$ & & $0.033^{*}$ \\
\hline & & $(1.89)$ & & $(1.95)$ & & $(1.95)$ \\
\hline No. obs. & 2581 & 2060 & 2581 & 2060 & 2581 & 2060 \\
\hline No. firms & 631 & 540 & 631 & 540 & 631 & 540 \\
\hline R sq. & 0.000 & 0.022 & 0.000 & 0.021 & 0.000 & 0.021 \\
\hline
\end{tabular}

Robust standard errors; t-statistics in parentheses. ${ }^{* * *}, * *, *$ denote significance at the $1 \%, 5 \%, 10 \%$ level respectively.

Table B.4: Regression results for other firm indicators

\begin{tabular}{|llllll|}
\hline \multicolumn{7}{|l}{$\begin{array}{l}\text { Fixed Effects Regression, effect of conflict on other firm indicators } \\
\text { Dep. Var.: }\end{array}$} & No. new workers & $\begin{array}{l}\text { New workers/ } \\
\text { total workers }\end{array}$ & Sales & Firm size & Profit rate \\
\hline Battles 50km & $-0.208^{* * *}$ & 0.011 & -0.019 & -0.006 & 0.002 \\
Profit rate & $(-3.08)$ & $(1.19)$ & $(-0.08)$ & $(-0.98)$ & $(0.21)$ \\
& $0.575^{*}$ & $0.049^{* * *}$ & & 0.008 & \\
Output variation & $(1.72)$ & $(2.83)$ & & $(0.43)$ & $0.230^{*}$ \\
& 0.532 & -0.025 & 4.399 & -0.029 & $(1.83)$ \\
Road connection & $(0.48)$ & $(-0.41)$ & $(1.04)$ & $(-0.46)$ & -0.088 \\
& $3.414^{* *}$ & 0.112 & 7.373 & 0.126 & $(-0.68)$ \\
Total sales & $(2.08)$ & $(1.55)$ & $(1.55)$ & $(1.27)$ & 0.000 \\
& $0.000^{* * *}$ & -0.000 & & $0.000^{* * *}$ & $(1.53)$ \\
Iog Firmsize (Workers) & $1.214^{*}$ & $(-0.26)$ & & $(2.61)$ & 0.035 \\
& $(1.88)$ & & $4.600 * * *$ & & $(0.43)$ \\
\hline No. obs. & 1493 & & $(3.48)$ & & 2060 \\
No. firms & 490 & 1493 & 2300 & 2060 & 540 \\
R sq. & 0.039 & 490 & 566 & 540 & 0.007 \\
\hline
\end{tabular}

Robust standard errors; t-statistics in parentheses. ${ }^{* * *},{ }^{* *},{ }^{*}$ denote significance at the $1 \%, 5 \%, 10 \%$ level respectively. 
Table B.5: Regression results firm investment in Addis Ababa

\begin{tabular}{|llll|}
\hline $\begin{array}{l}\text { Dep. Variable Investment Rate, Fixed Effects Regression } \\
\text { Sample from Addis Ababa }\end{array}$ & \multicolumn{3}{l|}{} \\
\hline Battles 50km & 0.004 & 0.002 & 0.006 \\
Profit rate & $(0.85)$ & $(0.36)$ & $(0.15)$ \\
& & $0.052^{* * *}$ & $0.052^{* * *}$ \\
Output variation & $(4.09)$ & $(4.09)$ \\
& & 0.005 & 0.005 \\
Road connection & $(0.11)$ & $(0.11)$ \\
& & -0.048 & -0.272 \\
Total sales & & $(-0.54)$ & $(-1.13)$ \\
& & -0.000 & -0.000 \\
log Firmsize (Workers) & & $(-0.40)$ & $(-0.39)$ \\
& & $0.068^{* * *}$ & $0.069^{* * *}$ \\
Year dummies & & $(3.04)$ & $(3.06)$ \\
No. obs. & no & no & yes \\
No. firms & 4271 & 3297 & 3297 \\
R sq. & 928 & 776 & 776 \\
\hline
\end{tabular}

Robust standard errors; t-statistics in parentheses. ${ }^{* * *}, * *, *$ denote significance at the $1 \%, 5 \%, 10 \%$ level respectively. 


\section{B.3 Technical Notes}

As mentioned in the text, the data on the location of towns was obtained using two different datasets. The first is a data compilation done by UN-OCHA (2011, available at: http://cod.humanitarianresponse.info/sites/default/files/towns.zip last accessed March 14,2013), which is a part of the so-called Common Operational Datasets and gives coordinates for populated places in Ethiopia. The original data was gathered by the CSA, the International Red Cross and the Food and Agriculture Organization of the United Nations. The data is contained in a GIS Dataset in the ESRI Shapefile format. This data was complemented and counterchecked by a dataset of official (US-American) foreign names published by the GEOnet Names Server and developed by the National GeospatialIntelligence Agency (available at: http://earth-info.nga.mil/gns/html/cntyfile/et.zip, last accessed March 14,2013). The data is a text-file containing the name, type and some more information about each listed location as well as the GPS coordinates.

In the firm data a variable indentifies the town only by a number and a list was obtained from the CSA, giving the names of the 107 towns belonging to the numbers. The list contains no further information like regions or other political divisions. Ethiopian town names are problematic because quite often there is more than one town with the same name and there are different ways of transcribing Ethiopian names. To identify the correct town, further information from the firm survey was used, which identifies more detailed political divisions where the firm is located, although that information is not always completely consistent. This additional information was then compared to the different entries in the two above databases, finally identifying the GPS coordinates of all towns except for three (with a negligible number of firm-observations or no observations at all).

The resulting table was converted to a point-shapefile (ESRI shapefile format) using ArcGIS and with the same program a polygon-shapefile containing the buffer-zones of various sizes were produced. The ACLED data is contained in a point-shapefile that identifies the incident locations and contains information about the year and type of incident in the file's attribute table. The counting exercise was not done in ArcGIS but with a Python script using the Python bindings of the OGR library (part of the GDAL library originally written for the C language: http://www.gdal.org/ogr/index.html, last accessed March 14,2013). The OGR library creates an object from a shapefile that provides methods for manipulation and 
analysis. Among others it allows to set filters according to the geography (spatial extent) or the feature attributes of such objects. This was done with the shapefiles containing the buffer zones and the one containing the ACLED data. Then looping through all years for all event-types, the features falling into each of the buffer zones were counted and the results saved in a SQLite database (this was of course done for all buffer-zones of different sizes). The resulting dataset could then be merged with the firm data based on the town identifier. 


\section{Appendix C}

\section{C.1 Additional Tables}

Table C.1: Regression results organization duration, including political orientation

\begin{tabular}{|c|c|c|c|c|}
\hline \multicolumn{5}{|c|}{ Duration of Terrorist Organizations } \\
\hline \multirow[t]{2}{*}{ Nationalist/Sep. } & $0.579 * *$ & 0.761 & 0.740 & 0.910 \\
\hline & $(-2.20)$ & $(-1.11)$ & $(-1.34)$ & $(-0.40)$ \\
\hline \multirow[t]{2}{*}{ Left Wing } & $0.533^{* *}$ & $0.551^{* *}$ & 0.655 & 0.660 \\
\hline & $(-1.96)$ & $(-1.98)$ & $(-1.53)$ & $(-1.48)$ \\
\hline \multirow[t]{2}{*}{ Right Wing } & 0.804 & 0.743 & 0.658 & 0.655 \\
\hline & $(-0.61)$ & $(-0.83)$ & $(-1.28)$ & $(-1.27)$ \\
\hline \multirow[t]{2}{*}{ Anarchist } & 0.982 & 1.123 & 0.812 & 0.861 \\
\hline & $(-0.04)$ & $(0.30)$ & $(-0.56)$ & $(-0.39)$ \\
\hline \multirow[t]{2}{*}{ Polit. Change } & & $2.848^{* * *}$ & & $1.955^{* * *}$ \\
\hline & & $(4.26)$ & & (3.29) \\
\hline \multirow[t]{2}{*}{ Regime Change } & & $1.558 * *$ & & $1.459 * *$ \\
\hline & & $(2.55)$ & & $(2.19)$ \\
\hline \multirow[t]{2}{*}{ StatusQuo } & & 1.642 & & 1.275 \\
\hline & & $(1.48)$ & & $(0.76)$ \\
\hline \multirow[t]{2}{*}{ Religious } & $0.462 * * *$ & $0.500 * * *$ & $0.559 * * *$ & $0.585^{* * *}$ \\
\hline & $(-3.52)$ & $(-3.40)$ & $(-3.13)$ & $(-2.88)$ \\
\hline \multirow[t]{2}{*}{ Int. operations } & $0.493 * * *$ & $0.526 * * *$ & $0.553 * * *$ & $0.593 * * *$ \\
\hline & $(-3.01)$ & $(-3.26)$ & $(-3.25)$ & $(-2.95)$ \\
\hline \multirow[t]{2}{*}{ State oppression } & & & 0.966 & 0.974 \\
\hline & & & $(-0.54)$ & $(-0.40)$ \\
\hline \multirow[t]{2}{*}{ GDP p.c. 1000 's Int.\$ } & & & $1.036 * * *$ & $1.034^{* * *}$ \\
\hline & & & (3.59) & $(3.33)$ \\
\hline \multirow[t]{2}{*}{ Pop. Density } & & & $0.999 * *$ & 0.999* \\
\hline & & & $(-2.19)$ & $(-1.87)$ \\
\hline \multirow[t]{2}{*}{ Size 2nd ethnicity } & & & 0.997 & 0.995 \\
\hline & & & $(-0.52)$ & $(-0.66)$ \\
\hline \multirow[t]{2}{*}{ Democracy } & & & $0.690 * *$ & $0.728 *$ \\
\hline & & & $(-2.01)$ & $(-1.67)$ \\
\hline No. Subjects & 645 & 645 & 612 & 612 \\
\hline No. Failures & 435 & 435 & 402 & 402 \\
\hline No. Obs. & 6985 & 6985 & 5800 & 5800 \\
\hline
\end{tabular}

Hazard ratios reported; t-statistics in parentheses. ${ }^{* * *}, * * *$ denote significance at the $1 \%, 5 \%, 10 \%$ level respectively. 


\section{C.2 Technical Notes}

The main data source for information about terrorist and other armed groups that is used here, are the Terrorist Organization Profiles (TOP; MIPT, 2008). This database was updated until 2008 when the project ceased to exist. To this point, the organization profiles are made available from the website of the 'National Consortium for the Study of Terrorism and Responses to Terrorism' (START) but they are not maintained, checked or updated. The TOP data is not downloadable as a dataset but is hosted on more than 800 separate webpages (one page per organization). The data was gathered from the pages using a self-written webscraper (written in Python) that extracted the relevant information from each page.

The dataset from Jones and Libicki (2008) is a printed table in the appendix of their study.

Both databases were merged after the names had been manually adjusted (different sources sometimes use different names for the same organization, often due to ambiguous translation possibilities).

Manual additions and changes that are based on the text descriptions in the TOP data, the Global Terrorism Database, the RAND/MIPT Terrorist Incidents Database, the 'Violent Extremism Knowledge Base' (VKB) of the Institute for the Study of Violent Groups (ISVG), the research project 'Mapping Militant Organizations' from Stanford University, the 'South Asia Terrorism Portal' and internet news searches, were made in Stata. A documentation of the about 1400 manual changes and additions in the data is available upon request.

The resulting dataset contained one row (observation) per organization. To merge in the time-varying components it was extended to contain one row for each year an organization existed, resulting in a data-structure suitable for discrete-time duration analysis with one year time intervals. 


\section{Eidestattliche Versicherung}

Ich versichere an Eides Statt, dass ich die eingereichte Dissertation „Micro-Level Impacts of Conflict and the Duration of Armed Groups" selbstständig verfasst habe. Anderer als der von mir angegebenen Hilfsmittel und Schriften habe ich mich nicht bedient. Alle wörtlich oder sinngemäß den Schriften anderer Autorinnen und/oder Autoren entnommenen Stellen habe ich kenntlich gemacht.

Göttingen, 18.06.2013

Dominik Noe 